
Published as volume 11 in the Series B as part of the „Biodiversity and Ecology Series“

Peter Hajek

Intra- and Interspecific Variation of Functional Traits, Growth Performance and Belowground Competition in Populus Species

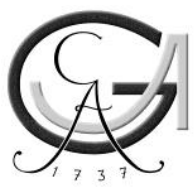

Georg-August-Universität Göttingen 2014

Dieses Werk ist lizenziert unter einer Creative Commons

Namensnennung - Weitergabe unter gleichen Bedingungen 4.0 International Lizenz.

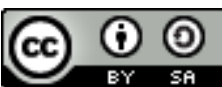


Bibliographische Information der Deutschen Nationalbibliothek

Die Deutsche Nationalbibliothek verzeichnet diese Publikation in der Deutschen Nationalbibliographie; detaillierte bibliographische Daten sind im Internet über $<$ http://dnb.ddb.de> abrufbar.

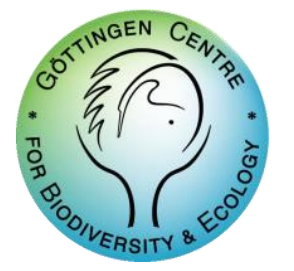

Editor Dr. Dirk Gansert

Göttingen Centre for Biodiversity and Ecology,

Georg-August-Universität Göttingen, www.biodiversitaet.gwdg.de

Dissertation zur Erlangung des Doktorgrades der

Naturwissenschaftlichen Fakultäten der

Georg-August-Universität Göttingen

vorgelegt von Peter Hajek

Referent: Prof. Dr. Christoph Leuschner

Korreferent: Prof. Dr. Markus Hauck

Anscbrift des Autors

Peter Hajek

e-mail: peter.hajek@biologie.uni-goettingen.de

Typesetting and layout: Peter Hajek

Cover image: Peter Hajek

DOI http://dx.doi.org/10.3249/webdoc-3936 


\title{
INTRA- AND INTERSPECIFIC VARIATION OF FUNCTIONAL TRAITS, GROWTH PERFORMANCE AND BELOWGROUND COMPETITION IN Populus SPECIES
}

\author{
Dissertation zur Erlangung des Doktorgrades der \\ Mathematisch-Naturwissenschaftlichen Fakultät der \\ Georg-August-Universität Göttingen \\ vorgelegt von \\ Dipl.-Ing. Silv. M.Sc. \\ Peter Hajek \\ aus \\ Augsburg
}

Göttingen, im Januar 2014 

Referent: Prof. Dr. Christoph Leuschner

Korreferent: Prof. Dr. Markus Hauck

Tag der mündlichen Prüfung: 27. März 2014 



\section{CONTENT}

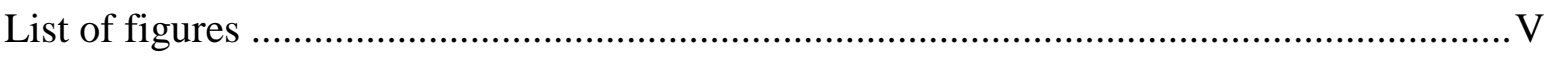

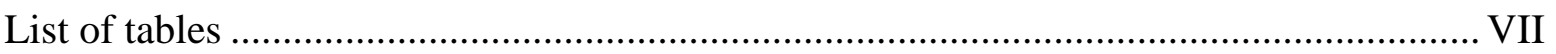

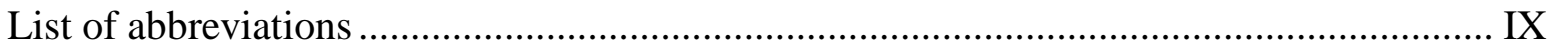

\section{Chapter 1}

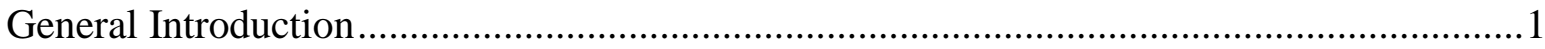

Global forest resources, plantation forests and cultivation of Populus ................................

Intra- and interspecific diversity, trait variation and trait linkages in Populus....................5

Fine root structure and belowground competition ........................................................6

Aspects of hydraulic architecture in trees ...................................................................

Study design .............................................................................................................14

The 'POPDIV' field experiment...................................................................................14

The ‘Cavitron’ approach - hydraulic features of branches and coarse roots .....................16

The rhizobox root competition experiment …………………………………………....16

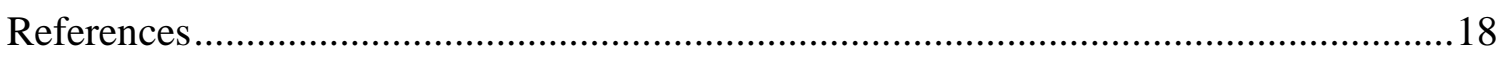

\section{Chapter 2}

Intraspecific variation in root and leaf traits and leaf-root trait linkages in eight aspen

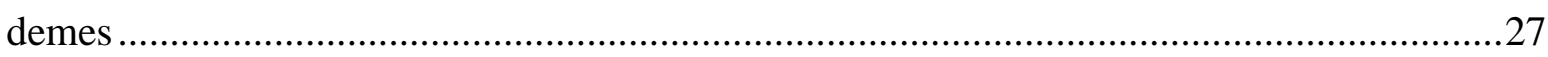

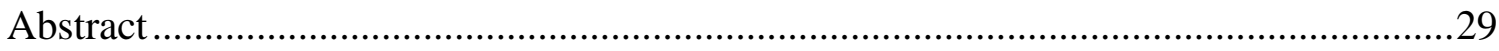

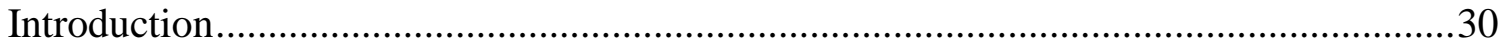

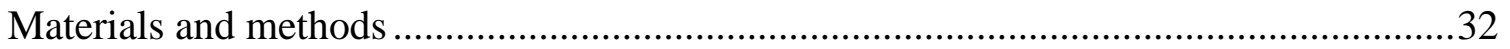

Study site description ...........................................................................................32

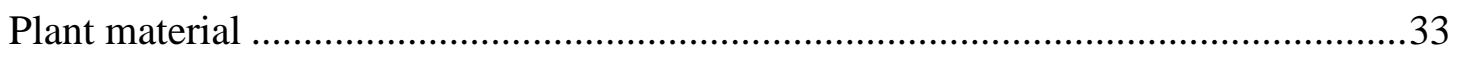

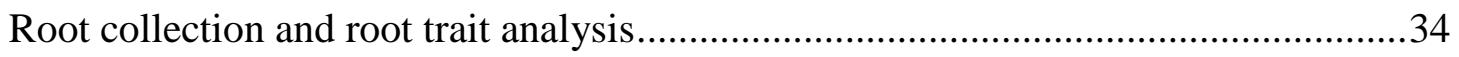

Leaf collection and leaf trait analysis............................................................................35

Relative growth rate and aboveground biomass ........................................................35

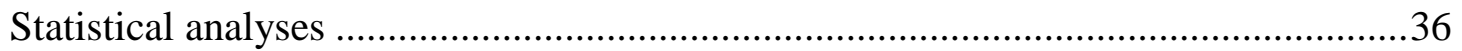

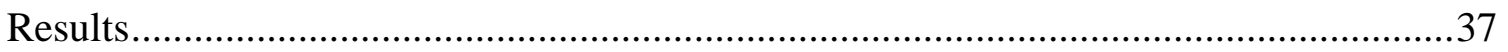

Between- and within-deme variation in root morphology and root $\mathrm{N}$ concentration ..37

Between- and within-deme variation in leaf morphological and chemical traits..........38

The influence of genetic variation on leaf and root trait variation.................................40

Relationships among leaf traits, root traits and RGR...................................................41 


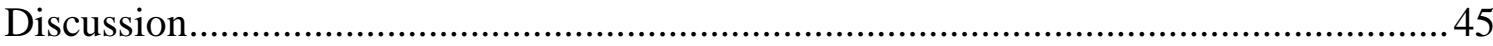

The aspen fine root system: Genotypic variation vs. phenotypic plasticity ................. 45

Co-variation between root and leaf traits.................................................................. 46

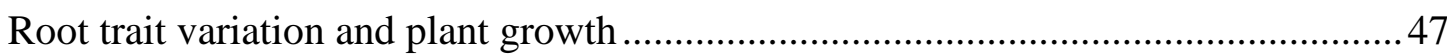

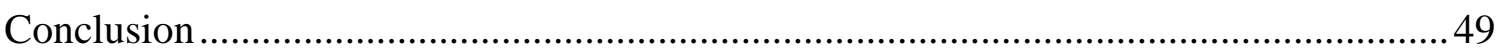

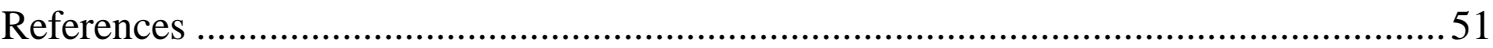

\section{Chapter 3}

Trade-offs between xylem hydraulic properties, wood anatomy and yield in Populus ........ 57

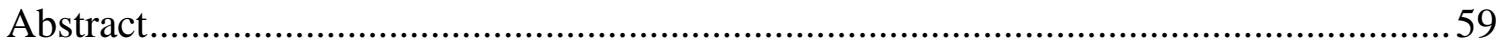

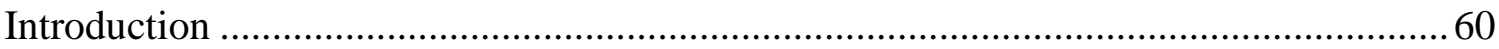

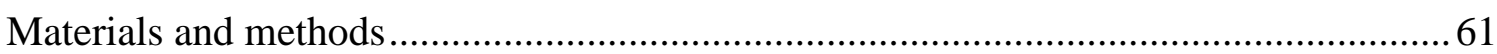

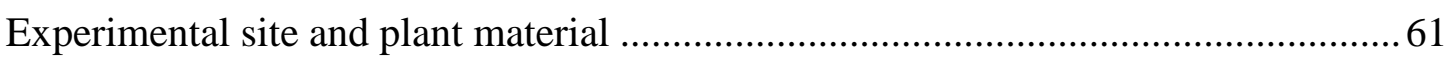

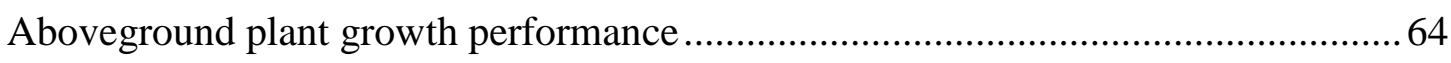

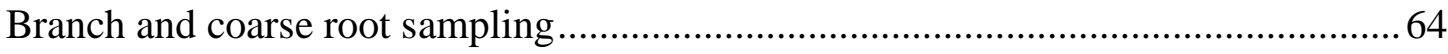

Xylem anatomy of branches and coarse roots ............................................................64 64

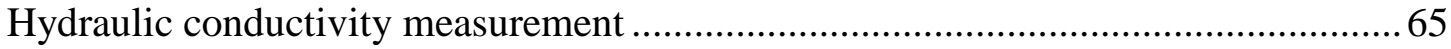

Xylem resistance to cavitation and estimation of hydraulic safety margins................66

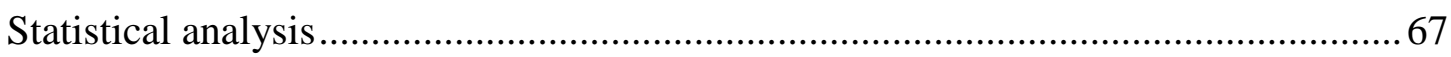

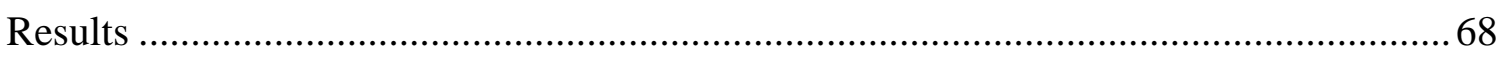

Between-deme variation in branch and coarse root xylem anatomy and hydraulics... 68

The influence of genetic variation on xylem anatomy and hydraulic properties......... 77

Aboveground growth performance and its relatedness with xylem anatomy and

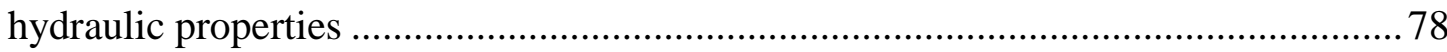

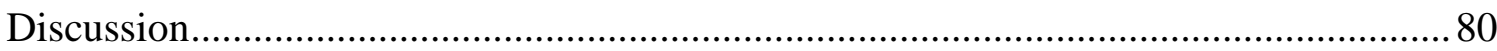

Intraspecific differences in xylem architecture and hydraulic conductivity in the

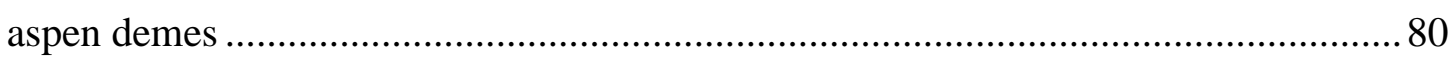

Trade-off between growth performance, branch hydraulic conductivity and

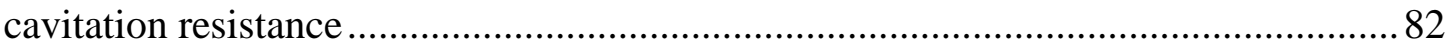

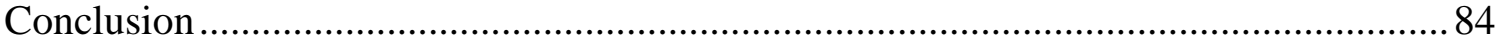

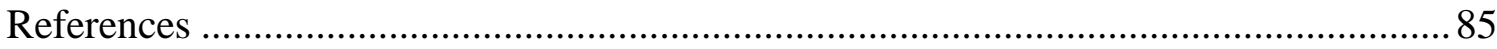




\section{Chapter 4}

Root order- and root age-dependent response of two poplar species to belowground

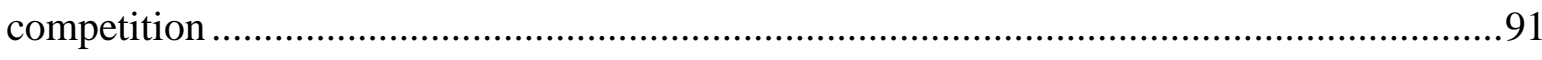

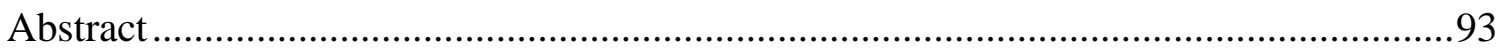

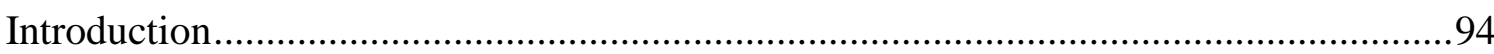

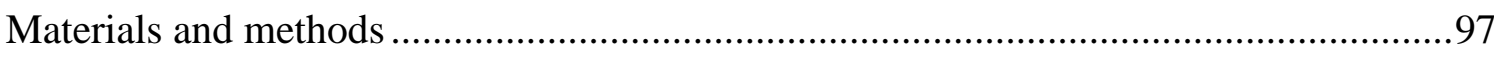

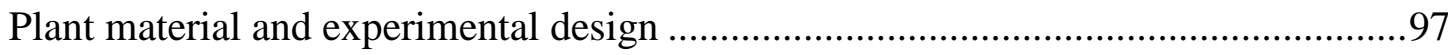

Root order-related analysis .................................................................................99

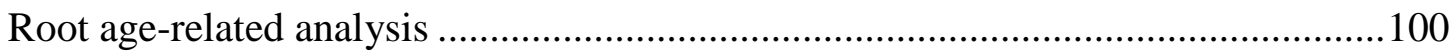

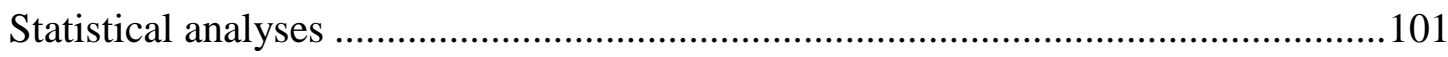

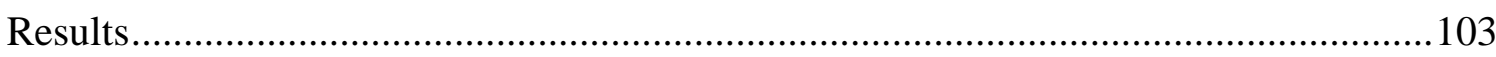

Species differences in plant biomass and growth rate ............................................103

Effects of intra- and interspecific competition on the morphology and chemistry

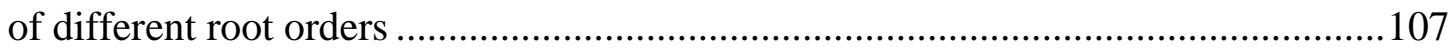

Changes in root morphology and chemistry with root age .....................................110

Effects of intra- and interspecific competition on root morphology and chemistry

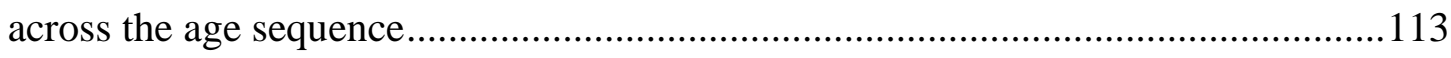

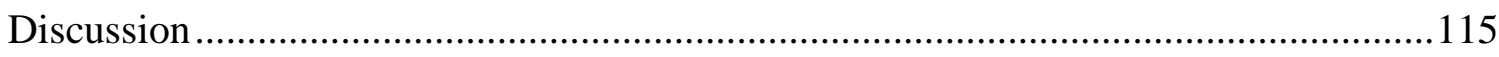

Asymmetric belowground competition................................................................ 115

Species differences in root properties along the fine root branching network...........116

Effects of intra- and interspecific competition on the morphology of different

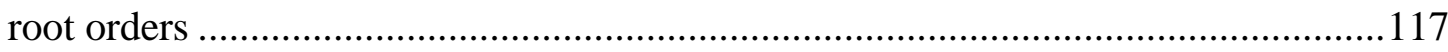

Age-dependent change in root morphology and chemistry and effects of

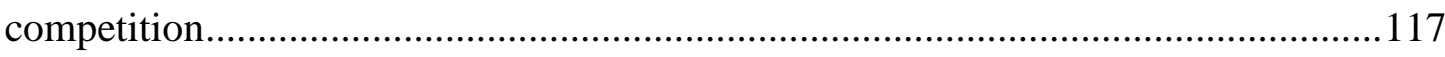

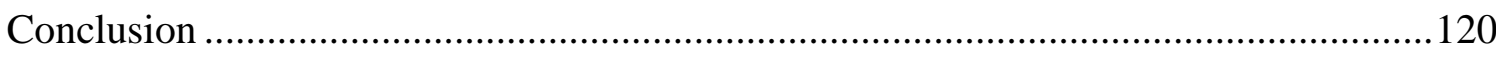

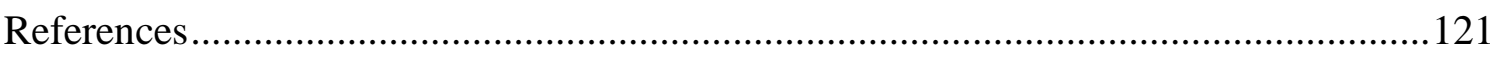

\section{Chapter 5}

Synthesis

The intra- and interspecific trait variation in Populus ..................................................130

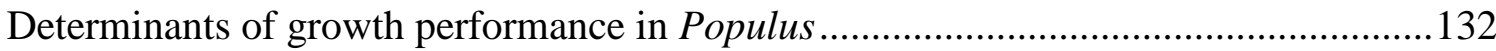

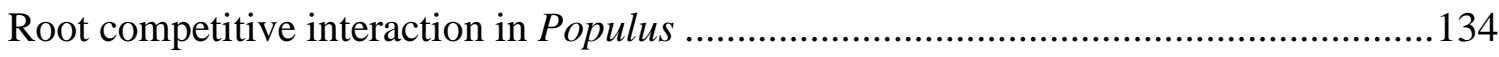

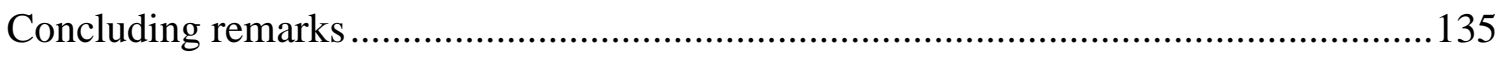

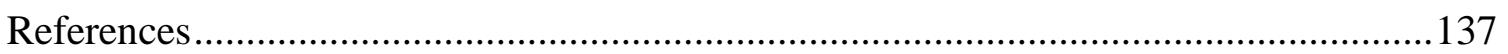




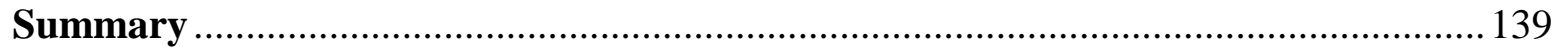

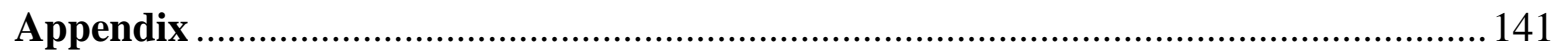

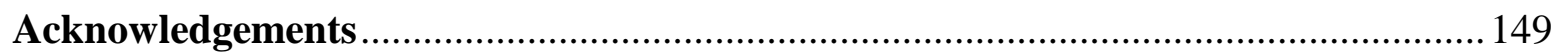




\section{LIST OF FIGURES}

Figure 1.1 Layout of the 'Göttingen Poplar Diversity Experiment' .................................. 15

Figure 1.2 Schematic diagram of a rhizobox plant container ......................................... 17

Figure 2.1 Distribution of the RGR, leaf and root morphological traits in the orthogonal plane of the PCA for the eight aspen demes.................................................... 44

Figure 3.1 Cross-sectional images of branch or coarse root segments and graphs of xylem vulnerability curves for branch or coarse root segments ........................ 69

Figure 3.2 Relative abundance of vessels and relative contribution of vessel size class to total hydraulic conductivity in the branch and root xylem of aspen plants........ 74

Figure 3.3 Hydraulically-weighted vessel diameter in relation to cavitation vulnerability $\left(\mathrm{P}_{50}\right)$ or cavitation safety margin in the sample of five demes

Figure 3.4 Sapwood area-specific hydraulic conductivity in relation to absolute or relative growth rate in the sample of five demes

Figure 4.1 Biomass of leaves, stem, coarse and fine roots of $P$. tremula and $P$. trichocarpa saplings grown under different competition treatments

Figure 4.2 Root morphological and chemical traits of $P$. tremula and $P$. trichocarpa along four different root orders

Figure 4.3 Competition-induced modifications in root morphology and chemistry along four different root orders of $P$. tremula and $P$. trichocarpa

Figure 4.4 Morphological and chemical traits of 1 to 19-wk-old P. tremula and $P$. trichocarpa fine root segments

Figure 4.5 Competition-induced modifications in root morphology and chemistry along 1 to 19 -wk-old $P$. tremula and $P$. trichocarpa root segments

Figure A 1 The POPDIV field trail and a 4-yr old stand of aspen demes at the experimental in the Solling mountains

Figure A 2 The characteristical fine root branching patterns of $P$. tremula and $P$. trichocarpa 
Figure A 3 Installation of the rhizobox experiment and root branching patterns at the

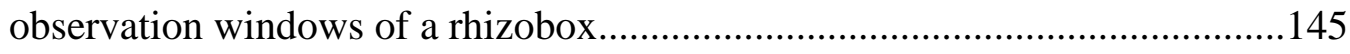




\section{LIST OF TABLES}

Table 2.1. Soil characteristics at the POPDIV experimental site ....................................... 33

Table 2.2. The eight aspen demes used in the study and their origin............................... 34

Table 2.3. ANOVA table of leaf and root properties of eight aspen demes....................... 38

Table 2.4. Morphological and chemical traits of leaves and fine roots of the eight aspen demes, their relative growth rates and coefficients of genetic variation

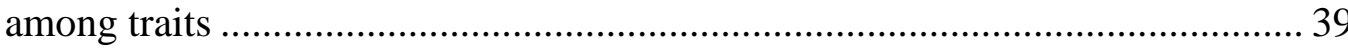

Table 2.5. Pearson correlation matrix of leaf and root traits across the eight demes .......... 40

Table 2.6. Mantel test - correspondence of morphological trait variance and phylogenetic relatedness of eight aspen demes

Table 2.7. PCA table on relative growth rate, leaf and root morphological properties of the eight aspen demes

Table 3.1. Plant characteristics of the five aspen demes selected for hydraulic

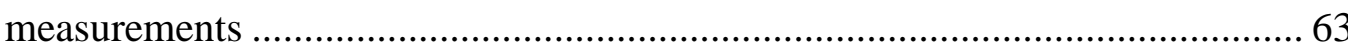

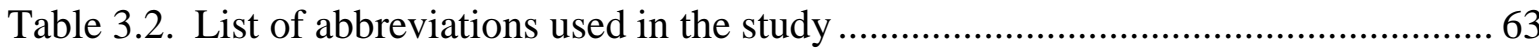

Table 3.3. Traits related to plant size and morphology, to biomass production and to wood anatomy and hydraulics of branch and coarse root samples of aspen demes

Table 3.4. Pearson correlation matrix for growth-related traits and xylem anatomical and wood hydraulic traits of branch and coarse root segments of aspen demes

Table 3.5. Differences in wood anatomical traits and derived hydraulic conductivity for different branch and coarse root categories.

Table 3.6. Mantel test on the relationship between trait variance and phylogenetic relatedness of five demes

Table 4.1. Initial plant characteristics of the saplings used in this study 98

Table 4.2. Categories used for root segment classification according to age and the respective surface properties as visible at the observation windows 
Table 4.3. RGR of $P$. tremula and $P$. trichocarpa leaves, stems, coarse and fine roots of saplings grown underdifferent competition treatment.

Table 4.4. Effect of root order, treatment and species on root morphological and chemical traits

Table 4.5. PCA table, integrating root morphological and chemical properties, root order, species and treatment

Table 4.6. Effects of root age, treatment and species on root morphological and chemical traits

Table 4.7. PCA table, integrating root morphological and chemical parameters, root age, species and treatment

Table A 1 Dependency of xylem cross-sectional area on cross-sectional sapwood area for branch and coarse root segments of the five aspen demes

Table A 2 Relation between hydraulics and xylem anatomy at different positions along branch or root segments 


\section{LIST OF ABBREVIATIONS}

a. s. l.

$A_{\text {cross }}$

AFLP

AGB

AGR

$A_{\text {lumen }}$

$\mathrm{AM}$

ANOVA

$A_{\text {xylem }}$

$\mathrm{CaCO}_{3}$

CV

d

$d_{\mathrm{h}}$

$d_{\mathrm{wm}}$

EM

$\eta$

EV

FAO

FBR

GLM

$\mathrm{h}$

IPCC

$\mathrm{KCl}$

$K_{\mathrm{s}}$

$K_{\mathrm{p}}^{\text {theo }}$

NPP

$\mathrm{P}_{12}$

$\mathrm{P}_{50}$ above sea level

cross sectional area

amplified fragment-length polymorphism

aboveground biomass

absolute aboveground biomass increment

relative vessel lumen area

arbuscular mycorrhizal fungi

analysis of variances

xylem sapwood area

calcium carbonate

coefficient of variation

vessel diameter

hydraulically-weighted vessel diameter

weighted mean diameter according to vessel size

distribution

ectomycorrhizal fungi

viscosity of water at $20^{\circ} \mathrm{C}\left(1.00210^{-9} \mathrm{MPa} s\right)$

Eigen value

Food and Agricultural Organization

functional biodiversity research

general linear model

tree height

Intergovernmental Panel on Climate Change

potassium chloride

empirical sapwood area-specific hydraulic conductivity

potential sapwood area-specific hydraulic conductivity

net primary production

xylem pressure causing $12 \%$ loss of hydraulic

conductivity

xylem pressure causing $50 \%$ loss of hydraulic

conductivity 
xylem pressure causing $88 \%$ loss of hydraulic conductivity

PCA

principal components analysis

PLC

percent loss of conductivity

POPDIV

Göttingen Poplar Diversity Experiment

$\Psi_{\min }$

minimum leaf water potential (midday)

RCD

root collar diameter

RGR

$\rho$

relative growth rate

RTA

the density of water at $20{ }^{\circ} \mathrm{C}\left(998.2 \mathrm{~kg} \mathrm{~m}^{-3}\right)$

RTD

root tip abundance

RVN

root tissue density

SE

relative vessel number

standard error

SRA

specific fine root area

SRF

short rotation forestry

SRL

specific fine root length

SSR

simple sequence repeats

$\mathrm{VD}$

vessel density

VOC

volatile organic compounds

VSC

vessel size class 


\section{ChAPTER 1}

\section{GENERAL INTRODUCTION}





\section{Global forest resources, plantation forests and cultivation of Populus}

Forest ecosystems provide valuable sources of forest goods (wood, fiber or non-timber forest products), and bare non-market values and various ecosystem processes (e.g. carbon sequestration, erosion control or wildlife habitat) as well as social functions (recreation value, landscape esthetics and preservation of biodiversity). Forests cover over $30 \%$ of the Earth's total land mass ( 4 billion hectares) and are prerequisite for the economic and social wellbeing of modern society. However, the stock of natural forests continuously declines and is converted to other land use types. This trend is assumed to continue through 2020 (Rounsevell et al. 2006; FAO 2011). Moreover, forest ecosystems are heavily affected by overexploitation, pollution and changes in the Earth's climate (Ciais et al. 2005; IPCC 2007; Allen et al. 2010). Consequently, the growing demand for wood and energy resources is being accompanied by a steadily increasing risk of extreme weather events such as an overall increase in temperatures and decreased summer precipitation, which is certainly affecting forest yield (Lindner et al. 2010). Moreover, a dramatic loss in biodiversity (Purvis and Hector 2000; Rands et al. 2010) reinforces the risk of pests and instable ecosystems within such habitats where diversity is comparatively low. Thus, the occurrence of uncertain impacts during the long rotation times until an expected harvesting age in 2080-2100 is likely to increase the already substantially challenging sustainability of the current forest ecosystems management.

The imbalance between a steady increase in demand of forest products on the one hand, and the ongoing exploitation of natural forests and loss in forest cover on the other hand, requires alternative solutions to be found for the maintenance of forest goods. A possible way to produce industrial wood, pulp wood or bioenergy are short rotation plantations with cultivation of fast-growing tree species with rotation times of less than 30 years (Berndes et al. 2003; Evans 2009). Despite some major criticisms and concerns considering the ecological value, specifically in tropical landscapes (Brockerhoff et al. 2008), tree plantations became increasingly important in the past decades (Paquette and Messier 2009). This is evidenced by a continuing trend in establishment of new forest plantation areas on a global scale and especially within Western Europe (category 'planted forests', FAO 2010). Since the 1970s, those short rotation forestry systems are increasingly subject to applied science (Steinbeck 1999; Dickmann 2006) aiming to steadily improve the aspects of yield, pest resistance and drought tolerance. Those plantation management 
regimes are advantageous in certain aspects. From an economic perspective, short-rotation

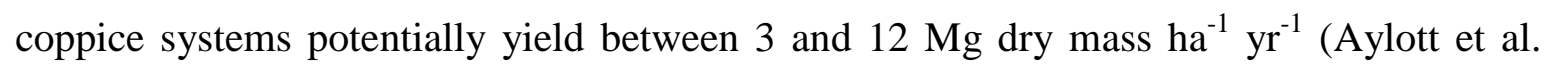
2008; Mantau 2010; Tallis et al. 2013), thus contribute to meet the requirements of future wood demands (Evans 2009). Additionally, a considerable belowground carbon storage potential to reduce $\mathrm{CO}_{2}$ emission is attributed to forest plantations (Fang et al. 2007). Short rotation forestry also contributes to the desired 20\% increase in the share of renewable energy sources to the overall use of energy in Europe by 2020 (European Commission 2009). Dependent on temporal (rotation period and stand age) and spatial scale (size of the plantation) of the management regime, short rotation forestry (SRF) may also provide important wildlife habitats, hosting numerous associated plant and animal species (Christian et al. 1998), hence contributing to a significantly higher plant (Weih et al. 2003; Baum et al. 2012) and fauna diversity (Dimitriou et al. 2011) in agricultural landscapes. Furthermore, native forests benefit from the establishment of short rotation plantations as they slow the pace of their irretrievable destruction and thereby the inherent loss of their habitats and endangered wildlife (Fox 2000). For the improvement of plantations in terms of species adaptation, pest resistance and productivity, ecological and genetic research with the highly productive poplar species as a model organism describe a long history (Rose and DeBell 1978; Pellis et al. 2004; Marron and Ceulemans 2006; Monclus et al. 2006; Rae et al. 2009).

Specifically poplar species (Populus spec.), which have been cultivated in systematic plantations since antiquity (Dickmann 2006), still represent the most popular cultivar in plantation establishment due to various economically and ecologically favorable attributes. First and foremost, poplars exhibit outstanding growth rates even on marginal sites with unfavorable habitat conditions (Hofmann 1998). The rapid growth and extensive distribution of the tree roots provide access to a large volume of soil and soil resources. Second, their vegetative propagation from branch or root cuttings is uncomplicated, a trait mirrored in the plant's capacity for rapid reoccupation via root suckering following harvest or disturbance (Bärring 1988; Frey et al. 2003; Rood et al. 2007). Third, poplar species allow facile hybridization, genetic transformation and genetic engineering, qualities which resulted in the first fully sequenced tree genome for the species ( $P$. trichocarpa, $550 \mathrm{Mb}$, Tuskan et al. 2006). In addition, poplar forest stands host endangered species, prevent erosion by reducing overland flow and maintain the water balance when colonizing early successive or disturbed sites (Kouki et al. 2004; Dimitriou et al. 2011). Moreover, aspen 
forest stands ( $P$. tremula and $P$. tremuloides) have a large potential to reduce $\mathrm{CO}_{2}$ by sequestering high amounts of belowground carbon in natural stands (David et al. 2001) as well as in plantation management regimes (Fang et al. 2007). Those features make the species a promising study subject, especially in the face of future climate scenarios, and this has given poplars their much vaunted “model organism” status (Bradshaw et al. 2000; Taylor 2002; Wullschleger et al. 2002; Brunner et al. 2004) in a multitude of studies.

\section{Intra- and interspecific diversity, trait variation and trait linkages in Populus}

The genus Populus includes 29-40 single species worldwide which can be attributed to six sections (Bradshaw et al. 2000; Cronk 2005). Poplars are dioecious (i.e. having the male and female reproductive organs on separate plants), obligate outcrossing species and reproduce either sexually by seeds (seed pollen has a wide distribution) or asexually by root suckers. Hence, populations may comprise both, a considerable genetic variation (David et al. 2001) as well as large stands of clonal structures with a single clone consisting of several trees (ramets) (Mitton and Grant 1996). Doubtless, poplar species are exceptionally widely distributed across various ecosystems of the Northern hemisphere (Dickmann and Kuzovkina 2008). In their natural habitats, reaching from flood plains to montane forests in temperate as well as boreal climates, they represent a climax species and can form large forest stands (Hultén 1986; Bradshaw et al. 2000; Pakull et al. 2009). By contrast, poplars may also occur as a typical pioneer tree species in early successional plant communities in temperate zones (Ellenberg and Leuschner 2010) and tolerate the low nutrient and water supply of disturbed sites, though they are more susceptible to shading. Some species exhibit a larger range of distribution (e.g. P. tremula and P. tremuloides) while others have narrow ecological amplitudes e.g. P. nigra or P. deltoides and are predominantly associated with riparian ecosystems (Rood et al. 2003).

The outstanding potential of poplar species to occur along such a wide range of environmental gradients bears witness to their high degree of intra- and interspecific diversity (Cervera et al. 2005). The cause for the high intraspecific diversity is a high level of genetic variation in populations, which manifests itself in differences of various functional and morphological plant traits. Plant traits can be phenotypically plastic i.e. the plant genotype codes for ability to express different phenotypes as a response to different habitat conditions (Bell and Lechowicz 1994; Gregorius and Kleinschmit 1999; Agrawal 2001). Both, intraspecific diversity and phenotypic plasticity carry adaptive capacities of 
plants to cope with environmental changes as anticipated from climate warming (Hamrick 2004; Matesanz et al. 2010).

The quantification of above- and belowground variation pattern in key traits (morphological and functional) enables evaluation of the relative importance for species adaptation and growth performance. It is important to note, that traits should not be considered in isolation, because pairs of traits are often coordinated (Westoby and Wright 2006). Such trait relatedness between above- and belowground pairs of traits characterize key processes of acquisition and the allocation of limiting resources (e.g. assimilation and nutrient uptake), adaptation mechanisms to climatic stressors (e.g. hydraulic architecture) or mechanism of structure-related resource capture (specific leaf area vs. specific root length). A better understanding of those mechanisms may lead to an important component of breeding approaches for providing proper plant material to establish resilient forest ecosystems under changing environmental and habitat conditions as suggested in Spittlehouse and Stewart (2004). So far, investigations on aboveground trait variations are well established, but only a few reports exist on the corresponding belowground traits and even less is known about how variations between aboveground and belowground organs coordinate (Liu et al. 2010). Therefore, it should be of primary interest to emphasize the belowground component of trait variability and trait interrelations within and between species in order to describe the underlying mechanisms of belowground processes such as root response to heterogeneous soil conditions or belowground competition and the relatedness to aboveground plant functions. This may help to detect promising synergistic (or antagonistic) effects as provided by an increased intraspecific diversity in mixture compared to monocultures for example in tree plantations (Richards et al. 2010).

\section{Fine root structure and belowground competition}

The tree root systems account for approximately one third (13-43\%) of the total carbon pool of forest stands (Puri et al. 1994; Helmisaari et al. 2002). Such systems consist of a hierarchically branching network and can be arbitrarily classified into root stock, coarse roots and fine roots. Coarse roots are persistent support organs which account for long-distance water transport and are conducive to tree anchorage. In contrast, fine roots are roots of a smaller diameter and high surface area which explore large volumes of soil to absorb water and nutrients from the rhizosphere. Their close association with soil microorganisms (rhizosphere microbes) and symbiosis with ectomycorrhizal (EM) or 
arbuscular mycorrhizal fungi (AM) contributes to nutrient absorption, hence overall plant fitness and growth (Miransari 2014).

Even though the living fine root biomass contributes only 1-15\% to total tree biomass, fine root productivity can exceed aboveground productivity due to high turnover rates. Fine root production varies from 10-60\% of total net primary production (Caldwell and Richards 1986) with a lifespan recorded between less than 30 and up to 900 days (Block et al. 2006; Withington et al. 2006). Fine roots mediate two significant components of the global C cycle (Jackson et al. 1997). First of all they account for the large C input to soil due to rapid production, senescence and decomposition (Nadelhoffer and Raich 1992). Already a high rate, this is predicted to increase further under elevated atmospheric $\mathrm{CO}_{2}$ (Lukac et al. 2003). Second, about 50\% of the $\mathrm{CO}_{2}$ efflux from the soil results from fine root growth and maintenance respiration (Brüggemann et al. 2011).

Despite the overall importance of fine roots, their investigation is hindered by several methodical and conceptual barriers. Root systems are general inaccessible and difficult to excavate owing to their varying architecture and spatial distribution in the soil. Moreover, fine root classification according to various arbitrary diameter classes (the most frequent is the $2 \mathrm{~mm}$ diameter threshold) complicates a comparison of different root studies and, most importantly, neglects the inherent functional complexity of different parts of the fine root system.

Individual root sections occur in different proportions along the complex lateral branching system. Therefore, position and age of the segment essentially determine their physiological and functional properties. The youngest root segments are characterized by high respiration rates, high $\mathrm{N}$ concentration, small diameter low tissue density and high specific root length (SRL). Their pigmentation is white and their primary function is as absorptive organs, whereas mature roots function as transport and storage organs (Hishi 2007). Therefore, prominent studies have advocated the description of the systematic change in anatomy, chemistry, morphology and inherent functions e.g. turnover, respiration, water/nutrient uptake along different root orders (Fitter 1982; Fitter 1987; Pregitzer et al. 1997; Eissenstat et al. 2000; Hishi 2007; Guo et al. 2008; Pregitzer 2008; Valenzuela-Estrada et al. 2008; Goebel et al. 2010; Rewald et al. 2011; Beyer et al. 2013). 
Fine roots are subject to belowground competitive interactions which constitute a ubiquitous phenomenon in the foraging process for limited belowground resources (nutrients, water and space). Belowground competition was described as an important structuring force in species communities and may even exceed the intensity of aboveground competition (Wilson 1988). The mechanisms employed to prevail in the struggle for belowground resources constitute either interference competition i.e. the inhibition of other plants to access soil resources, or explorative competition which is characteristically resource occupation through depletion (Schenk 2006). Both strategy types can be subject to different modes regarding root system size (size-symmetric and size-asymmetric) and range at different species levels (intraspecific, interspecific) (Weiner and Thomas 1986; Weiner 1990; Schwinning and Weiner 1998; Cahill Jr and Casper 2000; Schenk 2006).

At a population scale (e.g. in forest stands), a strategy to allow the coexistence of species can be niche partitioning, i.e. spatial segregation enables species to avoid competitive exclusion by variability either in temporal or spatial soil resource occupation (Schmid and Kazda 2002; Jose et al. 2006). Furthermore, coexistence among species can also be achieved by the plasticity in the pattern of root architecture (Caldwell 1987; Bauhus and Messier 1999) or morphological adaptation of functional traits such as specific root length (SRL) and number of root tips (Fitter 1987; Bolte and Villanueva 2006). The question arises, however, of how poplar species adapt to belowground competition in fine root structure, and which competition strategy can be derived for the species.

Therefore, a characterization of the fine root system according to morphological and chemical parameters along its complex branching structure is prerequisite to describing the morphological response to changing environments e.g. to soil heterogeneity (Hodge 2004) or competitive species interactions (Schenk 2006) within and between different species.

\section{Aspects of hydraulic architecture in trees}

Water is the most essential medium for biochemical processes and a transport medium of nutrients and assimilates in plants. Most of the water is taken up by roots and transpired to the atmosphere from leaves at the plant-atmosphere interface located in the stomata. The driving force of water flow in plants along the soil plant atmosphere continuum (SPAC) is 
the pressure gradient occuring between absorbing root elements and evaporating leaf surfaces according to the cohesion-tension theory (Tyree and Zimmermann 2002).

Thereby, the tree hydraulic system (an interconnected network of water conducting pipes of the xylem conduits) enables the continuous supply of water from the fine roots to the leaves. Important traits to describe the hydraulic efficiency are for example the number, diameter, and length of the conducting vessels. These key traits determine water flow rate, maintenance of water potential gradients as well as vulnerability to xylem cavitation.

Extremely negative xylem pressure occurs in vessels during water limitation (drought events). When the negative hydrostatic pressure exceeds a species-specific threshold, the watercolumn in the vessels breaks due to cavitation (Tyree and Sperry 1989) and causes embolism to the cells that leads to their dysfunction (Tsuda and Tyree 1997). A result of excessive cavitation within the xylem pathway may be hydraulic failure. The anatomical characteristics that essentially determine embolism resistance of trees are subject to ongoing debates. For example wood density or pit field wall strength (Hacke et al. 2001) as well as vessel grouping and the porosity of pit walls (Lens et al. 2011) or fiber wall thickness (Cochard et al. 2007) are discussed. Instead, Cruiziat et al. (2002); Tyree and Zimmermann (2002); Hacke et al. (2006); Maherali et al. (2006) and Cai and Tyree (2010) state, that the strongest effect on hydraulic resistance is the size of the vessels, where larger vessels are assumed to be more prone to cavitation.

Intra- and interspecific differences in the xylem vessel anatomy and the associated hydraulic properties can be large, and the size of the conducting elements has a fundamental effect on water flow within a tree, since the flow rate is proportional to the fourth power of the radius of conducting vessels (Tyree and Zimmermann 2002). Accordingly, it is a trade-off between either constructing small vessels that are more resistant to cavitation or constructing larger vessels which enable higher growth rates. The hydraulic traits consequently determine species-specific drought resistance (Wikberg and Ögren 2004; Cochard et al. 2007; Fan et al. 2012), but are hypothesized to account for differences in species growth performance to the same extent (Tyree 2003).

Within a tree, the mean conduit size is largely different between above- and belowground organs (Tyree and Zimmermann 2002; McElrone et al. 2004). Therefore, coarse root vessels are assumed to be longer and have larger pits and thinner cell walls than the xylem 
of branches or the stem, and may therefore be more prone to cavitation (Hacke and Sauter 1996). Root anatomical characteristics which determine their hydraulic conductivity may also limit the regulation of the overall tree water flux (Jackson et al. 2000), and thus may affect the growth performance of trees as well. This indicates a further important role of tree coarse roots, however, studies comparing transport capacities of coarse roots and branches to describe the functional role of the respective organ along the water flow path are scarce (McElrone et al. 2004).

The intraspecific variation in xylem anatomy and hydraulic properties thus may account for differences in growth performance and drought resistance within populations. The high productivity of poplar species is coupled with high water consumption (Zsuffa et al. 1996; Monclus et al. 2006) which also makes the species relatively vulnerable to drought events compared to other temperate tree species. Here, the question arises as to what extent a high degree of intraspecific variation in poplar species contributes to variation in drought resistance and yield. 


\section{STUDY OUTLINE AND OBJECTIVES}

The thesis was conducted in the framework of the Göttingen cluster of excellence 'Functional Biodiversity Research' (FBR), which was established at the University of Göttingen in 2008. This multidisciplinary research project has the overall goal to answer key questions on biodiversity and ecosystem functionality cover studies in grassland. It also investigates populations of woody plants and includes a modeling-based approach. As a sub-project, the 'Göttingen Poplar Diversity Experiment' (POPDIV) involves several working groups to investigate key questions on the effects of intraspecific diversity on ecosystem functions and services in woody plants using aspen (Populus tremula and $P$. tremuloides) as the model tree species. So far, research on the variability in several traits has been carried out within this project. This includes the genetic analyses within the diversity experiment, carried out by the Department of Forest Genetics and Forest Tree Breeding and multitrophic interactions between plant volatile organic compounds (VOC) and herbivorous insects as investigated by the Department of Forest Zoology and Forest Conservation. The Department of Forest Botany and Tree Physiology investigated plant-fungi interactions as well as the relatedness of genetic diversity (genetic reservoir) and stand productivity. The Department of Plant Ecology and Ecosystems Research focused on aboveground, mostly leaf-related morphological, phenological and physiological traits and the impact on plant growth performance and yield within the first phase of the project (Müller 2011).

The first part of the presented thesis (Chapter 2) focuses on the belowground plant components, particularly the plant fine root system of aspen. The relevance of root studies arises from the general importance of roots for resource capture, carbon allocation (carbon storage potential), species adaptation (drought resistance) and overall plant performance. Despite ranking among the most extensively documented tree species, remarkably little is known about the intraspecific trait variability within structure and function of the fine root system of poplar species and how it integrates within the physiology of the aboveground parts.

The second part (Chapter 3) starts with the assumption that assimilation rates and water status traits are of minor importance when describing variations in productivity among aspen assemblages. Instead, total leaf size and the duration (phenology) of the leafy period 
were reported to determine growth performance and yield (Müller et al. 2012a). But what about the importance of constant water supply as provided by an efficient water transport system and xylem anatomy of coarse roots and branches? To answer this question, we compared intraspecific variation in xylem anatomy, vulnerability to cavitation, and specific hydraulic conductivity of branches and coarse roots of five aspen demes (Chapter 3). In this chapter, the relative importance of these processes on overall plant growth performance and variability in vulnerability to cavitation within the genus are analyzed.

In the third part of this thesis (Chapter 4), intra- and interspecific belowground competition effects on important root traits along different root orders and root ages are assessed. There is evidence that fine roots adapt to altered belowground resource availability by changes in fine root morphology and chemistry. Root response in terms of morphological adaptation may occur under limited resource availability due to belowground competition between trees. Therefore, different growth strategies may essentially contribute to the superiority of a species or certain population.

In the following chapters, eight genetically closely related, field grown $P$. tremula assemblages (demes) including two further poplar species obtained from micro propagation ( $P$. tremula and $P$. trichocarpa) were used to address my research questions. The specific aims were developed as follows.

Chapter 2: The aim was a morphological characterization of the fine root system of closely related aspen demes and to identify any intraspecific variations in functionally important root traits, the above-belowground trait linkages and the significance of these root traits to explain intraspecific variability in aboveground growth performance among the demes. The following hypotheses were tested.

(i) The within-deme and between-deme variation in leaf morphological traits matches with similar patterns in root morphological trait variation.

(ii) The intraspecific variation in root and leaf morphology is related to genetic differences between the demes.

(iii) Root and leaf morphological traits relate to aboveground productivity.

Chapter 3: The aim was to identify intraspecific differences in the dependence of aboveground growth performance on hydraulic efficiency and on xylem safety by 
investigating physiologically important key traits in aspen demes, i.e. branch and coarse root xylem anatomy and hydraulic conductivity. We tested the hypotheses that

(iv) Demes differ in wood anatomical and hydraulic properties.

(v) Hydraulic efficiency and vulnerability to cavitation are related to xylem anatomy.

(vi) Hydraulic efficiency is a main determinant of aboveground productivity which trades off with xylem safety.

Chapter 4: The aim was the description of various fine root properties on the level of root orders and root age for species differentiation as well as the investigation of trait modification as a response to belowground competition in a shared soil volume. Competition-induced changes in fine root morphology may indicate species-specific resource acquisition strategies among coexisting species and essentially contribute to species performance. The following hypotheses were tested:

(vii) The fast-growing species ( $P$. trichocarpa) has a higher fine root productivity and interspecific competition is asymmetric in favour of this species.

(viii) Species differences in fine root morphological and chemical traits are consistent across the root order and age classes.

(ix) Competition effects on fine root morphology and chemistry occur mainly in the first order- and juvenile (apical) root segments. 


\section{STUDY DESIGN}

In order to address the different research questions posed in this thesis, the following experimental setups and methods were chosen.

\section{The 'POPDIV' field experiment}

The investigations presented in this work on the intraspecific variability in leaf and fine root morphological traits (Chapter 2) as well as branch and coarse root hydraulic properties (Chapter 3) in $P$. tremula demes and $P$. tremuloides were carried out on saplings grown in the field trail of the Göttingen Poplar Diversity Experiment (POPDIV). The experimental site is located at the Relliehausen Experimental Farm near Silberborn (514ㄴ $56^{\prime \prime} \mathrm{N}$, $9^{\circ} 32^{\prime 2} 28^{\prime \prime} \mathrm{O}$ ) in the Solling Mountains (Figure A 1), about $60 \mathrm{~km}$ West of Göttingen (500 m a. s. l., mean annual temperature $6.9{ }^{\circ} \mathrm{C}$, mean annual precipitation $1030 \mathrm{~mm}$ ).

The setup of the plantation on unfertilized, moderately nutrient-poor soil (22\% sand, $67 \%$ silts tone, $12 \%$ loam and $8 \%$ humus soil) reflects the structure of forest marginal stands as likewise selected for short rotation plantation establishment as an alternative to agricultural land use.

The poplar plant material was selected according to a temperature (North-South) and continental gradient (East-West) within Europe (Germany, Poland, Switzerland, Austria, Sweden) and include $P$. tremuloides from North America as out-grouped representatives concerning the gradient of genetic relatedness between native and non-native aspen species. More detailed information on plant material is given in the methods section of Chapter 2 and 3.

The design of the POPDIV experiment was primarily aimed at investigating the effects of a reduced intraspecific diversity on ecosystem functioning with a special focus on alterations in productivity. The field trail comprised 20 blocks $(18 \times 25.5 \mathrm{~m})$ each consisting of six plots. In each plot, 25 three-year-old poplar plants were arranged in a rectangular grid with a planting distance of $1.5 \mathrm{~m}$. The underlying plot layout was comprised of four diversity levels (A-D, Figure 1.1). In the presented studies (Chapter 2 and 3) the complex layout of the POPDIV field trail functioned as a species pool, in order to select our sampling trees from a population, which could be the result of a natural cross-pairing from a small founder aspen population grown at uniform site conditions. 
To identify and distinguish the different progeny arrays, the term 'deme' was used in the related investigations, and for the description throughout this thesis, following the definition given in Gilmour and Gregor (1939). "A deme can denote any group of organisms of a specified taxon, describing a group of plants from a single location irrespective of pedigree and family relations ... demes can be clone mixtures, single tree progenies after open pollination, progenies from presumably few seed parents and population samples” (Zhang 2012).

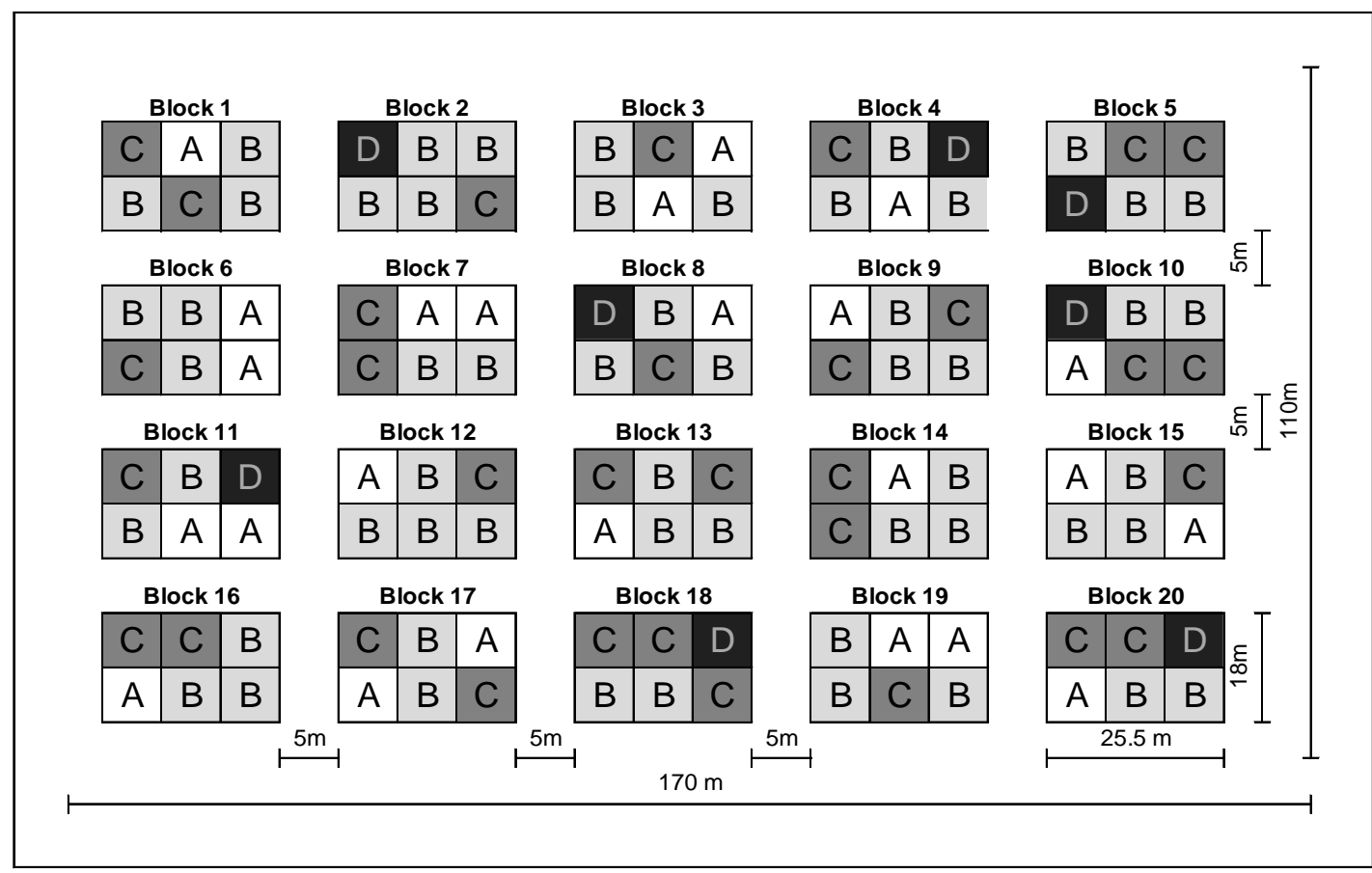

Figure 1.1 Layout of the 'Göttingen Poplar Diversity Experiment' field trail from which our sampling individuals were chosen. Aspen demes (seven P. tremula and one P. tremuloides) were planted in four different diversity levels (A: monoculture, $n=24$; B: two deme mixture, $n=56$; C: four deme mixture, $n=32$ and D: eight deme mixture, $n=8$ ) with a planting distance of $1.5 \mathrm{~m}$. Each block was surrounded by a single tree row serving as buffer zone to avoid edge effects.

Parameters investigated in Chapter 2:

- Tree height, root collar diameter (RCD) and biomass (obtained from allometric function)

- Leaf characteristics (leaf size, SLA, leaf carbon and nitrogen concentration)

- Fine root morphology (diameter, SRA, SRL, RTA, RTD, root carbon and nitrogen concentration) 


\section{The 'Cavitron' approach - hydraulic features of branches and coarse roots}

The investigation concerning xylem anatomical and hydraulic features, xylem vulnerability to cavitation and the relatedness of those parameters to aboveground biomass productivity and drought resistance is investigated in Chapter 4. Measurements were carried out on branch and coarse root samples of four different $P$. tremula demes and the species $P$. tremuloides differing widely in their aboveground growth performance. All samples were obtained from trees grown on the field trail of the Göttingen Poplar Diversity Experiment (see section above). Branch and coarse root samples were collected from 10-15 individual trees in 13 of the 120 plots during the months of June and July 2012. We applied recent techniques such as the Xylem embolism-meter and the Cochard-Cavitron to determine hydraulic properties. Both devices were invented to measure hydraulic conductivity and the embolism rate of plant segments on a larger number of samples. The Cavitron technique uses high negative pressures generated by centrifugation to obtain xylem vulnerability curves to cavitation, thereby indicating species resistance to drought events. The Xylem embolism-meter (Xyl'em) is a stand-alone device enabling researchers to determine the hydraulic conductivity and the embolism rate of plant segments according to Sperry et al. (1988). In addition, cross sections of the sampled coarse and fine roots were analyzed for key xylem anatomical traits to investigate trait relatedness to corresponding growth rates obtained from field measurements using a high resolution stereo-microscope (SteREOV20, Carl Zeiss MicroImaging GmbH, Göttingen, Germany).

Parameters investigated in Chapter 3:

- Tree height, root collar diameter (RCD) and biomass (obtained from allometric function)

- Absolute- and relative growth rates

- Branch anatomy and hydraulic traits

- Coarse root anatomy and hydraulic traits

\section{The rhizobox root competition experiment}

To observe belowground competitive interactions within and between Populus tremula and $P$. trichocarpa saplings (Chapter 4), a competition experiment was set up in a climatized greenhouse chamber in the Experimental Botanical Garden of the University of Göttingen. The study design comprises a total of 36 plant containers (rhizoboxes, Figure 1.2) 
equipped with transparent front plates $(30 \mathrm{~cm} \times 42 \mathrm{~cm}$ ), enabling researchers to record root development and subsequent dissection according to selected root age classes along the observation windows (Figure A 3). Two different treatments were established to generate intraspecific and interspecific competition effects: mono-specific treatments (two plants of the same species) and the mixed treatment (one P. tremula and one P. trichocarpa sapling), each replicated 12 times. A digital image series of the front plates generated in weekly intervals enabled final harvest according to root age in addition to a root orderbased analysis from root material of the box interior. Along with key characteristics of the respective fine root segments, above-and belowground biomass accumulation and relative growth rates were also documented.

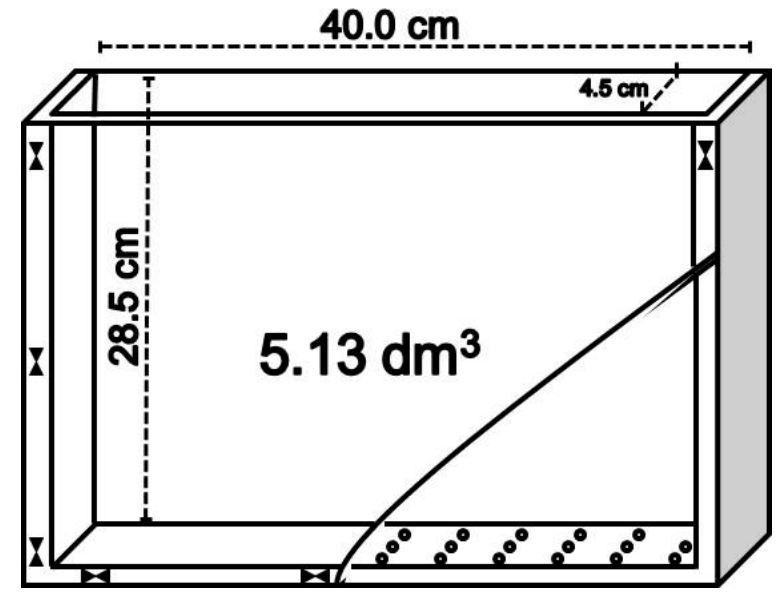

Figure 1.2 Schematic diagram of a rhizobox plant container, equipped with transparent plexiglass front plates to monitor root growth along the observation windows (Chapter 4). Wing bolts lock the plates in place and allow their easy removal to access the rhizosphere for root sampling. The ground element is perforated to facilitate leakage of irrigation water.

Parameters investigated in Chapter 4:

- Above- and belowground biomass

- Species-specific separation according to:

o root order: root morphology and chemistry

o root age: root morphology and chemistry

- Belowground competition treatment (allo- and conspecific species constellation) 


\section{References}

Agrawal A.A. (2001) Phenotypic plasticity in the interactions and evolution of species. Science 294:321-326.

Allen C.D., Macalady A.K., Chenchouni H., ET Al. (2010) A global overview of drought and heat-induced tree mortality reveals emerging climate change risks for forests. Forest Ecology and Management 259:660-684.

Aylott M.J., Casella E., Tubby I., Street N.R., Smith P., TAylor G. (2008) Yield and spatial supply of bioenergy poplar and willow short-rotation coppice in the UK. New Phytologist 178:358-370.

BÄRRING U. (1988) On the reproduction of aspen (Populus tremula L.) with emphasis on its suckering ability. Scandinavian Journal of Forest Research 3:229-240.

Bauhus J., Messier C. (1999) Soil exploitation strategies of fine roots in different tree species of the southern boreal forest of eastern Canada. Canadian Journal of Forest Research 29:260-273.

BAUM S., Bolte A., WeIH M. (2012) High value of short rotation coppice plantations for phytodiversity in rural landscapes. GCB Bioenergy 4:728-738.

BeLl G., LeCHOWICZ M.J. (1994) Spatial heterogeneity at small scales and how plants respond to it. In: CALDWELL MM, PEARCY RW (eds) Exploitation of environmental heterogeneity by plants. pp 391-414

Berndes G., HoOgWIJK M., VAN Den Broek R. (2003) The contribution of biomass in the future global energy supply: a review of 17 studies. Biomass and Bioenergy 25:128.

Beyer F., Hertel D., Leuschner C. (2013) Fine root morphological and functional traits in Fagus sylvatica and Fraxinus excelsior saplings as dependent on species, root order and competition. Plant and Soil 1-14.

Block R., VAn Rees K., Knight J. (2006) A review of fine root dynamics in Populus plantations. Agroforestry Systems 67:73-84.

Bolte A., VillanueVA I. (2006) Interspecific competition impacts on the morphology and distribution of fine roots in European beech (Fagus sylvatica L.) and Norway spruce (Picea abies (L.) Karst.). European Journal of Forest Research 125:15-26.

Bradshaw H.D., Ceulemans R., Davis J., Stettler R. (2000) Emerging model systems in plant biology: poplar (Populus) as a model forest tree. Journal of Plant Growth Regulation 19:306-313.

Brockerhoff E.G., Jactel H., PArrotta J.A., Quine C.P., SAYer J. (2008) Plantation forests and biodiversity: oxymoron or opportunity? Biodiversity and Conservation 17:925-951. 
BRÜGgemann N., Gessler A., KAYler Z., ET AL. (2011) Carbon allocation and carbon isotope fluxes in the plant-soil-atmosphere continuum: a review. Biogeosciences 8:3457-3489.

Brunner A.M., Busov V.B., Strauss S.H. (2004) Poplar genome sequence: functional genomics in an ecologically dominant plant species. Trends in Plant Science 9:4956.

CAHILL JR J.F., CASPER B.B. (2000) Investigating the relationship between neighbor root biomass and belowground competition: field evidence for symmetric competition belowground. Oikos 90:311-320.

Cai J., Tyree M.T. (2010) The impact of vessel size on vulnerability curves: data and models for within-species variability in saplings of aspen, Populus tremuloides Michx. Plant, Cell \& Environment 33:1059-1069.

CALdwell M.M. (1987) Plant Architecture and Resource Competition. In: Schulze E-D, ZwÖLFER H (eds) Potentials and limitations of ecosystem analysis. Springer Berlin Heidelberg, pp 164-179

CALDWELl M.M., RiCHARDS J.H. (1986) Competing root systems: morphology and models of absorption. 251-273.

Cervera M.T., Storme V., Soto A., Ivens B., Montagu M.V., Rajora O.P., Boerjan W. (2005) Intraspecific and interspecific genetic and phylogenetic relationships in the genus Populus based on AFLP markers. Theoretical and Applied Genetics 111:1440-1456.

Christian D.P., Hoffman W., Hanowski J.M., Niemi G.J., Beyea J. (1998) Bird and mammal diversity on woody biomass plantations in North America. Biomass and Bioenergy 14:395-402.

Ciais P., Reichstein M., Viovy N., et AL. (2005) Europe-wide reduction in primary productivity caused by the heat and drought in 2003. Nature 437:529-533.

Cochard H., CASElla E., MEnCUCCINI M. (2007) Xylem vulnerability to cavitation varies among poplar and willow clones and correlates with yield. Tree Physiology 27:1761-1767.

Cronk Q.C.B. (2005) Plant eco-devo: the potential of poplar as a model organism. New Phytologist 166:39-48.

Cruiziat P., Cochard H., AmÉglio T. (2002) Hydraulic architecture of trees: main concepts and results. Annals of Forest Science 59:723-752.

DAVID A.J., Zasada J.C., Gilmore G.W., LANDHAusser S.M. (2001) Current trends in the management of aspen and mixed aspen forests for sustainable production. Forestry Chronicle 77:525-532.

DiCKMANN D.I. (2006) Silviculture and biology of short-rotation woody crops in temperate regions: Then and now. Biomass and Bioenergy 30:696-705. 
Dickmann D.I., KuZOVkinA J. (2008) Poplars and willows of the world, with emphasis on silviculturally important species. Rome, Italy: FAO Forest Management Division Working Paper IPC/9-2 129.

Dimitriou G., BAuM C., AitKen S. (2011) Quantifying environmental effects of short rotation coppice (SRC) on biodiversity, soil and water. IEA Bioenergy Task 43:34.

Eissenstat D.M., Wells C.E., YANAi R.D., WhitBeCK J.L. (2000) Building roots in a changing environment: implications for root longevity. New Phytologist 147:33-42.

ElLenberG H., LeuschneR C. (2010) Vegetation Mitteleuropas mit den Alpen in ökologischer, dynamischer und historischer Sicht, 6th ed. Ulmer, Stuttgart

EuRopeAn Commission (2009) Directive 2009/28/EC of the European Parliament and of the Council of 23 April 2009 on the promotion of the use of energy from renewable sources and amending and subsequently repealing Directives 2001/77/EC and 2003/30. Official Journal of the European Union 5:2009.

EvANS J. (2009) Planted forests: Uses, impacts and sustainability. CABI

FAN Z.-X., Zhang S.-B., HaO G.-Y., Ferry SliK J. W., CAO K.-F. (2012) Hydraulic conductivity traits predict growth rates and adult stature of 40 Asian tropical tree species better than wood density. Journal of Ecology 100:732-741.

FANG S., XUE J., TANG L. (2007) Biomass production and carbon sequestration potential in poplar plantations with different management patterns. Journal of Environmental Management 85:672-679.

FAO (2011) State of the world's forests 2011. FAO, Rome

FAO (2010) Global Forest Resources Assessment 2010. FAO, Rome

FITTER A.H. (1987) An architectural approach to the comparative ecology of plant root systems. New Phytologist 106:61-77.

FITTER A.H. (1982) Morphometric analysis of root systems: application of the technique and influence of soil fertility on root system development in two herbaceous species. Plant, Cell \& Environment 5:313-322.

Fox T.R. (2000) Sustained productivity in intensively managed forest plantations. Forest Ecology and Management 138:187-202.

FREY B.R., LiEFFERS V.J., LANDHÄUSSER S.M., COMEAU P.G., GREENWAY K.J. (2003) An analysis of sucker regeneration of trembling aspen. Canadian Journal of Forest Research 33:1169-1179.

Gilmour J.S.L., Gregor J.W. (1939) Demes: A suggested new terminology. Nature 144:333-333.

Goebel M., Hobbie S.E., Bulaj B., Zadworny M., Archibald D.D., Oleksyn J., Reich P.B., EISSENSTAT D.M. (2010) Decomposition of the finest root branching orders: 
linking belowground dynamics to fine-root function and structure. Ecological Monographs 81:89-102.

GregORIUS H., KLEINSCHMIT J. (1999) The environmental dichotomy of adaptation and the role of genetic diversity. Silvae genetica 48:193-199.

Guo D., Xia M., Wei X., Chang W., LiU Y., WAng Z. (2008) Anatomical traits associated with absorption and mycorrhizal colonization are linked to root branch order in twenty-three Chinese temperate tree species. New Phytologist 180:673-683.

HACKe U., SAUTER J.J. (1996) Drought-induced xylem dysfunction in petioles, branches, and roots of Populus balsamifera L. and Alnus glutinosa (L.) Gaertn. Plant Physiology 111:413-417.

Hacke U.G., SPERry J.S., PoCKMAN W.T., Davis S.D., McCulloh K.A. (2001) Trends in wood density and structure are linked to prevention of xylem implosion by negative pressure. Oecologia 126:457-461.

HACKe U.G., SPERRY J.S., WheEler J.K., CASTRO L. (2006) Scaling of angiosperm xylem structure with safety and efficiency. Tree Physiology 26:689-701.

HAMRICK J. (2004) Response of forest trees to global environmental changes. Forest Ecology and Management 197:323-335.

Helmisaari H.-S., MaKkonen K., KellomäKi S., Valtonen E., Mälkönen E. (2002) Below- and above-ground biomass, production and nitrogen use in Scots pine stands in eastern Finland. Forest Ecology and Management 165:317-326.

HISHI T. (2007) Heterogeneity of individual roots within the fine root architecture: causal links between physiological and ecosystem functions. Journal of Forest Research 12:126-133.

Hodge A. (2004) The plastic plant: root responses to heterogeneous supplies of nutrients. New Phytologist 162:9-24.

Hofmann M. (1998) Bewirtschaftung schnellwachsende Baumarten auf landwirtschaftlichen Flächen im Kurzumtrieb. Forschungsinstitut für schnellwachsende Baumarten. Merkblatt 11.

Hultén E. (1986) Atlas of North European vascular plants north of the Tropic of Cancer. Koeltz Scientific Books, Königstein

IPCC (2007) Climate change 2007: the physical science basis. Agenda 6:07.

Jackson R.B., MoOney H.A., Schulze E.-D. (1997) A global budget for fine root biomass, surface area, and nutrient contents. Proceedings of the National Academy of Sciences 94:7362-7366.

JACKSON R.B., SPERRY J.S., DAWSON T.E. (2000) Root water uptake and transport: using physiological processes in global predictions. Trends in Plant Science 5:482-488. 
Jose S., Williams R., ZAMORA D. (2006) Belowground ecological interactions in mixedspecies forest plantations. Forest Ecology and Management 233:231-239.

KouKi J., ARnold K., MARTIKAinen P. (2004) Long-term persistence of aspen - a key host for many threatened species - is endangered in old-growth conservation areas in Finland. Journal for Nature Conservation 12:41-52.

Lens F., Sperry J.S., Christman M.A., ChOAt B., RABAey D., Jansen S. (2011) Testing hypotheses that link wood anatomy to cavitation resistance and hydraulic conductivity in the genus Acer. New Phytologist 190:709-723.

Lindner M., MaroscheK M., Netherer S., Kremer A., Barbati A., Garcia-GonZalo J., Seidl R., Delzon S., Corona P., Kolström M., LeXer M.J., MarchetTi M. (2010) Climate change impacts, adaptive capacity, and vulnerability of European forest ecosystems. Forest Ecology and Management 259:698-709.

LiU G., Freschet G.T., Pan X., Cornelissen J.H.C., Li Y., Dong M. (2010) Coordinated variation in leaf and root traits across multiple spatial scales in Chinese semi-arid and arid ecosystems. New Phytologist 188:543-553.

LuKac M., Calfapietra C., Godbold D.L. (2003) Production, turnover and mycorrhizal colonization of root systems of three Populus species grown under elevated CO2 (POPFACE). Global Change Biology 9:838-848.

Maherali H., Moura C.F., Caldeira M.C., Willson C.J., Jackson R.B. (2006) Functional coordination between leaf gas exchange and vulnerability to xylem cavitation in temperate forest trees. Plant, Cell \& Environment 29:571-583.

MANTAU U. (2010) Is there enough wood for Europe? EU wood-real potential for changes in growth and use of EU forests, Final Report. Hamburg, Germany

Marron N., Ceulemans R. (2006) Genetic variation of leaf traits related to productivity in a Populus deltoides $\times$ Populus nigra family. Canadian Journal of Forest Research 36:390-400.

Matesanz S., Gianoli E., Valladares F. (2010) Global change and the evolution of phenotypic plasticity in plants. Annals of the New York Academy of Sciences 1206:35-55.

McElrone A.J., Pockman W.T., Martínez-Vilalta J., Jackson R.B. (2004) Variation in xylem structure and function in stems and roots of trees to $20 \mathrm{~m}$ depth. New Phytologist 163:507-517.

MirAnsARI M. (2014) Plant, mycorrhizal fungi, and bacterialnetwork. In: HAKEEM KR, REHMAN RU, TAHIR I (eds) Plant signaling: Understanding the molecular crosstalk. Springer India, pp 315-325

MitTon J.B., Grant M.C. (1996) Genetic variation and the natural history of quaking aspen. BioScience 46:25-31.

Monclus R., Dreyer E., Villar M., Delmotte F.M., Delay D., Petit J.-M., Barbaroux C., Le Thiec D., Bréchet C., Brignolas F. (2006) Impact of drought 
on productivity and water use efficiency in 29 genotypes of Populus deltoides $\times$ Populus nigra. New Phytologist 169:765-777.

MÜLLER A. (2011) Variability of physiological traits and growth performance in aspen assemblages differing in genetic relatedness. Dissertation, University of Göttingen

Müller A., Horna V., Zhang C., Leuschner C. (2012) Different growth strategies determine the carbon gain and productivity of aspen collectives to be used in shortrotation plantations. Biomass and Bioenergy 46:242-250.

NADELHOFFER K.J., RAICH J.W. (1992) Fine root production estimates and belowground carbon allocation in forest ecosystems. Ecology 73:1139-1147.

Pakull B., Groppe K., Meyer M., Markussen T., Fladung M. (2009) Genetic linkage mapping in aspen (Populus tremula L. and Populus tremuloides Michx.). Tree Genetics \& Genomes 5:505-515.

Paquette A., Messier C. (2009) The role of plantations in managing the world's forests in the Anthropocene. Frontiers in Ecology and the Environment 8:27-34.

Pellis A., Laureysens I., Ceulemans R. (2004) Genetic variation of the bud and leaf phenology of seventeen poplar clones in a short rotation coppice culture. Plant Biology 6:38-46.

Pregitzer K.S. (2008) Tree root architecture - form and function. New Phytologist 180:562-564.

PregitZer K.S., KubisKe M.E., Yu C.K., HENDRICK R.L. (1997) Relationships among root branch order, carbon, and nitrogen in four temperate species. Oecologia 111:302308.

Puri S., Singh V., Bhushan B., Singh S. (1994) Biomass production and distribution of roots in three stands of Populus deltoides. Forest Ecology and Management 65:135-147.

Purvis A., Hector A. (2000) Getting the measure of biodiversity. Nature 405:212-219.

Rae A.M., Street N.R., Robinson K.M., Harris N., TAylor G. (2009) Five QTL hotspots for yield in short rotation coppice bioenergy poplar: The Poplar Biomass Loci. BMC Plant Biology 9:23.

Rands M.R.W., AdAms W.M., Bennun L., ButChart S.H.M., Clements A., CoOmes D., Entwistle A., Hodge I., Kapos V., Scharlemann J.P.W., Sutherland W.J., VIRA B. (2010) Biodiversity Conservation: Challenges Beyond 2010. Science 329:1298-1303.

Rewald B., Ephrath J.E., RachmiLeVitch S. (2011) A root is a root is a root? Water uptake rates of Citrus root orders. Plant, Cell \& Environment 34:33-42.

Richards A.E., Forrester D.I., BAuHus J., SCHERER-LorenZEN M. (2010) The influence of mixed tree plantations on the nutrition of individual species: a review. Tree Physiology 30:1192-1208. 
RoOD S.B., BRAATNE J.H., Hughes F.M.R. (2003) Ecophysiology of riparian cottonwoods: stream flow dependency, water relations and restoration. Tree Physiology 23:11131124.

Rood S.B., Goater L.A., Mahoney J.M., Pearce C.M., Smith D.G. (2007) Floods, fire, and ice: disturbance ecology of riparian cottonwoods. Canadian Journal of Botany 85:1019-1032.

Rose D.W., DeBell D.S. (1978) Economic assessment of intensive culture of shortrotation hardwood crops. Journal of Forestry 76:706-711.

Rounsevell M.D.A., Reginster I., AraúJo M.B., CARTer T.R., DendOnCKer N., Ewert F., House J.I., KanKaAnPÄÄ S., LeEmans R., MEtzGer M.J., SCHMit C., SMith P., TUCK G. (2006) A coherent set of future land use change scenarios for Europe. Agriculture, Ecosystems \& Environment 114:57-68.

SCHENK H.J. (2006) Root competition: beyond resource depletion. Journal of Ecology 94:725-739.

SCHMID I., KAzDA M. (2002) Root distribution of Norway spruce in monospecific and mixed stands on different soils. Forest Ecology and Management 159:37-47.

SCHWINNING S., WeINER J. (1998) Mechanisms determining the degree of size asymmetry in competition among plants. Oecologia 113:447-455.

Sperry J.S., Donnelly J.R., Tyree M.T. (1988) A method for measuring hydraulic conductivity and embolism in xylem. Plant, Cell \& Environment 11:35-40.

SpitTlehouse D.L., Stewart R.B. (2004) Adaptation to climate change in forest management. Journal of Ecosystems and Management, North America 4. Available at: <http://www.jem.forrex.org/forrex/index.php/jem/article/view/254/173>.

STEINBECK K. (1999) Thirty years of short-rotation hardwoods research. Proceedings of the 10th biennial southern silvicultural research conference, Shreveport, LA. pp 16-18.

Tallis M.J., Casella E., Henshall P.A., Aylott M.J., Randle T.J., Morison J.I.L., TAYLOR G. (2013) Development and evaluation of ForestGrowth-SRC a processbased model for short rotation coppice yield and spatial supply reveals poplar uses water more efficiently than willow. GCB Bioenergy 5:53-66.

TAYlor G. (2002) Populus: Arabidopsis for forestry. Do we need a model tree? Annals of Botany 90:681-689.

TsudA M., TYREE M.T. (1997) Whole-plant hydraulic resistance and vulnerability segmentation in Acer saccharinum. Tree Physiology 17:351-357.

TusKan G.A., DiFAziO S., JANSSON S., ET AL. (2006) The genome of black cottonwood, Populus trichocarpa (Torr. \& Gray). Science 313:1596-1604.

TYREE M.T. (2003) Hydraulic limits on tree performance: transpiration, carbon gain and growth of trees. Trees 17:95-100. 
Tyree M.T., SPerry J.S. (1989) Vulnerability of xylem to cavitation and embolism. Annual Review of Plant Physiology and Plant Molecular Biology 40:19-36.

Tyree M.T., Zimmermann M.H. (2002) Xylem structure and the ascent of sap. Springer, Berlin Heidelberg

Valenzuela-Estrada L.R., Vera-Caraballo V., Ruth L.E., Eissenstat D.M. (2008) Root anatomy, morphology, and longevity among root orders in Vaccinium corymbosum (Ericaceae). American Journal of Botany 95:1506 -1514.

Weih M., Karacic A., Munkert H., Verwijst T., Diekmann M. (2003) Influence of young poplar stands on floristic diversity in agricultural landscapes (Sweden). Basic and Applied Ecology 4:149-156.

WeINER J. (1990) Asymmetric competition in plant populations. Trends in Ecology \& Evolution 5:360-364.

WeINER J., THOMAS S.C. (1986) Size variability and competition in plant monocultures. Oikos 47:211.

WeSTOBY M., WRIGHT I.J. (2006) Land-plant ecology on the basis of functional traits. Trends in Ecology \& Evolution 21:261-268.

WIKBERG J., ÖGREN E. (2004) Interrelationships between water use and growth traits in biomass-producing willows. Trees 18:70-76.

WILSON J.B. (1988) Shoot competition and root competition. Journal of Applied Ecology 25:279.

Withington J.M., Reich P.B., Oleksyn J., Eissenstat D.M. (2006) Comparisons of structure and life span in roots and leaves among temperate trees. Ecological Monographs 76:381-397.

Wullschleger S.D., JANSSON S., TAYlor G. (2002) Genomics and forest biology Populus emerges as the perennial favorite. The Plant Cell Online 14:2651-2655.

ZHANG C. (2012) Genetic analysis of aspen (Populus tremula L. and Populus tremuloides Michx.) in a diversity experiment. Dissertation, University of Göttingen, Germany

Zsuffa L., Giordano E., Pryor L., STETTLER R.F. (1996) Trends in poplar culture: some global and regional perspectives. In: BRADSHAw HD, HEILMAN PE, HiNCKLEY TM (eds) Biology of Populus and its implications for management and conservation. NRC Research Press, Ottawa, Canada, pp 515-539 . 



\title{
CHAPTER 2
}

\section{INTRASPECIFIC VARIATION IN ROOT AND LEAF TRAITS AND \\ LEAF-RoOT TRAIT LINKAGES IN EIGHT ASPEN DEMES}

\author{
(PoPUlus tREMULA AND P. TREMULOIdES) \\ Peter HajeK, Dietrich Hertel AND Christoph Leuschner
}

IN: Frontiers in Plant Sciences 2013, Vol. 4, ARticle 415

DOI: 10.3389/FPLS.2013.00415 



\section{Abstract}

Leaf and fine root morphology and physiology have been found to vary considerably among tree species, but not much is known about intraspecific variation in root traits and their relatedness to leaf traits. Various aspen progenies (Populus tremula and $P$. tremuloides) with different growth performance are used in short-rotation forestry. Hence, a better understanding of the link between root trait syndromes and the adaptation of a deme to a particular environment is essential in order to improve the match between planted varieties and their growth conditions. We examined the between-deme (genetic) and within-deme (mostly environmental) variation in important fine root traits [mean root diameter, specific root area (SRA) and specific root length (SRL), root tissue density (RTD), root tip abundance, root $\mathrm{N}$ concentration] and their co-variation with leaf traits [specific leaf area (SLA), leaf size, leaf $\mathrm{N}$ concentration] in eight genetically distinct $P$. tremula and $P$. tremuloides demes. Five of the six root traits varied significantly between the demes with largest genotypic variation in root tip abundance and lowest in mean root diameter and RTD (no significant difference). Within-deme variation in root morphology was as large as between-deme variation suggesting a relatively low genetic control. Significant relationships existed neither between SLA and SRA nor between leaf $\mathrm{N}$ and root $\mathrm{N}$ concentration in a plant. Contrary to expectation, high aboveground relative growth rates (RGR) were associated with large, and not small, fine root diameters with low SRA and SRL. Compared to leaf traits, the influence of root traits on RGR was generally low. We conclude that aspen exhibits large intraspecific variation in leaf and also in root morphological traits which is only partly explained by genetic distances. A root orderrelated analysis might give deeper insights into intraspecific root trait variation. 


\section{Introduction}

Leaf morphology and foliar nitrogen $(\mathrm{N})$ content are easy to measure plant traits that have widely been used for characterizing plant growth and resource use strategies (e.g. Reich et al. 1997; Diaz et al. 2004). The analysis of large data bases has revealed general patterns of leaf trait syndromes (e.g. Reich et al. 2003) which reflect trade-offs in terms of energy requirements (Wright et al. 2004) and physical constraints of plant growth. Much less information exists about root traits, in particular traits of fine roots $(<2 \mathrm{~mm}$ in diameter), and their indicative value for recognizing strategies of soil resource exploitation and belowground competitive ability (Bauhus and Messier 1999). Besides total root biomass and maximum rooting depth (Schenk and Jackson 2002), important fine root morphological traits are specific root area (SRA, root surface area per mass), specific root length (SRL, root length per mass), root tissue density (RTD, mass per root volume) and fine root tip abundance (no. of tips per root mass) which may have a large influence on the rates of resource uptake (Jackson et al. 1997), root respiration (Pregitzer et al. 1998; Reich et al. 1998b) and rhizodeposition (Nadelhoffer and Raich 1992; Jackson et al. 1997). Other functionally important traits are root $\mathrm{N}$ concentration and fine root lifespan that influence a root's economy of resource capture (Ryan et al. 1996; Pregitzer et al. 1998; Volder et al. 2005). Roots with greater length and surface development per biomass (high SRL and SRA) can explore larger soil volumes more efficiently and typically have higher resource uptake rates per unit root mass produced than roots with lower SRL and/or SRA. A higher surface (or length) per mass can be achieved either by reducing root tissue density or/and by decreasing root diameters (Eissenstat 1991; Reich et al. 1998a; Ryser 1998; Wright and Westoby 1999). It has been found that root life span increases with growing root tissue density, decreased SRA and lowered root $\mathrm{N}$ concentration (Withington et al. 2006) in a similar manner as it is characteristic for leaf life span, SLA and foliar N concentration.

Despite their small contribution to overall tree biomass (Vogt et al. 1995), fine roots are functionally highly important tree organs that form the plant's interface with the soil and thus may sensitively reflect belowground responses to the environment. While basic knowledge exists about tree species differences in the structure and dynamics of fine roots (Leuschner and Hertel 2003; Withington et al. 2006), root traits might also differ among the different genotypes of a species. However, information on the genetic background of intraspecific variation in fine root system structure and its architectural, morphological and 
physiological properties is very scarce. This is also true for the linkage between root and leaf traits within the genotypes of a species (Ryser and Eek 2000). A notable exception with respect to woody plants is the study by Withington et al. (2006) who compared various root traits among 11 temperate tree species and investigated root-shoot relationships on the species level.

The maintenance of intraspecific diversity (i.e. genetic diversity) is an important component of adaptive evolution, driving the ability of plants to colonize habitats of wide ecological amplitudes and to tolerate environmental change (Gregorius and Kleinschmit 1999; Albert et al. 2011). Early-successional tree species such as Betula, Populus and Salix taxa with broad ecological niches and large distribution ranges should reveal a particularly large intraspecific diversity with respect to leaf and root traits. Trembling aspen with the European species Populus tremula L. (European Common Aspen) and its close North American relative Populus tremuloides Michx. (American Quaking Aspen) belong to the most widespread woody species in the world (Hultén 1986; Dickmann and Kuzovkina 2008). Due to their large genotypic and also phenotypic variability, aspen may achieve a higher adaptability to future climatic changes than species with less intraspecific variation in leaf and root traits (Hamrick 2004). Examining this variability particularly for rootrelated functional traits should substantially improve our understanding of the potential of trees to respond to different environmental conditions.

The present study investigates genotypic variation in fine root traits of aspen populations that originate from a broad range of sites in Central Europe and eastern North America with different climatic conditions. Aspen (P. tremula and P. tremuloides) as fast-growing pioneer trees with considerable drought tolerance and relatively low nutrient demand are one of the species being considered in short-rotation forestry for producing fiber, wood and energy (Bradshaw et al. 2000; Taylor 2002). Due to the continent-wide distribution, aspen may represent a promising study object for investigating genotypic and phenotypic variation in root traits and their linkage to variation in leaf traits. In plantation forestry, it is increasingly important to select genotypes which combine maximum wood production with broad tolerance of stresses associated with climate change. While the intraspecific variation in aboveground morphological, phenological and physiological traits in aspen and their relation to growth have been investigated in much detail (e.g. Barnes 1975; Calagari et al. 2006; Müller et al. 2012a), it is not known whether this variation is similarly 
reflected in root morphology. However, a better understanding of intraspecific trait variation in the root system and its dependence on the genetic relatedness between demes could improve the match between sown varieties and their growth conditions, hence improve growth performance under altered environmental conditions.

The overall goal of this study was to investigate how aspen demes of different geographic origin vary in important root and leaf morphological traits and biomass $\mathrm{N}$ contents when grown at a common site. Following the definition of Gilmour and Gregor (1939), we use the term 'deme', i.e. an assemblage of taxonomically closely related individuals, for identifying the progeny arrays. These aspen demes do not necessarily represent a specific taxonomic category (e.g. species, subspecies or varieties) or a specific origin of a species in the sense of a locally interbreeding population (Zhang 2012). More specifically, we aimed to examine whether (i) the within-deme and between-deme variation in leaf morphological traits matches with similar patterns in root morphological trait variation, (ii) the intraspecific variation in root and leaf morphology is related to genetic differences between the demes, and (iii) how root and leaf morphological traits relate to aboveground productivity.

\section{Materials and methods}

\section{Study site description}

The study was conducted in the framework of the multidisciplinary experiment POPDIV at the University of Göttingen which investigates the role of intraspecific diversity in aspen for productivity and selected ecosystem functions. The common garden experiment was established on the Relliehausen Experimental Farm near Silberborn (51 $44^{\prime} 56^{\prime \prime} \mathrm{N}$, 09³2'28'E) in the Solling Mountains, about $60 \mathrm{~km}$ west of Göttingen (Lower Saxony, Germany). The study area is located at $485 \mathrm{~m}$ a.s.l. in the uplands of Central Germany with a sub-oceanic, cool-temperate climate (mean annual temperature of $6.6{ }^{\circ} \mathrm{C}$; annual mean precipitation of $1110 \mathrm{~mm}$ ). The soil is unfertilized relatively nutrient-poor haplic Cambisol on Triassic sandstone (Middle Bunter) of sandy-loamy texture (Keuter et al. 2013). The site was previously used as extensive cattle pasture. A coring campaign prior to the experiment's start showed that the soil is homogenous across the site, thus effects of soil 
heterogeneity can be excluded throughout all 14 investigated blocks. Some soil characteristics are given in Table 2.1.

Table 2.1. Soil characteristics of the experimental site $(0-10 \mathrm{~cm}$, total contents).

\begin{tabular}{llrl}
\hline \multicolumn{2}{c}{ Variable } & Mean & $\mathrm{SE}$ \\
\hline \hline soil pH & $\left(\mathrm{H}_{2} \mathrm{O}\right)$ & $5.32 \pm 0.21$ \\
$\mathrm{C}$ & $(\%)$ & $4.36 \pm 0.03$ \\
$\mathrm{~N}$ & $(\%)$ & $0.33 \pm 0.01$ \\
$\mathrm{~K}$ & $\left(\mathrm{mg} \mathrm{g}^{-1}\right)$ & $3.7 \pm 0.02$ \\
$\mathrm{Ca}$ & $\left(\mathrm{mg} \mathrm{g}^{-1}\right)$ & $1.58 \pm 0.02$ \\
$\mathrm{Mg}$ & $\left(\mathrm{mg} \mathrm{g}^{-1}\right)$ & $1.52 \pm 0.01$ \\
$\mathrm{Mn}$ & $\left(\mathrm{mg} \mathrm{g}^{-1}\right)$ & $0.67 \pm 0.01$ \\
Fe & $\left(\mathrm{mg} \mathrm{g}^{-1}\right)$ & $12.01 \pm 0.08$ \\
\hline Given are means $\pm \mathrm{SE}$ across 14 blocks \\
(after Kleemann 2010).
\end{tabular}

\section{Plant material}

For the study, we used saplings of seven demes of $P$. tremula and one deme of the closely related $P$. tremuloides. The American taxon P. tremuloides and its close Eurasian relative P. tremula are either considered as sister species (Cervera et al. 2005; Pakull et al. 2009; Grant and Mitton 2010) or as conspecific subspecies (Eckenwalder 1996), depending on the criteria of relatedness used. Both taxa are assumed to have split in the late Miocene about 5-10 Ma ago (Schoell et al. 1994; Shevenell et al. 2004). The data on genetic differentiation among the demes, i.e. the analysis of simple sequence repeats (SSR) and amplified fragment length polymorphism (AFLP) markers, was kindly provided by the Department of Forest Genetics and Forest Tree Breeding at the University of Göttingen (Zhang 2012). The places of origin cover a broad range of moderately warm to cool and oceanic to continental temperate climates and include gradients in mean annual temperature (5.4-10.7 ${ }^{\circ} \mathrm{C}$ ) and annual precipitation (592-1112 mm, Table 2.2). Saplings were raised from seeds or provided as wildlings and out-planted according to a randomized block design comprising 20 blocks $(18.0 \times 25.5 \mathrm{~m})$ each consisting of six plots. All blocks were surrounded by an additional single tree row serving as buffer zone to avoid edge effects. In each plot, 25 3-yr-old poplar plants of a deme were arranged in a rectangular grid with a plant distance of $1.5 \mathrm{~m}$. 
Table 2.2. The eight aspen demes used in the study and their origin.

\begin{tabular}{|c|c|c|c|c|c|c|c|}
\hline Acronym & Country, location & $\begin{array}{l}\text { Type of } \\
\text { culture }\end{array}$ & Coordinates & $\begin{array}{l}\text { Elevation } \\
\text { (m) }\end{array}$ & $\begin{array}{l}\text { Mean annual } \\
\text { precipitation } \\
\quad(\mathrm{mm})\end{array}$ & $\begin{array}{l}\text { Mean annual } \\
\text { temperature } \\
\left({ }^{\circ} \mathrm{C}\right)\end{array}$ & Climate characteristics \\
\hline $\mathrm{AU}$ & Austria, Vienna & Seeds & $48^{\circ} 16^{\prime} \mathrm{N} 16^{\circ} 19^{\prime} \mathrm{E}$ & 390 & 600 & 9.9 & $\begin{array}{l}\text { Moderately cold } \\
\text { winters, warm summers }\end{array}$ \\
\hline $\mathrm{CH}$ & Switzerland, Birmensdorf & Seeds & $47^{\circ} 21^{\prime} \mathrm{N} 08^{\circ} 24^{\prime} \mathrm{E}$ & 692 & 1101 & 8.5 & $\begin{array}{l}\text { Moderately cold } \\
\text { winters, moder. warm } \\
\text { summers }\end{array}$ \\
\hline G1 & Germany, Ahrensbök & Seeds & $53^{\circ} 59^{\prime} \mathrm{N} 10^{\circ} 38^{\prime} \mathrm{E}$ & 25 & 664 & 8.8 & $\begin{array}{l}\text { Maritime winters, mild } \\
\text { summers }\end{array}$ \\
\hline G2 & Germany, Göttingen & Seeds & $51^{\circ} 32^{\prime} \mathrm{N} 09^{\circ} 56^{\prime} \mathrm{E}$ & 315 & 645 & 8.7 & $\begin{array}{l}\text { Mild winters, moder. } \\
\text { warm summers }\end{array}$ \\
\hline G8 & Germany, Göttingen & Seedlings & $51^{\circ} 32^{\prime} \mathrm{N} 09^{\circ} 56^{\prime} \mathrm{E}$ & 315 & 645 & 8.7 & $\begin{array}{l}\text { Mild winters, moder. } \\
\text { warm summers }\end{array}$ \\
\hline PL & Poland, Bialystok & Seedlings & $53^{\circ} 08^{\prime} \mathrm{N} 23^{\circ} 09^{\prime} \mathrm{E}$ & 160 & 592 & 6.7 & $\begin{array}{l}\text { Cold winters, moder. } \\
\text { warm summers }\end{array}$ \\
\hline S & Sweden, Edsvalla & Wildlings & $59^{\circ} 26^{\prime} \mathrm{N} 13^{\circ} 12^{\prime} \mathrm{E}$ & 101 & 635 & 5.4 & $\begin{array}{l}\text { Cold winters, cool } \\
\text { summers }\end{array}$ \\
\hline USA & $\begin{array}{l}\text { U.S.A.: Mass., } \\
\text { Boston/Sandwich }\end{array}$ & Seeds & $42^{\circ} 14^{\prime} \mathrm{N} 71^{\circ} 23^{\prime} \mathrm{W}$ & 80 & 1112 & 10.7 & $\begin{array}{l}\text { Relatively cold winters, } \\
\text { warm summers }\end{array}$ \\
\hline
\end{tabular}

\section{Root collection and root trait analysis}

For the root study, 44 of the 120 plots (in 14 of the 20 blocks) were chosen by random. Between June and early September 2010, fine root $(<2 \mathrm{~mm}$ in diameter) samples were collected from 18-20 tree individuals per deme in the 44 plots; the sampled individuals were chosen by random from the each 25 plants per plot. With a spade, root samples were collected from the upper $30 \mathrm{~cm}$ of the mineral soil at a stem distance of $15-30 \mathrm{~cm}$. To ensure that the root samples taken consisted indeed of fine roots of the nearby target tree, coarse roots from the respective stem were traced toward the terminal root endings and root coring was carried out at this location. We excavated soil monoliths of approximately $4000 \mathrm{~cm}^{3}$ volume containing coarse and fine roots of the respective plant individual, transported them to the laboratory and cleaned it with tap water from adherent soil. Fine roots of herbaceous plants were separated from the aspen fine roots and discarded. One aspen fine root branch of approximately $10 \mathrm{~cm}$ length was extracted from each monolith and used for subsequent analyses of root morphological traits and $\mathrm{C}$ and $\mathrm{N}$ concentrations in the dry mass. Thus, 18-20 replicate root samples per deme were analysed.

The fine root branches were spread out in a water bath and scanned for their surface area with a transmitting scanner system (Epson Expression 1680 1.0, Japan). Image analysis for 
determining the surface area, length and mean diameter of the root segments with a maximum diameter of $2 \mathrm{~mm}$ was conducted with WinRhizo software (Régent, Quebec, Canada). Additionally, the number of root tips per fine root individual was counted under a stereo-microscope and related to root dry mass. The analysed rootlets were oven-dried at $70{ }^{\circ} \mathrm{C}$ for $48 \mathrm{~h}$ until constant weight. Specific root length SRL $\left(\mathrm{cm} \mathrm{g}^{-1}\right)$ was calculated from root length divided by dry mass, specific root area SRA $\left(\mathrm{cm}^{2} \mathrm{~g}^{-1}\right)$ and root tissue density RTD $\left(\mathrm{g} \mathrm{cm}^{-3}\right.$ ) were obtained from surface area divided by dry mass or dry mass divided by fine root volume, respectively. The dried root material was ground and the $\mathrm{C}$ and $\mathrm{N}$ concentrations determined with an elemental analyser (Vario III EL, elementar Analysensysteme GmbH, Hanau, Germany).

\section{Leaf collection and leaf trait analysis}

Simultaneously with root sampling, leaf samples were collected from the same 18-20 individuals per deme chosen for root sampling. Four leaves of the first-order twig on the main terminal shoot of a plant were collected from each tree. Digital images of the leaves were taken using a flatbed scanner (Epson Expression 1680 1.0, Japan). The images were analysed with the software WinFolia 2005b (Régent, Quebec, Canada) for their leaf area. The leaves were dried until constant weight at $70{ }^{\circ} \mathrm{C}$ for $48 \mathrm{~h}$ and specific leaf area (SLA) calculated. The leaves were ground and the leaf material analysed for the $\mathrm{C}$ and $\mathrm{N}$ contents with an elemental analyser (Vario III EL elementar Analysensysteme GmbH, Hanau, Germany).

\section{Relative growth rate and aboveground biomass}

Because the poplar plants were part of a long-term experiment, destructive harvests for determining biomass data and relative growth rate directly were not possible. Alternatively, we estimated aboveground biomass (AGB) from root collar diameter $\left(\mathrm{D}_{0}\right)$ and tree height (h) applying an allometric equation (Eq.1) established empirically by Heinrichs (2010) in a nearby young P. tremula stand on a forest clear-cut with similar site conditions. 


$$
\mathrm{AGB}=0.038 \times \mathrm{D}_{0}^{1.270} \times \mathrm{h}^{1.388}
$$

The calculation of aboveground productivity and aboveground relative growth rate RGR $\left(\mathrm{g} \mathrm{g}^{-1} \mathrm{~d}^{-1}\right.$ ) based on two sequential measurements of tree height and root collar diameter done for 4-15 plants per deme in April 2010 and April 2011.

\section{Statistical analyses}

Statistical analyses were carried out with the software R, version 2.13.2 (R Development Core Team 2011). The dataset was tested for normal distribution by the Shapiro \&Wilk test. In case of non-gaussian distribution, the parameters were log-transformed to meet the assumptions of parametric tests. To test for heteroscedasticity, the fitted values were plotted against the residuals and inspected graphically. We used one-way ANOVA to analyse the influence of deme identity on the investigated morphological trait interactions. The General Linear Hypotheses (glht) procedure with Tukey's post hoc test (contained in the 'multcomp' -package) was applied to detect significant differences in the analysed trait means among the eight demes. Pearson correlation analysis was used to test for relationships between different root traits of the plants and for investigating interrelationships between above- and belowground traits. To test for the relatedness of morphological trait variation and genetic variation across the eight demes, a Mantel test was performed (5000 permuted data sets) using the software Past (Hammer et al. 2001). The information on genetic differentiation among the demes, which bases on the analysis of simple sequence repeats (SSR) and amplified fragment length polymorphism (AFLP) markers, was kindly provided by the Department of Forest Genetics and Forest Tree Breeding at the University of Göttingen (Zhang 2012). We calculated coefficients of within-deme variation $\left(\mathrm{CV}_{\text {intra }}\right)$ and of between-deme variation $\left(\mathrm{CV}_{\text {inter }}\right)$ using Eq. 2:

$$
\mathrm{CV}(\text { in percent })=\mathrm{SD} / \text { mean } \times 100
$$

for allocating total measured trait variation to a genetic component $\left(\mathrm{CV}_{\text {inter }}\right)$ and a predominantly environmental component $\left(\mathrm{CV}_{\text {intra }}\right)$.

A Principal Components Analysis (PCA) was performed on leaf and root morphological and growth-related traits using the software Canoco for Windows 4.5. Means of all 
investigated parameters were standardized and constructed on the two main axes (PC1 and PC2) in the orthogonal plane in addition to the allocation of the eight demes.

All traits that were found in the PCA to be most closely related to relative growth rate were used as explanatory variables in a multiple linear regression to identify their relative importance for plant productivity; traits with close interrelationship or derived from each other were excluded (except for leaf size and SLA). Multiple linear regressions were calculated by stepwise backward model selection using the 'stepAIC'-function from the ‘MASS’-package (Venables and Ripley 2002) for model simplification.

\section{Results}

Between- and within-deme variation in root morphology and root $N$ concentration

Five of the six investigated root traits (diameter, SRA, SRL, root tip abundance, root N concentration) differed significantly between the demes while one (root tissue density) did not (Table 2.3). Mean fine root diameter was very uniform across the seven $P$. tremula demes (means: 0.23-0.27 mm), while the American $P$. tremuloides deme had a significantly larger mean diameter $(0.30 \mathrm{~mm}$; Table 2.4$)$. The relatively large diameter of this deme corresponded to a particularly small SRA and SRL, while the G1, G2 and G8 demes ( $P$. tremula) had the highest SRA and SRL means in correspondence with low diameters (0.23-0.25 mm); however, the difference between these two deme groups mark only a non-significant trend (Table 2.4). The highest between-deme variation was observed for root tip abundance (means ranging from 22.5-39.1 $\mathrm{n} \mathrm{mg}^{-1}$; between-deme variation 47.7\%; Table 2.4). The root $\mathrm{N}$ concentration mean ranged between 1.39 and $1.75 \%$ among the demes and between-deme variation was relatively small (21.3\%). Root tissue density (RTD) was not significantly different between the demes (Table 2.4). The three demes Austria (AU), Germany (G1) and Poland (PL) showed a particularly high within-deme variation that exceeded for most of the seven root traits the between-deme variation. In the other five demes, $\mathrm{CV}_{\text {intra }}$ was mostly smaller than $\mathrm{CV}_{\text {inter }}$. Between-deme (geneticallydetermined) variation was largest in root tip abundance and SRL, intermediate in SRA and root $\mathrm{N}$ concentration, and lowest in root diameter, (Table 2.4). 
Table 2.3. Results of ANOVA on leaf and root trait differences between the eight demes. Parameters with significant variation across the demes are printed in bold.

\begin{tabular}{lccc}
\hline Trait & F & df & $P$ \\
\hline \hline Relative growth rate & 4.34 & 73 & $<\mathbf{0 . 0 0 1}$ \\
Leaf size & 29.8 & 146 & $<\mathbf{0 . 0 0 1}$ \\
SLA & 3.49 & 146 & $<\mathbf{0 . 0 0 1}$ \\
Leaf N concentration & 3.26 & 146 & $<\mathbf{0 . 0 1}$ \\
Fine root diameter & 5.81 & 146 & $<\mathbf{0 . 0 0 1}$ \\
SRA & 2.73 & 146 & $<\mathbf{0 . 0 1}$ \\
SRL & 3.84 & 146 & $<\mathbf{0 . 0 0 1}$ \\
Tip abundance & 5.33 & 145 & $<\mathbf{0 . 0 0 1}$ \\
RTD & 2.04 & 146 & n.s. \\
Root N concentration & 3.25 & 146 & $<\mathbf{0 . 0 1}$ \\
\hline
\end{tabular}

Between- and within-deme variation in leaf morphological and chemical traits

Leaf $\mathrm{N}$ concentration showed a similarly small variation between the demes (means of 2.21-2.65\%; $\mathrm{CV}_{\text {inter }}=16.9 \%$ ) as root $\mathrm{N}$ concentration. A low between-deme variation (14.2\%) was also found for SLA (relatively high SLA means in the P. tremula deme G1, particularly low SLA in the P. tremuloides deme USA; Table 2.4). In contrast, leaf size was the trait with by far largest between-deme variability (70.5\%; Table 2.4). The $P$. tremuloides deme had a four times greater mean leaf size than the deme with smallest leaves (G8) and it exceeded the deme with second largest leaves (AU) nearly twofold (Table 2.4). In contrast to all other investigated leaf or root traits, leaf size showed a much smaller within-deme than between-deme variation (34.5-69.7 vs. 70.5\%). A larger leaf size was associated with a higher foliar $\mathrm{N}$ concentration; leaf $\mathrm{N}$ also increased with increases in SLA (Table 2.5). SLA itself was not related to leaf size in our sample. 
Table 2.4. Morphological and chemical traits of leaves (fully expanded leaves on terminal twigs) and fine roots ( 2 mm in diameter) of the eight aspen demes and their mean relative growth rates (RGR, only aboveground biomass; in $\mathrm{mg} \mathrm{g}^{-1} \mathrm{~d}^{-1}$ for the period April 2010 to April 2011). For deme acronyms see Table 2.2. The eight aspen demes used in the study and their origin. Given are means \pm SE, morphological and chemical traits: $n=18-20$, relative growth rate $n=4-15 ; P<0.05$. The coefficient of variation within the demes (CVintra, \%) and between the eight demes (CVinter, \%; last column) are given. Different letters indicate significant differences in the means between the demes. RTA - root tip abundance.

\begin{tabular}{|c|c|c|c|c|c|c|c|c|c|c|c|c|c|c|c|c|c|c|c|c|c|c|c|c|c|c|}
\hline & & AU & & $\begin{array}{c}\mathrm{CV} \\
\text { intra } \\
(\%)\end{array}$ & $\mathrm{CH}$ & & $\begin{array}{c}\mathrm{CV} \\
\text { intra } \\
(\%)\end{array}$ & G1 & & $\begin{array}{c}\mathrm{CV} \\
\text { intra } \\
(\%)\end{array}$ & G2 & & $\begin{array}{c}\mathrm{CV} \\
\text { intra } \\
(\%)\end{array}$ & G8 & & $\begin{array}{c}\mathrm{CV} \\
\text { intra } \\
(\%)\end{array}$ & $\mathrm{PL}$ & & $\begin{array}{c}\mathrm{CV} \\
\text { intra } \\
(\%)\end{array}$ & $\mathrm{s}$ & & $\begin{array}{c}\mathrm{CV} \\
\text { intra } \\
(\%)\end{array}$ & USA & & $\begin{array}{c}\mathrm{CV} \\
\text { intra } \\
(\%)\end{array}$ & $\begin{array}{l}\mathrm{CV} \\
\text { inter } \\
(\%)\end{array}$ \\
\hline$R G R\left(m g g^{-1} d\right.$ & d 3.20 & \pm 0.55 & $a b$ & 48.4 & $2.46 \pm 0.42$ & $\mathrm{~b}$ & 64.5 & $3.67 \pm 0.68$ & $a b$ & 42.7 & $1.68 \pm 0.24$ & $\mathrm{~b}$ & & $2.42 \pm 0.96$ & $\mathrm{~b}$ & 88.1 & $1.59 \pm 0.9$ & $a b$ & - & $5.25 \pm 0.69$ & $a$ & 49.2 & $5.55 \pm 0.98$ & $\mathrm{a}$ & 43.2 & 76.6 \\
\hline \multicolumn{27}{|l|}{ Leaf traits } \\
\hline Leaf size $\left(\mathrm{cm}^{2}\right)$ & 10.2 & $2 \pm 0.84$ & $\mathrm{a}$ & 36.6 & $6.40 \pm 1.02$ & $\mathrm{~b}$ & 69.7 & $5.55 \pm 0.50$ & $\mathrm{~b}$ & 39.6 & $5.15 \pm 0.40$ & $\mathrm{~b}$ & 34.5 & $4.68 \pm 0.50$ & $\mathrm{~b}$ & 48.3 & $8.19 \pm 0.93$ & $a b$ & 48.0 & $6.31 \pm 0.63$ & $\mathrm{~b}$ & 44.3 & $19.11 \pm 1.58$ & $\mathrm{c}$ & 35.2 & 70.5 \\
\hline SLA $\left(\mathrm{cm}^{2} \mathrm{~g}^{-1}\right)$ & 105 & $5 \pm 3.25$ & $\mathrm{ab}$ & 13.8 & $102.68 \pm 2.57$ & $\mathrm{~b}$ & 10.9 & $119.51 \pm 5.19$ & $\mathrm{a}$ & 18.9 & $103.0 \pm 2.56$ & $\mathrm{~b}$ & 11.1 & $109.47 \pm 3.31$ & $a b$ & 13.5 & $111.33 \pm 3.62$ & $a b$ & 13.8 & $110.15 \pm 2.23$ & $a b$ & 9.0 & $100.05 \pm 3.03$ & $\mathrm{~b}$ & 12.9 & 14.2 \\
\hline Leaf N (\%) & 2.65 & $5 \pm 0.09$ & a & 15.9 & $2.45 \pm 0.11$ & $a b$ & 19.5 & $2.52 \pm 0.07$ & $a b$ & 12.1 & $2.22 \pm 0.06$ & $\mathrm{~b}$ & 12.8 & $2.24 \pm 0.10$ & $\mathrm{~b}$ & 20.0 & $2.41 \pm 0.1$ & $a b$ & 18.1 & $2.21 \pm 0.08$ & $\mathrm{~b}$ & 15.4 & $2.42 \pm 0.07$ & $a b$ & 12.6 & 16.9 \\
\hline \multicolumn{27}{|l|}{ Root traits } \\
\hline Diameter (mm) & 0.27 & $7 \pm 0.01$ & $\mathrm{ab}$ & 11.7 & $0.25 \pm 0.01$ & $\mathrm{bc}$ & 9.5 & $0.23 \pm 0.01$ & $\mathrm{c}$ & 16.4 & $0.25 \pm 0.01$ & $\mathrm{bc}$ & 8.9 & $0.25 \pm 0.01$ & $\mathrm{bc}$ & 9.2 & $0.26 \pm 0.01$ & $\mathrm{bc}$ & 18.7 & $0.26 \pm 0.01$ & $\mathrm{bc}$ & 15.7 & $0.30 \pm 0.01$ & $\mathrm{a}$ & 18.9 & 15.8 \\
\hline SRA $\left(\mathrm{cm}^{2} \mathrm{~g}^{-1}\right)$ & 393 & $3 \pm 31.83$ & $\mathrm{a}$ & 36.2 & $455.13 \pm 22.28$ & $a b$ & 21.3 & $501.09 \pm 35.21$ & $a b$ & 30.6 & $515.73 \pm 27.28$ & $a b$ & 23.7 & $530.91 \pm 23.95$ & $\mathrm{~b}$ & 20.2 & $454.8 \pm 37.61$ & $a b$ & 35.1 & $471.07 \pm 29.01$ & $a b$ & 27.5 & $415.64 \pm 23.78$ & $a b$ & 24.3 & 28.5 \\
\hline $\operatorname{SRL}\left(\mathrm{m} \mathrm{g}^{-1}\right)$ & 58.7 & $7 \pm 6.10$ & a & 46.5 & $74.74 \pm 4.60$ & $a b$ & 26.8 & $90.59 \pm 8.97$ & $\mathrm{~b}$ & 43.2 & $84.83 \pm 5.99$ & $a b$ & 31.6 & $88.82 \pm 4.72$ & $\mathrm{~b}$ & 23.7 & $74.73 \pm 8.22$ & $a b$ & 46.6 & $75.14 \pm 5.31$ & $a b$ & 31.6 & $58.61 \pm 5.31$ & $\mathrm{a}$ & 38.4 & 38.6 \\
\hline RT A (n mg $\left.{ }^{-1}\right)$ & 22.5 & $5 \pm 2.47$ & $a b$ & 49.2 & $30.37 \pm 2.28$ & $\mathrm{bc}$ & 32.8 & $39.09 \pm 3.68$ & $\mathrm{c}$ & 41.0 & $33.83 \pm 2.46$ & $\mathrm{ac}$ & 32.5 & $36.08 \pm 2.56$ & c & 31.0 & $31.13 \pm 3.43$ & $\mathrm{bc}$ & 46.7 & $33.30 \pm 2.55$ & $\mathrm{ac}$ & 34.2 & $20.58 \pm 2.37$ & $\mathrm{~b}$ & 48.8 & 42.7 \\
\hline RTD $\left(\mathrm{g} \mathrm{cm}^{-3}\right)$ & 0.31 & $1 \pm 0.01$ & $\mathrm{a}$ & n.s. & $0.32 \pm 0.02$ & $a b$ & n.s. & $0.34 \pm 0.02$ & $\mathrm{a}$ & n.s. & $0.28 \pm 0.01$ & $a$ & n.s. & $0.29 \pm 0.01$ & $\mathrm{a}$ & n.s. & $0.31 \pm 0.02$ & $\mathrm{a}$ & n.s. & $0.31 \pm 0.02$ & $a$ & n.s. & $0.27 \pm 0.01$ & $a$ & n.s. & n.s. \\
\hline Root N (\%) & 1.45 & $5 \pm 0.07$ & $a b$ & 21.1 & $1.73 \pm 0.07$ & b & 18.1 & $1.54 \pm 0.09$ & $a b$ & 24.7 & $1.68 \pm 0.06$ & $a b$ & 16.6 & $1.75 \pm 0.07$ & b & 19.2 & $1.39 \pm 0.07$ & a & 21.0 & $1.52 \pm 0.06$ & $a b$ & 16.3 & $1.53 \pm 0.09$ & $a b$ & 25.4 & 21.3 \\
\hline
\end{tabular}


The influence of genetic variation on leaf and root trait variation

The results of the Mantel test revealed a close relation between the genetic variation among the demes as visible in the AFLP markers and the variation in aboveground plant biomass recorded for the demes in the year $2011(r=0.87, P=0.04)$. Significant relations were also observed for the parameters leaf size and SLA, whereas aboveground growth rate (RGR) and leaf $\mathrm{N}$ concentration revealed no correspondence in the distances between the molecular and the trait datasets (Table 2.6). From all investigated root traits, only root tissue density and root tip abundance showed a significant correspondence between the two data matrices, while the other root traits (root diameter, SRA, SRL, root N concentration) varied independently from genetic variation across the demes. None of the morphological parameters revealed significant relations to simple sequence repeats (SSR) markers (data not shown). When the leaf or root traits are pooled in the Mantel test analysis, e.g. all investigated leaf traits or all root traits were merged together, the relations remained significant for the aboveground parameters ( $r=0.77, P=0.001$ ), while this was not the case for the root traits ( $r=0.71, P=0.07$ ). When all measured above- and belowground traits were investigated together, the relation was significant $(r=0.84, P=0.05)$.

Table 2.5. Pearson correlation coefficients for linear relationships between three leaf and six root traits across the eight demes $(n=154)$. Significant correlations are marked by $*(P<0.05)$, ** $(P<0.01)$ or $* * *(P<0.001)$ and are printed in bold.

\begin{tabular}{|c|c|c|c|c|c|c|c|c|c|}
\hline & Leaf size & SLA & Leaf $\mathrm{N}$ & Root diam. & SRA & SRL & Tip abund. & RTD & Root N \\
\hline Leaf size & - & & & & & & & & \\
\hline SLA & -0.11 & - & & & & & & & \\
\hline Leaf $N$ & $0.24 * *$ & $0.32^{* * *}$ & - & & & & & & \\
\hline Root diameter & $0.22 * *$ & $-0.23^{* *}$ & -0.02 & - & & & & & \\
\hline SRA & $-0.18 *$ & 0.09 & -0.03 & $-0.52^{* * *}$ & - & & & & \\
\hline SRL & $-0.21^{* *}$ & 0.15 & -0.01 & $-0.70^{* * *}$ & $0.95^{* * *}$ & - & & & \\
\hline Tip abundance & $-0.26 * *$ & 0.15 & -0.02 & $-0.63^{* * *}$ & $\mathbf{0 . 8 0}^{* * *}$ & $\mathbf{0 . 8 4} 4^{* * *}$ & - & & \\
\hline RTD & -0.06 & 0.07 & 0.07 & $-0.27^{* * *}$ & $-0.54^{* * *}$ & $-0.29 * * *$ & $-0.22^{* *}$ & - & \\
\hline Root N & -0.12 & 0.01 & 0.10 & $-0.29 * * *$ & $0.46^{* * *}$ & $0.46^{* * *}$ & $0.36^{* * *}$ & -0.13 & - \\
\hline
\end{tabular}


Table 2.6. Results of a Mantel test conducted to analyse the relationship between morphological trait variance (first matrix) and genetic variance according to AFLP markers (second matrix) in the sample of eight demes. Significantly correlating leaf or root traits are printed in bold $(P<0.05)$.

\begin{tabular}{lcc}
\hline & Mantel's $r$ & Probability $P$ \\
\hline \hline Aboveground RGR & 0.416 & 0.082 \\
Aboveground biomass 2010 & 0.310 & $\mathbf{0 . 0 2 5}$ \\
Aboveground biomass 2011 & 0.870 & $\mathbf{0 . 0 4 1}$ \\
Leaf size & 0.916 & $\mathbf{0 . 0 4 0}$ \\
SLA & 0.362 & $\mathbf{0 . 0 0 2}$ \\
Leaf N concentration & -0.165 & 0.773 \\
Fine root diameter & 0.855 & 0.087 \\
SRA & 0.280 & 0.196 \\
SRL & 0.478 & 0.065 \\
Root tip abundance & 0.493 & $\mathbf{0 . 0 4 7}$ \\
RTD & 0.518 & $\mathbf{0 . 0 4 6}$ \\
Root N concentration & 0.516 & 0.129 \\
& & \\
All leaf morphological traits & 0.767 & $\mathbf{0 . 0 0 9}$ \\
Biomass and growth traits & 0.784 & 0.055 \\
Leaf morphological traits & 0.852 & $\mathbf{0 . 0 0 9}$ \\
& & \\
All root traits & 0.711 & 0.074 \\
All root morphological traits & 0.567 & 0.067 \\
All traits & & \\
\hline
\end{tabular}

Relationships among leaf traits, root traits and RGR

As expected, SRA and SRL showed highly significant negative correlations to root diameter across the sample ( $P<0.001, r=-0.52$ and -0.70 , respectively; Table 2.5). Further, we found inverse relations of RTD to SRA, SRL and root diameter, i.e. higher tissue densities in thinner roots. Root tip abundance increased with SRA and SRL and decreased with increasing diameter (Table 2.5). Roots with smaller diameter but relatively high SRA and SRL had higher root N concentrations; low tissue density was also linked to higher $\mathrm{N}$ concentrations.

Of the 18 tested relationships between root and leaf traits, only five were significant. Demes with higher SLA had smaller fine root diameters, and large-leaved demes had larger root diameters but lower SRA, SRL and tip numbers than demes with smaller leaves 
(Table 2.5). No significant relationships were found between leaf $\mathrm{N}$ concentration and root $\mathrm{N}$ concentration, and between SLA and SRA or SRL. While root N concentration and leaf $\mathrm{N}$ concentration showed similar variation among the eight demes $\left(\mathrm{CV}_{\text {inter }}\right.$ values of 21.3 and 16.9\%), SRA and SRL were more variable than SLA ( $\mathrm{CV}_{\text {inter: }} 28.5$ and 38.6\% vs. 14.2\%). Mean leaf size varied up to twofold among the demes and showed a higher total variation $\left(\mathrm{CV}_{\text {inter: }}: 70.5 \%\right)$ than any root trait.

The estimate of mean aboveground relative growth rate (RGR) for the period April 2010 to April 2011 revealed large differences between the eight demes. The demes with highest RGR (USA: 5.55 and $\mathrm{S}: 5.25 \mathrm{mg} \mathrm{g}^{-1} \mathrm{~d}^{-1}$ ) grew more than three times faster than the two demes with lowest growth rate (PL: 1.59 and G2: $1.68 \mathrm{mg} \mathrm{g}^{-1} \mathrm{~d}^{-1}$ ) (Table 2.4). The other four demes reached intermediate rates $\left(2.42-3.67 \mathrm{mg} \mathrm{g}^{-1} \mathrm{~d}^{-1}\right)$. The two main axes of the PCA explained $81 \%$ of the variability in the ten investigated above- and belowground variables including RGR (Table 2.7, Figure 2.1 ). Axis 1 with an eigenvalue of 0.64 was strongly positively correlated with leaf size and fine root diameter but negatively with the fine root morphological traits SRA, SRL, the number of root tips and root $\mathrm{N}$ concentration. However, none of these root traits were significantly related to relative growth rate indicating that the studied aspen genotypes do not achieve faster aboveground growth through alteration of root morphological characteristics in the range of trait variability investigated here. The second axis (eigenvalue 0.176 ) was primarily associated with leaf $\mathrm{N}$ concentration and RTD. Axis 3 contributed with only $11 \%$ to the variance and was strongly related to RGR, with no other trait being significantly related to this axis.

A multiple regression analysis with backward variable selection of the possible growthinfluencing factors leaf size, SLA, SRL and root tip abundance as predictor variables identified none of the belowground traits as influencing RGR, while leaf size (as a proxy of total leaf area) was detected as the single most important trait. However, the model fitted for the whole data set (eight demes) explained only $18 \%$ of the RGR variation (data not shown). 
Table 2.7. Principal Components Analysis of the eight aspen demes with respect to relative growth rate and leaf and root morphological properties. Given are the loadings of the selected variables along the three most important explanatory axes. Eigenvalues are given in brackets in the headline. Numbers in bold mark the variables with the closest correlation to the respective axis ( $n=4-15$ individuals per deme).

\begin{tabular}{lccc}
\hline Variables & Axis 1 & Axis 2 & Axis 3 \\
& $\mathrm{EV}(0.636)$ & $\mathrm{EV}(0.176)$ & $\mathrm{EV}(0.105)$ \\
\hline \hline
\end{tabular}

Growth-related variable

$\begin{array}{llll}\text { Aboveground RGR } & 0.484 & -0.035 & \mathbf{0 . 8 5 8}\end{array}$

Leaf-related variables

$\begin{array}{lrrr}\text { Leaf size } & \mathbf{0 . 9 2 5} & -0.167 & 0.264 \\ \text { SLA } & \mathbf{- 0 . 6 8 0} & 0.434 & 0.364 \\ \text { Leaf N concentration } & 0.504 & \mathbf{0 . 7 7 3} & -0.159\end{array}$

Root-related variables

\begin{tabular}{lrrr} 
Fine root diameter & $\mathbf{0 . 9 4 4}$ & -0.253 & -0.018 \\
SRA & $\mathbf{- 0 . 9 2 7}$ & -0.324 & 0.102 \\
SRL & $\mathbf{- 0 . 9 7 9}$ & -0.129 & 0.103 \\
Root tip abundance & $\mathbf{- 0 . 9 6 3}$ & -0.013 & 0.212 \\
RTD & -0.299 & $\mathbf{0 . 8 5 9}$ & 0.077 \\
Root N concentration & $\mathbf{- 0 . 9 0 8}$ & -0.146 & -0.120 \\
\hline
\end{tabular}




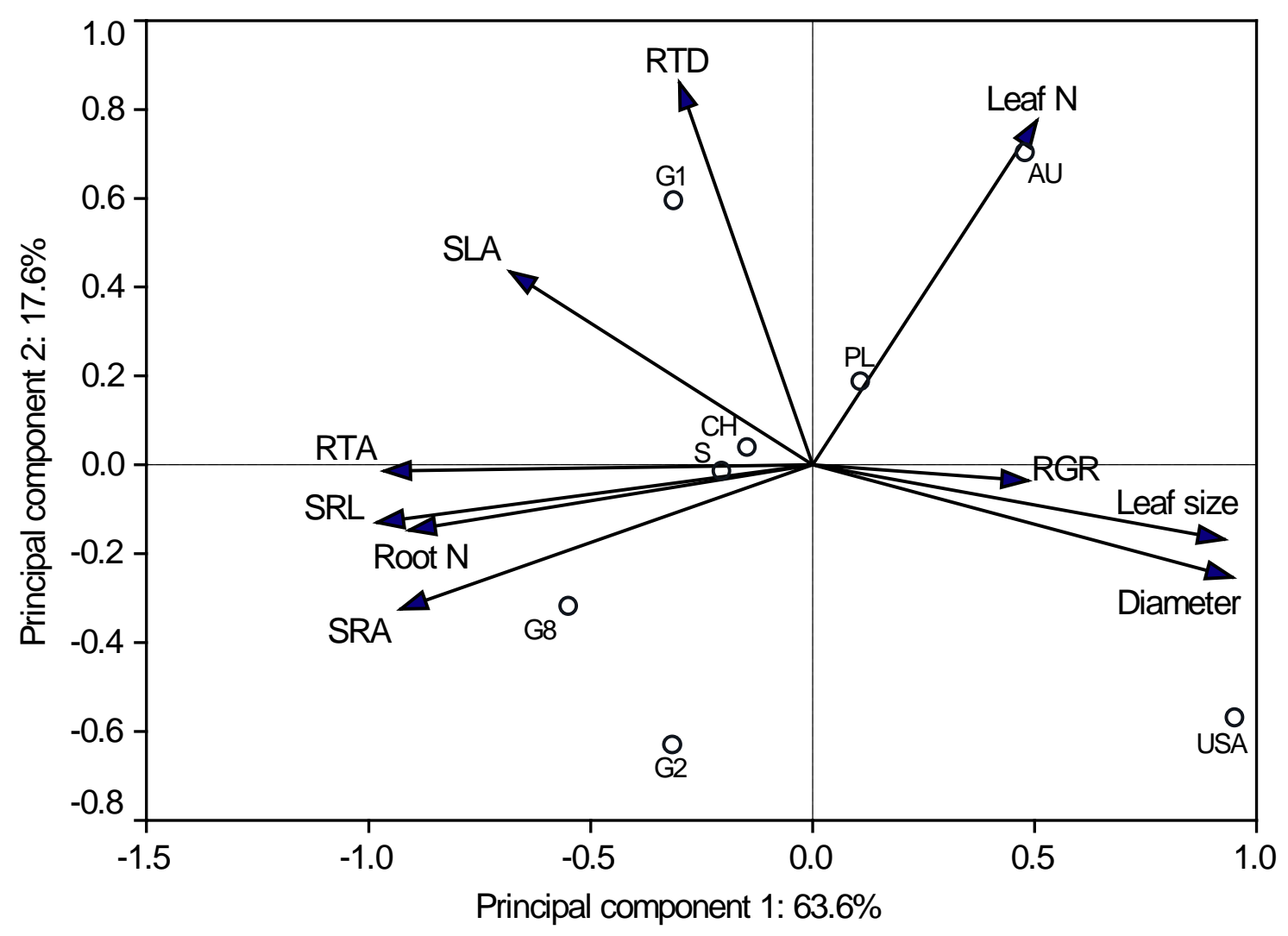

Figure 2.1 Distribution of relative growth rate and root and leaf morphological properties in the orthogonal plane of the Principal Components Analysis for the eight aspen demes and the percentage contribution of the respective axis to total variability, $n=4-15$ individuals per deme. G1, G2, G8, CH, S, PL, AU and USA stand for the eight demes. 


\section{Discussion}

The aspen fine root system: Genotypic variation vs. phenotypic plasticity

Across the eight demes and the 18-20 plants investigated per deme, fine root morphology showed a high variability in all parameters except in fine root diameter. Despite identical climatic conditions and uniform soil across the experimental site, within-deme variation was considerable which may be explained either by genetic variation within the deme or by small-scale soil heterogeneity (e.g. variable stone content at the plant scale). The 18-20 plants of a deme varied in their genetic constitution to a certain degree because they were reared after natural pollination on the same parent tree or represent the offspring of a few trees of a population. This genetic variation should add to the phenotypic plasticity due to small-scale environmental variation at the experimental site. An experiment with clonal plants instead of plants reared from seed would allow differentiating between the effects of genetic variability and those of phenotypic plasticity on root morphology. Measuring errors are another likely source of variation. The remarkably small variation in root diameter found across the 160 aspen plants has to be interpreted with care. It is well recognized that mean fine root diameter is not a good descriptor for the large variation in root morphology and function occurring along the branching hierarchy from the root ending to higher root orders (Pregitzer et al. 2002; Goebel et al. 2010; Rewald et al. 2011; Beyer et al. 2013). Inherent trait variation within the fine root system has also been found in other root traits and it should determine the uptake capacity for water and nutrients through alteration in root surface area or specific root length. For example, even though the means of SRL and root $\mathrm{N}$ concentration were similar to our data, these traits varied by a factor of two among the different fine root orders in the Populus balsamifera plants examined by (Pregitzer et al. 2002). A more detailed analysis of aspen root systems based on root orders might well have detected morphological differences between the demes that were not visible in our analysis. All five investigated root morphological traits revealed a withindeme variation that was in the same magnitude or higher than between-deme variation. Addressing our second study objective, these findings indicate that the studied traits do not underlie strong genetic control. High phenotypic plasticity represents an adaptive advantage when resource availability varies rapidly in time and space as is the case in soils where alternating periods of infiltration and soil drying and pulsed nutrient release from mineralization require a high flexibility in the placing of roots and in root uptake activity. 
In contrast to root morphological traits, genotype had a strong influence on leaf morphology and aboveground plant biomass what is in line with a former study by Müller et al. (2012a).

Highly variable environmental conditions such as $\mathrm{N}$ and water availability exert a large influence on the structure and morphology of plant root systems; this may often mask the genotypic influence (e.g. Lohmus et al. 1989; Ostonen et al. 2007). Strategies for capturing belowground resources at minimal costs include the production of fine roots with high SRL and SRA allowing to achieve high root length densities in large parts of the soil at relatively low cost, or growing roots selectively into nutrient hotspots and moist patches as observed in two grass species (Mommer et al. 2011). Populus species produce very thin roots and can reach much higher SRL than other North American tree species (Pregitzer et al. 2002), what is in line with the observed fast spread of the mainly lateral-distributed root systems of poplars (Pregitzer and Friend 1996). Intensive lateral root growth indicates that poplars seem to follow strategies of short-term reaction to nutrient hotspots rather than maintaining active root systems in large soil volumes. Such a strategy would fit the adaptation to unstable habitats such as bare sandy soils or flooded alluvial soils where many poplars thrive.

\section{Co-variation between root and leaf traits}

In grassland plants, quite a number of studies have examined the interrelation between leaf and root traits for characterizing resource economic trade-offs, mostly with a focus on SLA and SRA or SRL, or leaf and root N concentrations (e.g. Craine and Lee 2003; Craine et al. 2005; Tjoelker et al. 2005). As far as we know, our study is the first to search for co variation in leaf and root traits among different genotypes of a single tree species or species aggregate. Across the eight aspen demes, SLA was inversely correlated with fine root diameter in a similar manner as it was found by Withington et al. (2006) in 11 Central European tree species. In contrast, the SLA-SRL relation was not significant in our study, even though we investigated a total of 160 plants. The missing SLA-SRL relation in aspen matches with results obtained from the comparison of different grass species (Reich et al. 2003; Tjoelker et al. 2005), but contrasts the tighter SLA-SRL relation detected when comparing the seedlings of different tree species (Reich et al. 1998a; Wright and Westoby 
1999; Withington et al. 2006). A significant relation between root and leaf $\mathrm{N}$ concentrations was also lacking in our aspen deme sample which contrasts with the close inter-relationships detected in grass species by Craine and Lee (2003), Craine et al. (2005), Tjoelker et al. (2005) but is in accordance with findings from 11 temperate tree species by Comas and Eissenstat (2009). We also tested for deme differences in the relationship between root and shoot traits using linear models with deme and the respective root trait as explanatory factors and SLA or leaf size as dependent variables, but similarly did not find a significant deme effect on the root-leaf trait linkage. It appears that the significance of inter-relationships between leaf and root properties in a plant is dependent on the variation in plant architectural types and life forms covered by the analysis. The range of trait variation is typically smaller in intraspecific than interspecific comparisons (Comas and Eissenstat 2009) with the consequence that possible relationships between root and leaf traits may well be masked when the within-deme variation in root traits is high as in our study. Again, a root order-related analysis of root traits might have revealed clearer relations between root and leaf traits even at the intraspecific level. However, applying a more sophisticated root order-related approach would result in a reduced number of replicate root samples that can be processed in due time.

\section{Root trait variation and plant growth}

Only few studies have examined how root traits are related to plant productivity and growth strategies. Most of the relevant research was carried out with tree seedlings (Reich et al. 1998b; Wright and Westoby 1999; Comas et al. 2002) or herbaceous plants in greenhouse experiments. Comas and Eissenstat (2004) studied the relation between fine root morphology and chemistry, and growth rate in six-year-old fast- or slow-growing deciduous tree species and found that trees with high potential growth rates constructed roots with smaller diameter, higher SRL, more root tips per unit length and higher root $\mathrm{N}$ concentration. In contrast, the recent results of Tobner et al. (2013) did not confirm significant coordination of fine root traits and RGR across North American temperate tree species. Observations in our study hint to the better studied aboveground trait syndromes where high RGR is typically associated with high SLA (Poorter and Garnier 1999) and a high leaf mass ratio (leaf mass per plant mass) (Poorter and Remkes 1990; Walters et al. 1993), high shoot $\mathrm{N}$ contents and a relatively short leaf longevity (Wright and Westoby 
2000). Müller et al. (2012a; 2012b) conducted a detailed growth analysis in four of the eight aspen demes of this study searching for growth-determining leaf and shoot traits. They concluded that aboveground RGR was primarily determined by total leaf area which itself was largely dependent on the onset of leaf abscission in early autumn in the aspen plants with their continuous leaf production throughout the growing season. Leaf assimilation rate was of minor importance; root traits were not investigated. The results of our regression analysis, which included the aboveground variables leaf size (as a proxy of total leaf area) and SLA and the belowground parameters SRL and root tip abundance, also showed leaf size to be the principal determinant of RGR in the eight-deme sample. Both the PCA and the multiple regression analysis revealed that root traits in general had only a weak or even no influence on aboveground RGR.

We had assumed that the aspen demes with highest SRA and SRL would grow fastest because high growth rates are generally linked to high rates of water and nutrient consumption (van den Driessche et al. 2003) requiring root systems with high uptake capacity as indicated in the study of Comas and Eissenstat (2004). Long thin roots with high SRL and SRA should be more effective in the exploration of water and nutrient reserves in a given soil volume (e.g. Bauhus and Messier 1999). However, they may be more costly in terms of plant resources needed for building them as compared to roots with smaller surface per mass ratios because the former are typically turned over faster and often contain more $\mathrm{N}$ per dry mass (Reich et al. 1998b). Surprisingly, we found in the aspen demes a tendency for a negative relation between (aboveground) RGR and SRA, SRL, and root tip abundance, while growth rate seemed to increase with growing fine root diameter. Even though this relation was not significant, it suggests that these root characteristics are not important for aboveground productivity.

The lack of a linkage between fast growth and a high specific fine root surface area (and root traits in general) may have several reasons. First, we investigated only aboveground, but not belowground productivity. Rapid growth requires a high leaf mass ratio which could lead to simultaneous resource limitation for root growth, demanding for the production of less costly thicker roots with higher longevity. Second, fast-growing trees with higher demand for soil resources can achieve the required uptake capacity either by producing thinner more active fine roots, which explore the space more intensively, or by extending their root system if sufficient unexplored soil space is available. The three-year- 
old aspen plants were still in the stage of expansive root system growth when root sampling took place. Thus, it is possible that the fast-growing demes achieved the assumed higher uptake rate mainly through root system extension and not by forming thinner, more uptake-efficient roots. Unfortunately, we have no information on total root mass and root system size in the eight demes. Finally, genotypic differences in root growth phenology could be as influential, or even more important, for RGR than root morphological traits. Pregitzer and Friend (1996) showed that fast growth in young Populus trees was associated with early root growth. Müller et al. (2012a; 2012b) identified phenological traits (the timing of bud burst and the onset of leaf abscission in late summer) as key factors determining aboveground productivity in P. tremula. While we found bud burst to differ by two weeks among the demes, we have no data on root phenology.

The aboveground phenological traits of aspen seem to be largely under genetic control but they showed no simple relation to the latitude or temperature at the place of origin (Kleemann 2010; Müller et al. 2012a). Monitoring of root growth and death by direct observation techniques has to show whether root phenology is indeed a factor influencing aboveground productivity, and how it depends on genetic or environmental control.

\section{Conclusion}

The fine root system of three-year-old aspen progenies (demes) from origins with broadly contrasting climate differed significantly in several morphological traits indicating that SRA, SRL, RTD, tip abundance and mean root diameter are at least to some extent determined by the genetic constitution. However, within-deme variation in the each 18-20 plants was of similar magnitude as between-deme variation, demonstrating a high intraspecific morphological plasticity of the fine root system probably in response to smallscale soil heterogeneity. We did not find a significant relationship between morphological trait variance and genetic variance suggesting that genetic distance is not an important determinant of root trait divergence. The relation between analogous above- and belowground traits was not very tight at the intraspecific level, probably due to masking by high within-deme variation. The large differences in aboveground RGR among the eight demes were tightly linked to genetically determined leaf morphological and phenological traits but were only to a small extent explained by variation in fine root morphology. Even 
though the studied fine root traits seem not to be good predictors of aspen growth performance, we need more information on genotypic differences in root morphology and function for aspen progenies and other fast-growing tree species used in short-rotation forestry. The limitations of a simple categorization of fine root biomass into diameter classes suggest applying a morphometric approach based on the separation of root orders for coping with the hierarchical heterogeneity in anatomy, chemistry and function of the branching structure of the fine root system. This may allow characterizing specific belowground resource acquisition and allocation strategies among different provenances of a tree species. 


\section{References}

Albert C.H., Grassein F., SchurR F.M., Vieilledent G., Violle C. (2011) When and how should intraspecific variability be considered in trait-based plant ecology? Perspectives in Plant Ecology, Evolution and Systematics 13:217-225.

BARNES B.V. (1975) Phenotypic variation of trembling aspen in western North America. Forest Science 21:319-328.

Bauhus J., Messier C. (1999) Soil exploitation strategies of fine roots in different tree species of the southern boreal forest of eastern Canada. Canadian Journal of Forest Research 29:260-273.

Beyer F., Hertel D., Leuschner C. (2013) Fine root morphological and functional traits in Fagus sylvatica and Fraxinus excelsior saplings as dependent on species, root order and competition. Plant and Soil 1-14.

Bradshaw H.D., Ceulemans R., Davis J., StetTler R. (2000) Emerging model systems in plant biology: poplar (Populus) as a model forest tree. Journal of Plant Growth Regulation 19:306-313.

Calagari M., ModirRahmati A.R., Asadi F. (2006) Morphological variation in leaf traits of Populus euphratica Oliv. natural populations. International Journal of Agriculture and Biology 8:754-758.

Cervera M.T., Storme V., Soto A., Ivens B., Montagu M.V., Rajora O.P., Boerjan W. (2005) Intraspecific and interspecific genetic and phylogenetic relationships in the genus Populus based on AFLP markers. Theoretical and Applied Genetics 111:1440-1456.

ComAs L.H., Bouma T., EIsSENSTAT D.M. (2002) Linking root traits to potential growth rate in six temperate tree species. Oecologia 132:34-43.

CoMAS L.H., EISSENSTAT D.M. (2004) Linking fine root traits to maximum potential growth rate among 11 mature temperate tree species. Functional Ecology 18:388397.

Comas L.H., EIsSENSTAT D.M. (2009) Patterns in root trait variation among 25 co-existing North American forest species. New Phytologist 182:919-928.

CRAINE J.M., LEE W.G. (2003) Covariation in leaf and root traits for native and non-native grasses along an altitudinal gradient in New Zealand. Oecologia 134:471-478.

Craine J.M., LEE W.G., Bond W.J., Williams R.J., JOHNSON L.C. (2005) Environmental constraints on a global relationship among leaf and root traits of grasses. Ecology 86:12-19.

DiAz S., Hodgson J., ThOMPson K., ET AL. (2004) The plant traits that drive ecosystems: Evidence from three continents. Journal of Vegetation Science 15:295-304. 
Dickmann D.I., KuZOVKINA J. (2008) Poplars and willows of the world, with emphasis on silviculturally important species. Rome, Italy: FAO Forest Management Division Working Paper IPC/9-2 129.

VAN DEN DRIESSChe R., Rude W., MARTENS L. (2003) Effect of fertilization and irrigation on growth of aspen (Populus tremuloides Michx.) seedlings over three seasons. Forest Ecology and Management 186:381-389.

ECKenWAlder J.E. (1996) Systematics and evolution of Populus. In: Stettler RF, Bradshaw HD, Heilman PE, HincKley TM (eds) Biology of Populus and its implications for management and conservation. NRC Research Press, Ottawa, Canada, pp 7-32

EisSENSTAT D.M. (1991) On the relationship between specific root length and the rate of root proliferation: a field study using citrus rootstocks. New Phytologist 118:63-68.

Gilmour J.S.L., Gregor J.W. (1939) Demes: A suggested new terminology. Nature 144:333-333.

Goebel M., Hobbie S.E., Bulaj B., Zadworny M., Archibald D.D., Oleksyn J., Reich P.B., EISSENSTAT D.M. (2010) Decomposition of the finest root branching orders: linking belowground dynamics to fine-root function and structure. Ecological Monographs 81:89-102.

GRANT M., MitTon J. (2010) Case study: the glorious, golden, and gigantic quaking aspen. Nature Education Knowledge 3(10):40.

GREGORIUS H., KLEINSCHMIT J. (1999) The environmental dichotomy of adaptation and the role of genetic diversity. Silvae genetica 48:193-199.

HAMMER, HARPER D.A.T., RYAN P.D. (2001) PAST- Palaeontological statistics software package for education and data analysis. 9.

HAMRICK J. (2004) Response of forest trees to global environmental changes. Forest Ecology and Management 197:323-335.

HEINRICHS S. (2010) Response of the understorey vegetation to selection cutting and clear cutting in the initial phase of Norway spruce conversion. Dissertation. University of Göttingen, Germany

HulTÉN E. (1986) Atlas of North European vascular plants north of the Tropic of Cancer. Koeltz Scientific Books, Königstein

Jackson R.B., MoOney H.A., Schulze E.-D. (1997) A global budget for fine root biomass, surface area, and nutrient contents. Proceedings of the National Academy of Sciences 94:7362-7366.

Keuter A., Hoeft I., VeldKamp E., Corre M.D. (2013) Nitrogen response efficiency of a managed and phytodiverse temperate grassland. Plant and Soil 364:193-206. 
KLEEMANN F. (2010) Bedeutung von intraspezifischer Diversität für Ökophysiologie und organische Interaktionen bei der Pappel. Dissertation, University of Göttingen, Germany

LeusChner C., Hertel D. (2003) Fine root biomass of temperate forests in relation to soil acidity and fertility, climate, age and species. Progress in botany. Springer, Berlin Heidelberg, pp 405-438

LOHMUS K., OJA T., LASN R. (1989) Specific root area: a soil characteristic. Plant and Soil 119:245-249.

Mommer L., Visser E.J.W., van Ruijven J., de Caluwe H., Pierik R., De KroON H. (2011) Contrasting root behaviour in two grass species: a test of functionality in dynamic heterogeneous conditions. Plant and Soil 344:347-360.

Müller A., Horna V., Zhang C., Leuschner C. (2012a) Different growth strategies determine the carbon gain and productivity of aspen collectives to be used in shortrotation plantations. Biomass and Bioenergy 46:242-250.

Müller A., Leuschner C., Horna V., Zhang C. (2012b) Photosynthetic characteristics and growth performance of closely related aspen taxa: On the systematic relatedness of the Eurasian Populus tremula and the North American $P$. tremuloides. Flora 207:87-95.

NADELHOFFER K.J., RAICH J.W. (1992) Fine root production estimates and belowground carbon allocation in forest ecosystems. Ecology 73:1139-1147.

Ostonen I., PÜttsepp Ü., Biel C., Alberton O., BAKker M.R., LÕhmus K., Majdi H., Metcalfe D., Olsthoorn A.F.M., Pronk A., Vanguelova E., WeiH M., BRUNNER I. (2007) Specific root length as an indicator of environmental change. Plant Biosystems 141:426-442.

Pakull B., Groppe K., Meyer M., Markussen T., Fladung M. (2009) Genetic linkage mapping in aspen (Populus tremula L. and Populus tremuloides Michx.). Tree Genetics \& Genomes 5:505-515.

POORTER H., GARNIER E. (1999) Ecological significance of inherent variation in relative growth rate and its components. In: Pugnaire FI, VAlLAdAREs F (eds) Handbook of functional plant ecology. Marcel Dekker, New York, pp 81-120

PoORTER H., REMKES C. (1990) Leaf area ratio and net assimilation rate of 24 wild species differing in relative growth rate. Oecologia 83:553-559.

Pregitzer K.S., DeForest J.L., Burton A.J., Allen M.F., Ruess R.W., Hendrick R.L. (2002) Fine root architecture of nine North American trees. Ecological Monographs 72:293-309.

Pregitzer K.S., Friend A.L. (1996) The structure and function of Populus root systems. In: Stettler RF, Bradshaw HD, Heilman PE, HincKley TM (eds) Biology of Populus and its implications for management and conservation. NRC Research Press, Ottawa, Canada, pp 331-353 
Pregitzer K.S., LASKowski M.J., Burton A.J., Lessard V.C., ZAK D.R. (1998) Variation in sugar maple root respiration with root diameter and soil depth. Tree Physiology 18:665-670.

R Development Core Team (2011) R: A language and environment for statistical computing. R Foundation for Statistical Computing, Vienna, Austria

Reich P.B., Buschena C., Tuoelker M.G., Wrage K., Knops J., Tilman D., Machado J.L. (2003) Variation in growth rate and ecophysiology among 34 grassland and savanna species under contrasting $\mathrm{N}$ supply: a test of functional group differences. New Phytologist 157:617-631.

Reich P.B., TJoelker M.G., Walters M.B., VAnderklein D.W., Buschena C. (1998a) Close association of RGR, leaf and root morphology, seed mass and shade tolerance in seedlings of nine boreal tree species grown in high and low light. Functional Ecology 12:327-338.

Reich P.B., Walters M.B., Ellsworth D.S. (1997) From tropics to tundra: Global convergence in plant functioning. Proceedings of the National Academy of Sciences 94:13730-13734.

Reich P.B., Walters M.B., TjoelKer M.G., VAnderklein D., Buschena C. (1998b) Photosynthesis and respiration rates depend on leaf and root morphology and nitrogen concentration in nine boreal tree species differing in relative growth rate. Functional Ecology 12:395-405.

REWALD B., EPhrAth J.E., RACHMiLEVITCH S. (2011) A root is a root is a root? Water uptake rates of Citrus root orders. Plant, Cell \& Environment 34:33-42.

Ryan M.G., Hubbard R.M., Pongracic S., Raison R.J., McMurtrie R.E. (1996) Foliage, fine-root, woody-tissue and stand respiration in Pinus radiata in relation to nitrogen status. Tree Physiology 16:333-343.

RYSER P. (1998) Intra-and interspecific variation in root length, root turnover and the underlying parameters. In: LAMBERS H, POORTER H (eds) Inherent variation in plant growth. Physiological mechanisms and ecological consequences. Backhuys Publishers, Leiden, Netherlands, pp 441-465

RYSER P., EEK L. (2000) Consequences of phenotypic plasticity vs. interspecific differences in leaf and root traits for acquisition of aboveground and belowground resources. American Journal of Botany 87:402-411.

SCHENK H.J., JACKSON R.B. (2002) The global biogeography of roots. Ecological Monographs 72:311-328.

Schoell M., Schouten S., Sinninghe Damste J.S., De LeEuW J.W., Summons R.E. (1994) A molecular organic carbon isotope record of Miocene climate changes. Science 263:1122-1125.

SheVenell A.E., KennetT J.P., LEA D.W. (2004) Middle Miocene southern ocean cooling and Antarctic cryosphere expansion. Science 305:1766-1770. 
TAYLOR G. (2002) Populus: Arabidopsis for forestry. Do we need a model tree? Annals of Botany 90:681-689.

TJoelker M.G., Craine J.M., Wedin D., Reich P.B., Tilman D. (2005) Linking leaf and root trait syndromes among 39 grassland and savannah species. New Phytologist 167:493-508.

Tobner C.M., Paquette A., Messier C. (2013) Interspecific coordination and intraspecific plasticity of fine root traits in North American temperate tree species. Frontiers in Functional Plant Ecology 4:242.

Venables W.N., Ripley B.D. (2002) Modern applied statistics with S. Springer, New York

Vogt K.A., Vogt D.J., Palmiotto P.A., Boon P., O’Hara J., AsbJornsen H. (1995) Review of root dynamics in forest ecosystems grouped by climate, climatic forest type and species. Plant and Soil 187:159-219.

Volder A., Smart D.R., Bloom A.J., Eissenstat D.M. (2005) Rapid decline in nitrate uptake and respiration with age in fine lateral roots of grape: implications for root efficiency and competitive effectiveness. New Phytologist 165:493-502.

WAlters M.B., Kruger E.L., Reich P.B. (1993) Relative growth rate in relation to physiological and morphological traits for northern hardwood tree seedlings: species, light environment and ontogenetic considerations. Oecologia 96:219-231.

Withington J.M., Reich P.B., OleKsyn J., Eissenstat D.M. (2006) Comparisons of structure and life span in roots and leaves among temperate trees. Ecological Monographs 76:381-397.

Wright I.J., Reich P.B., Westoby M., ET AL. (2004) The worldwide leaf economics spectrum. Nature 428:821-827.

WRIGHT I.J., WESTOBY M. (2000) Cross-species relationships between seedling relative growth rate, nitrogen productivity and root vs leaf function in 28 Australian woody species. Functional Ecology 14:97-107.

WRIGHT I.J., WeSTOBY M. (1999) Differences in seedling growth behaviour among species: trait correlations across species, and trait shifts along nutrient compared to rainfall gradients. Journal of Ecology 87:85-97.

ZHANG C. (2012) Genetic analysis of aspen (Populus tremula L. and Populus tremuloides Michx.) in a diversity experiment. Dissertation, University of Göttingen, Germany 



\title{
CHAPTER 3
}

\section{Trade-Offs Between Xylem Hydraulic Properties, WoOd ANATOMY AND Yield IN POPULUS}

\author{
Peter Hajek, Christoph Leuschner, Dietrich Hertel, Sylvain Delzon and \\ BERNHARD SCHULDT
}

ACCEPTED IN: TREe PhySIOLOGY 



\begin{abstract}
Trees face the dilemma that achieving high plant productivity is accompanied with a risk of drought-induced hydraulic failure due to a trade-off in the trees' vascular system between hydraulic efficiency and safety. By investigating the xylem anatomy of branches and coarse roots, and measuring branch axial hydraulic conductivity and vulnerability to cavitation in 4-yr-old field-grown aspen plants of five demes (Populus tremula and $P$. tremuloides) differing in growth rate, we tested the hypotheses that (i) demes differ in wood anatomical and hydraulic properties, (ii) hydraulic efficiency and safety are related to xylem anatomical traits, and (iii) aboveground productivity and hydraulic efficiency are negatively correlated to cavitation resistance.

Significant deme differences existed in seven of the nine investigated branch-related anatomical and hydraulic traits but only in one of the four coarse root-related anatomical traits; this likely is a consequence of high intra-plant variation in root morphology and the occurrence of a few 'high-conductivity roots'. Growth rate was positively related to branch hydraulic efficiency (xylem-specific conductivity) but not to cavitation resistance; this indicates that no marked trade-off exists between cavitation resistance and growth. Both branch hydraulic safety and hydraulic efficiency significantly depended on vessel size and were related to the genetic distance between the demes, while the $\mathrm{P}_{88}$-value was closer related to hydraulic efficiency than the commonly used $\mathrm{P}_{50}$-value. Deme-specific variation in pit membrane structure may explain why vessel size was not directly linked to growth rate.
\end{abstract}

We conclude that branch hydraulic efficiency is an important growth-influencing trait in aspen, while the assumed trade-off between productivity and hydraulic safety is weak. 


\section{Introduction}

While the global demand for wood products is steadily growing (FAO 2009), drought exposure is likely to increase with climate warming in many temperate and tropical forests (IPCC 2007). Thus, forest management faces the challenge of combining high timber yield with drought resistance of the trees for minimizing the risk of failure. This may be even more relevant if the frequency of extreme climatic events increases in future (Schär et al. 2004). However, the production goal could be difficult to achieve due to a trade-off between hydraulic efficiency and hydraulic safety in the conducting system of trees. When plants produce larger vessel diameters in the xylem, hydraulic efficiency increases overproportionally according to Hagen-Poiseuille’s law (Tyree and Zimmermann 2002), but the risk of hydraulic failure due to embolism rises as well (Tyree et al. 1994, Awad et al. 2010). Since fast growth tends to be associated with elevated transpiration rates and higher hydraulic efficiency (Tyree 2003, Monclus et al. 2006), high forest productivity may only be achieved at the cost of increased cavitation vulnerability and thus higher drought sensitivity. How different trees cope with this trade-off, is not well studied. While much research has focused on intraspecific differences in productivity and in cavitation vulnerability (e.g. Martínez-Vilalta et al. 2009, Corcuera et al. 2011, Lamy et al. 2011, Wortemann et al. 2011), the relation between xylem anatomical traits, axial hydraulic conductivity and aboveground growth performance is not well understood. Several studies compared different tree species or hybrids (e.g. Wikberg and Ögren 2004, Cochard et al. 2007, Fichot et al. 2009, Delzon et al. 2010), while intraspecific differences in the hydraulics-growth relationship has only rarely been examined in field-grown trees (e.g., Rosner et al. 2008, Zhang and Cao 2009, Lamy et al. 2014). Although a growing number of studies has revealed a close relation between hydraulic efficiency and growth rate (e.g., Russo et al. 2010, Fan et al. 2012), these studies all were based on stem wood anatomical measurements and derived hydraulic traits, but they did not measure actual hydraulic conductivity in the branch wood directly. Thus, the results should be partly biased by the effect of vessel tapering with increasing tree height (Anfodillo et al. 2013).

One way of increasing woody biomass production is the establishment of short-rotation tree plantations with highly productive woody plants such as poplar (Populus spp.) or willow (Salix spp.). It is well established that genotype plays a crucial role for determining the productivity of Populus species or hybrids in plantation forestry (Marron and 
Ceulemans 2006, Müller et al. 2012a, b). Studies on the relatedness of vessel anatomy and drought resistance showed that the drought resistance of different poplar populations or genotypes differs also within a species (Sparks and Black 1999, Cochard et al. 2007, Awad et al. 2010). This suggests that intraspecific differences in hydraulic traits may be one factor influencing productivity, but information on within-species variation in wood hydraulic properties and their effect on plant growth is scarce. However, in the prospect of climate warming, a better understanding of the genetic control of anatomical and hydraulic properties and their relevance for productivity is a prerequisite for selecting productive and drought-tolerant plant material for short-rotation forestry.

The two aims of the present study were (a) to examine the genetic differentiation in wood anatomical and hydraulic properties of branches and coarse roots in five genetically distinct demes (groups of closely related individuals) of European and North American aspen (Populus tremula L. and P. tremuloides Michx.) and (b) to relate these results to the variation in aboveground productivity. The major study goal was to analyze the dependence of growth on xylem hydraulic efficiency and safety. We hypothesized that (i) demes differ in wood anatomical and hydraulic properties, (ii) hydraulic efficiency and vulnerability to cavitation are related to xylem anatomy, and (iii) hydraulic efficiency is a main determinant of aboveground productivity which trades off with xylem safety.

\section{Materials and methods}

\section{Experimental site and plant material}

The study was embedded in the framework of the research project 'POPDIV' at the University of Göttingen, which investigates the role of intraspecific diversity in aspen for productivity and selected ecosystem functions. A common garden experiment with different poplar (Populus) demes was established on the Relliehausen Experimental Farm near Silberborn (51 $\left.44^{\prime} 56^{\prime \prime} \mathrm{N}, 09^{\circ} 32^{\prime} 28^{\prime \prime} \mathrm{E}\right)$ in the Solling Mountains, about $60 \mathrm{~km}$ west of Göttingen (Lower Saxony, Germany). The study area is located at $485 \mathrm{~m}$ a.s.l. in the uplands of Central Germany with a sub-oceanic, cool-temperate climate (mean annual temperature of $6.6{ }^{\circ} \mathrm{C}$; annual mean precipitation of $1110 \mathrm{~mm}$ ). The soil is unfertilized 
relatively nutrient-poor haplic Cambisol on Triassic sandstone (Middle Bunter) of sandyloamy texture (Keuter et al. 2013). The site was previously used as extensive cattle pasture.

Our investigations were carried out on four $P$. tremula demes and one $P$. tremuloides deme. The term 'deme' is used here for defining aspen progeny arrays; it follows the definition of Gilmour and Gregor (1939) and relates to an assemblage of taxonomically closely related individuals. The demes do not necessarily represent a specific taxonomic category of poplars (e.g. species, subspecies or varieties) or a specific origin of a species in the sense of a locally interbreeding population (Zhang 2012). Since all demes were grown in the same common garden, possible effects of environmental variability on the investigated traits were minimized. Both aspen species are closely related and are considered as sister species (Cervera et al. 2005, Pakull et al. 2009, Grant and Mitton 2010) or as conspecific subspecies (Eckenwalder 1996), depending on the criteria of relatedness used. The places of origin of the different demes cover gradients in mean annual temperature $\left(8.5-10.7{ }^{\circ} \mathrm{C}\right.$ ) and annual precipitation (600-1112 mm; Table 3.1). Saplings of all demes were seed-grown and out-planted in 2008. The common garden trial consists of 120 plots each containing 25 poplar plants arranged in a rectangular grid with a planting distance of $1.5 \mathrm{~m}$. Blocks comprising six plots were surrounded by a single border tree row serving as buffer zone to avoid edge effects. Thirteen of the plots (i.e. two or three per deme) were selected and 10-15 plant individuals per deme (i.e. typically five per plot) were sampled for branch and root segments, but for some measures not all samples could be processed. In total, we selected 62 representative sample trees (replicates), chosen randomly from the different plots in June and July 2012. A list of all measured traits, their symbols and units are given in Table 3.2; the processed analyses are described below.

The data on genetic differentiation among the demes, i.e. the analysis of simple sequence repeats (SSR) and amplified fragment length polymorphism (AFLP) markers, was kindly provided by the Department of Forest Genetics and Forest Tree Breeding at the University of Göttingen (Zhang 2012). 
Table 3.1. Origin and some characteristics of the five aspen demes investigated in the study with deme acronym, climate data at the place of origin (elevation, mean annual precipitation (MAP), mean annual temperature (MAT)), root collar diameter (RCD) and plant height at the beginning of the experiment (2009). Given are means \pm SE (T-test, $P<0.05$ ).

\begin{tabular}{|c|c|c|c|c|c|c|c|c|c|}
\hline Acronym & Species & Place of origin & Coordinates & $\begin{array}{c}\text { Elevation } \\
\text { (m) }\end{array}$ & $\begin{array}{l}\text { MAP } \\
(\mathrm{mm})\end{array}$ & $\begin{array}{l}\text { MAT } \\
\left({ }^{\circ} \mathrm{C}\right)\end{array}$ & Climate characteristics & $\begin{array}{c}\mathrm{RCD}_{2009} \\
(\mathrm{~mm})\end{array}$ & $\begin{array}{l}\text { Height }_{2009} \\
\text { (cm) }\end{array}$ \\
\hline $\mathrm{AU}$ & P. tremula & Austria, Vienna & $48^{\circ} 16^{\prime} \mathrm{N} 16^{\circ} 19^{\prime} \mathrm{E}$ & 390 & 600 & 9.9 & $\begin{array}{l}\text { Moderately cold winters, } \\
\text { warm summers }\end{array}$ & $3.69 \pm 0.18 \mathrm{a}$ & $31.71 \pm 2.28 \mathrm{a}$ \\
\hline $\mathrm{CH}$ & P. tremula & $\begin{array}{l}\text { Switzerland, } \\
\text { Birmensdorf }\end{array}$ & $47^{\circ} 21^{\prime} \mathrm{N} 08^{\circ} 24^{\prime} \mathrm{E}$ & 692 & 1101 & 8.5 & $\begin{array}{l}\text { Moderately cold winters, } \\
\text { moder. warm summers }\end{array}$ & $2.65 \pm 0.29 \mathrm{~b}$ & $19.16 \pm 2.29 \mathrm{~b}$ \\
\hline G8 & P. tremula & $\begin{array}{l}\text { Germany, } \\
\text { Göttingen }\end{array}$ & $51^{\circ} 32^{\prime} \mathrm{N} 09^{\circ} 56^{\prime} \mathrm{E}$ & 315 & 645 & 8.7 & $\begin{array}{l}\text { Mild winters, moder. } \\
\text { warm summers }\end{array}$ & $4.33 \pm 0.10 \mathrm{a}$ & $39.67 \pm 2.44 \mathrm{ac}$ \\
\hline US & P. tremuloides & $\begin{array}{l}\text { U.S.A.: Mass., } \\
\text { Boston/Sandwich }\end{array}$ & $42^{\circ} 14^{\prime} \mathrm{N} 71^{\circ} 23^{\prime} \mathrm{W}$ & 80 & 1112 & 10.7 & $\begin{array}{l}\text { Relatively cold winters, } \\
\text { warm summers }\end{array}$ & $3.59 \pm 0.16 \mathrm{a}$ & $32.78 \pm 2.06$ ac \\
\hline
\end{tabular}

Table 3.2. List of abbreviations used in the study.

\begin{tabular}{lll}
\hline Symbol & Unit & Definition \\
\hline \hline $\mathrm{h}$ & $\mathrm{cm}$ & Tree height \\
RCD & $\mathrm{mm}$ & Root collar diameter \\
AGB & $\mathrm{g}$ & Aboveground biomass \\
AGR & $\mathrm{g} \mathrm{yr}^{-1}$ & Absolute aboveground biomass increment \\
RGR & $\mathrm{g} \mathrm{g}^{-1} \mathrm{yr}^{-1}$ & Relative growth rate \\
$d$ & $\mu \mathrm{m}$ & Vessel diameter \\
$d_{\mathrm{h}}$ & $\mu \mathrm{m}$ & Hydraulically-weighted diameter \\
$d_{\text {wm }}$ & $\mu \mathrm{m}$ & Weighted mean diameter according to vessel size distribution \\
VD & $\mathrm{n} \mathrm{mm}^{-2}$ & Vessel density \\
$A_{\text {cross }}$ & $\mathrm{mm}^{2}$ & Cross-sectional sapwood area \\
$A_{\text {xylem }}$ & $\mathrm{mm}^{2}$ & Xylem sapwood area \\
$A_{\text {lumen }}$ & $\%$ & Relative vessel lumen area (lumen to sapwood area ratio) \\
$K_{\mathrm{s}}$ & $\mathrm{kg} \mathrm{m}^{-1} \mathrm{MPa}^{-1} \mathrm{~s}^{-1}$ & Empirical sapwood area-specific hydraulic conductivity \\
$K_{\mathrm{p}}$ & $\mathrm{kg} \mathrm{m}^{-1} \mathrm{MPa}^{-1} \mathrm{~s}^{-1}$ & Potential sapwood area-specific hydraulic conductivity \\
$\mathrm{P}_{12}$ & $\mathrm{MPa}$ & Xylempressure causing 12\% loss of hydraulic conductivity \\
$\mathrm{P}_{50}$ & $\mathrm{MPa}$ & Xylem pressure causing 50\% loss of hydraulic conductivity \\
$\mathrm{P}_{88}$ & $\mathrm{MPa}$ & Xylem pressure causing 88\% loss of hydraulic conductivity \\
\hline
\end{tabular}


Aboveground plant growth performance

As the experiment was part of a long-term study, tree harvest for obtaining biomass data to assess the aboveground growth performance of the tree individuals was not possible. Instead, aboveground biomass (AGB, in g) was estimated from root collar diameter (RCD, in $\mathrm{mm}$ ) and tree height ( $\mathrm{h}$, in $\mathrm{cm}$ ) as $A G B=0.038 \times \mathrm{RCD}^{1.270} \times \mathrm{h}^{1.388}$ applying the allometric equation established empirically by Heinrichs (2010) in a nearby young $P$. tremula stand on a forest clear-cut with similar site conditions. Aboveground productivity was calculated from two sequential measurements of tree height and root collar diameter before the onset of bud flush in April 2010 and April 2011 as described above and was expressed as absolute growth rate (AGR, $\mathrm{g} \mathrm{yr}^{-1}$ ) or relative growth rate (RGR, $\mathrm{g} \mathrm{g}^{-1} \mathrm{yr}^{-1}$ ).

\section{Branch and coarse root sampling}

One three- to four-year old branch segment (first-order twig on the main terminal shoot, mean age \pm SE: $3.6 \pm 0.1 \mathrm{yr}$ ) of approximately $40 \mathrm{~cm}$ length was cut near the stem, defoliated and immediately put in water-filled plastic tubes for transport to the laboratory. Thereafter, all samples were placed in deionized water containing Micropur (Katadyn, Wallisellen, Switzerland) to prevent microbial activity and stored at $4{ }^{\circ} \mathrm{C}$ until further processing. From the same tree individuals, coarse root segments of similar length were excavated from the soil by tracing single root strands towards the stem to ensure the belonging to the respective tree. Immediately after cutting, coarse roots were cleaned from adherent soil and stored under the same conditions as the branch samples.

\section{Xylem anatomy of branches and coarse roots}

For each deme, 8-11 branch and 9-11 coarse root transverse sections were cut using a sliding microtome (G.S.L.1, Schenkung Dapples, Zürich, Switzerland), yielding 49 branch and 54 root samples in total. Prior to cutting the segments were stained with safranin (1\% in 50\% ethanol, Merck, Darmstadt, Germany) and samples washed three times with 70\% ethanol. The total transverse section of each sample was digitalized at 100x magnification using a stereo-microscope equipped with an automatic stage (SteREOV20, Carl Zeiss MicroImaging GmbH, Jena, Germany; Software: AxioVision v4.8.2., Carl Zeiss MicroImaging GmbH, Jena, Germany). Image processing was done using the software 
Adobe Photoshop CS2 (Version 9.0, Adobe Systems Incorporated, USA) and ImageJ (v1.44p, http://rsb.info.nih.gov/ij) using the particle analysis function. For all subsequent calculations the complete xylem cross-section without pith and bark was analyzed, yielding 4,133 to 21,863 measured vessels per branch sample and 293 to 5,421 measured vessels per root sample. Measured parameters included idealized vessel diameter $(d, \mu \mathrm{m})$ as obtained from major (a) and minor (b) vessel radii according to White (1991) as $d=\left(\left(32 \times(a \times b)^{3}\right) /\left(a^{2} \times b^{2}\right)\right)^{1 / 4}$, vessel density (VD, $\left.\mathrm{n} \mathrm{mm}^{-2}\right)$ and single and cumulative vessel lumen area $\left(A_{\text {lumen }}, \mathrm{mm}^{2}\right)$. Relative vessel lumen area $\left(A_{\text {lumen, }} \%\right)$ was obtained by dividing cumulative vessel lumen area $\left(A_{\text {lumen }}, \mathrm{mm}^{2}\right)$ by the corresponding sapwood area $\left(A_{\text {xylem }}, \mathrm{mm}^{2}\right)$. The diameter of individual vessels was used to calculate hydraulicallyweighted vessel diameter $\left(d_{\mathrm{h}}, \mu \mathrm{m}\right)$ according to Sperry and Saliendra (1994) as $d_{\mathrm{h}}=\Sigma d^{4} /$ $\Sigma d^{5}$. Additionally, weighted mean vessel diameter $\left(d_{\mathrm{wm}}, \mu \mathrm{m}\right)$ was calculated from relative vessel size distribution as $\left.d_{\mathrm{wm}}=\Sigma(\mathrm{VSC} \times \mathrm{RVN}) / d_{\mathrm{max}}\right)$, where VSC is the mean vessel diameter in a given vessel size class, RVN the relative vessel number in that class, and $d_{\max }$ the vessel diameter in the largest vessel size class. Potential sapwood area-specific hydraulic conductivity $\left(K_{\mathrm{p}}, \mathrm{kg} \mathrm{m}^{-1} \mathrm{MPa}^{-1} \mathrm{~s}^{-1}\right)$ was calculated according to the HagenPoiseuille equation as $\left.K_{\mathrm{p}}=\left(\left(\pi \times \Sigma \mathrm{r}^{4}\right) / 8 \eta\right) \times \rho\right) / A_{\mathrm{xylem}}$, where $\eta$ is the viscosity of water (1.002 $\left.10^{-9} \mathrm{MPa} \mathrm{s}\right), \rho$ the density of water $\left(998.2 \mathrm{~kg} \mathrm{~m}^{-3}\right)$, both at $20^{\circ} \mathrm{C}$ and $A_{\text {xylem }}\left(\mathrm{m}^{2}\right)$ the corresponding xylem area without pith and bark.

\section{Hydraulic conductivity measurement}

Hydraulic traits were measured in each 10-13 branch segments (replicates; mean diameter \pm SE: $7.01 \pm 0.27 \mathrm{~mm}$ ) per deme according to Sperry et al. (1988) using a Xyl'em apparatus (Bronkhorst, Montigny-les-Cormeilles, France), yielding 57 samples in total. Coarse roots, however, showed an extremely high conductivity and exceeded the measureable range $\left(20 \mathrm{~g} \mathrm{~h}^{-1}\right)$ of our Liqui-Flow meter inside the Xyl'em apparatus with approximately $300 \mathrm{~g} \mathrm{~h}^{-1}$ by far and were excluded from all further analyses.

In the laboratory, all lateral branches, if present, were cut off and the scares sealed with quick-drying superglue (Loctite 431, Henkel, Düsseldorf, Germany) applicable to wet surfaces, and segments subsequently shortened to a length of $294.9 \pm 2.0 \mathrm{~mm}$ (mean $\pm \mathrm{SE}$ ) under water. For the determination of maximal hydraulic conductivity $\left(K_{\mathrm{h}}, \mathrm{kg} \mathrm{m} \mathrm{MPa}^{-1} \mathrm{~s}^{-1}\right)$ 
at $6 \mathrm{kPa}$, demineralized filtered $(0.22 \mu \mathrm{m})$ and degassed water $(10 \mathrm{mM} \mathrm{KCl}$ and $1 \mathrm{mM}$ $\mathrm{CaCO}_{3}$ ) was used, interrupted by three 10 -min flushes at $120 \mathrm{kPa}$ to assure removal of all potential emboli. Subsequently, top-view images of the planed basipetal and distal ends of each branch segment were taken at high resolution with a stereo-microscope (SteREOV20, Carl Zeiss MicroImaging GmbH, Göttingen, Germany), and images analyzed with the software ImageJ (v1.44p, http://rsb.info.nih.gov/ij) for total cross-sectional $\left(A_{\text {cross, }}, \mathrm{mm}^{2}\right)$ and corresponding xylem area without pith and bark $\left(A_{\mathrm{xylem}}, \mathrm{mm}^{2}\right)$. Empirical sapwood area-specific hydraulic conductivity $\left(K_{\mathrm{S}}, \mathrm{kg} \mathrm{m}^{-1} \mathrm{MPa}^{-1} \mathrm{~s}^{-1}\right)$ was calculated by dividing $K_{\mathrm{h}}$ by corresponding basipetal maximal xylem area without pith and bark. However, in order to decide what corresponding xylem area from each c. $30 \mathrm{~cm}$ long branch segment should be used to calculate $K_{\mathrm{S}}$ due to the sample tapering effect, regression models for the relation between $A_{\text {xylem }}$ and the corresponding total cross-sectional $\left(A_{\text {cross }}, \mathrm{mm}^{2}\right.$ ) were derived for each deme (Table A 1) and applied to calculate corresponding maximal, mean or minimal xylem area for each segment from eight diameter measurements. Subsequently, $K_{\mathrm{h}}$ was divided by these three measures and related to four wood anatomical and hydraulic traits on sample level. According to this linear regression analyses, $K_{\mathrm{h}}{ }^{\text {emp }}$ divided by the maximal basipetal xylem area revealed stronger relations than when calculated with mean or minimum xylem area (Table A 2).

\section{Xylem resistance to cavitation and estimation of hydraulic safety margins}

We used the Cavitron technique (Cochard et al. 2005) for measuring vulnerability to xylem cavitation on 4-12 branch samples (replicates) per deme, each taken from different tree individuals. The same samples prior flushed with the Xyl'em apparatus were mounted in a custom-built rotor chamber of the Cavitron, which uses a commercially available centrifuge as basis (Sorvall RC-5C, Thermo Fisher Scientific, Waltham, MA, USA), and spun at defined velocities recorded with the software CaviSoft (version 2.1, University of Bordeaux, France). Measurements started at a pressure of $-0.37 \mathrm{MPa}$. The negative pressure was then increased stepwise until the percent loss of conductivity (PLC) reached at least 90\%. For each branch segment, a sigmoid function (Willigen and Pammenter 1998) was fitted to describe the relationship between PLC and xylem pressure (vulnerability curve, VC) using the expression $P L C=100 /\left(1+\exp \left(s / 25 \times\left(P_{\mathrm{i}}-P_{50}\right)\right)\right.$, where $\mathrm{P}_{50}(\mathrm{MPa})$ is the xylem tension causing $50 \%$ loss of hydraulic conductivity and $s\left(\% \mathrm{MPa}^{-1}\right)$ is the 
slope of the curve at the inflexion point. The xylem pressures causing $12 \%$ and $88 \%$ loss of conductivity were calculated as well following Domec and Gartner (2001) and Choat et al. (2012). We further used available leaf water potential data from the trees of this experiment after Müller et al. (2012a, b) to calculate deme-specific hydraulic safety margins, which are defined as the difference between minimum leaf water potential measured in the field and the corresponding $P_{50}$ value (Choat et al. 2012).

All coarse roots measured with the centrifuge technique revealed r-shaped vulnerability curves (Figure 3.1), i.e. these segments lose their conductance at modest pressure and must possess open vessels in segments of $28 \mathrm{~cm}$ length; this was confirmed for a subsample of 10 coarse roots by the air injection method (data not shown) and they thus were excluded from further analyses.

\section{Statistical analysis}

Statistical analyses were performed with the software R, version 2.13.2 (R Development Core Team 2011). Prior to analysis, the data were tested for normal distribution with the Shapiro-Wilk test and for homogeneity of variances with the Bartlett test. One-way ANOVA was used to analyze the influence of deme on the investigated traits. The General Linear Hypotheses (glht) procedure with Tukey's post hoc test was applied to detect significant differences in the analyzed trait means among the eight demes. Pearson correlation analysis was used to test for inter-relationships between different branch and coarse root traits of the plants and for detecting relationships between above- and belowground traits based on data pooled across all demes; some data had to be logtransformed in order to achieve normal distribution. To test for the relatedness of morphological trait variation and genetic variation across the five demes, a Mantel test was performed (5000 permuted data sets) using the software PAST (Hammer et al. 2001). Several linear and non-linear regression analyses were carried out with the software Xact 8.03 (SciLab, Hamburg, Germany). 


\section{Results}

Between-deme variation in branch and coarse root xylem anatomy and hydraulics

We found significant differences between the demes in four of the five branch anatomical traits (exception: $A_{\text {lumen; }}$ ANOVA) but in only one of the root anatomical traits (mean vessel diameter; Table 3.3). The demes from Austria (AU) and Germany (G2 and G8) were very similar in their branch anatomy; the Swiss deme $(\mathrm{CH})$ differed more from these three Central European demes than the P. tremuloides deme (US), despite its relatively large genetic distance to the $P$. tremula demes. In contrast, the coarse roots of $P$. tremuloides were more different in their anatomy from the European $P$. tremula demes (significant for vessel diameter). The comparison of branch and coarse root xylem in the same plants revealed a two times larger mean vessel diameter, a 2.4-2.7 times larger hydraulicallyweighted vessel diameter $\left(d_{\mathrm{h}}\right)$ and a twice as large relative vessel lumen area $\left(A_{\text {lumen }}\right)$, but a three times lower vessel density (VD) in coarse root xylem than branch xylem (Table 3.3, Figure 3.1) 

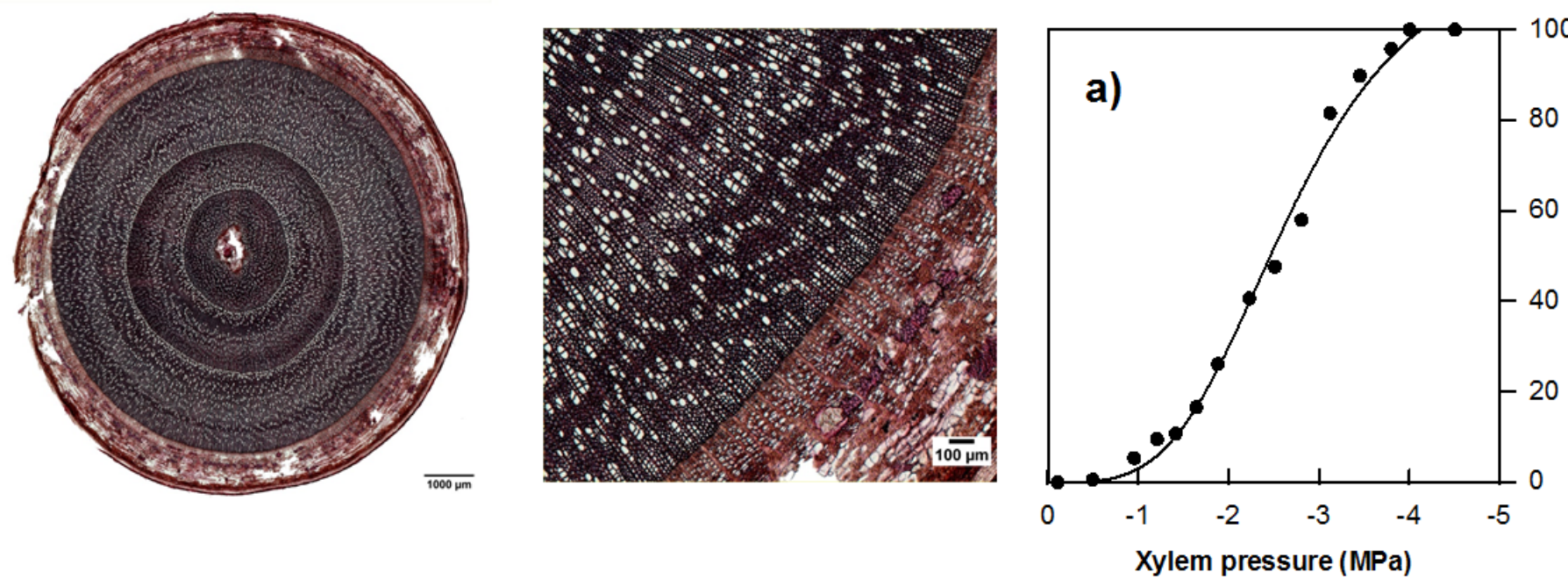

ํㅜㄹ
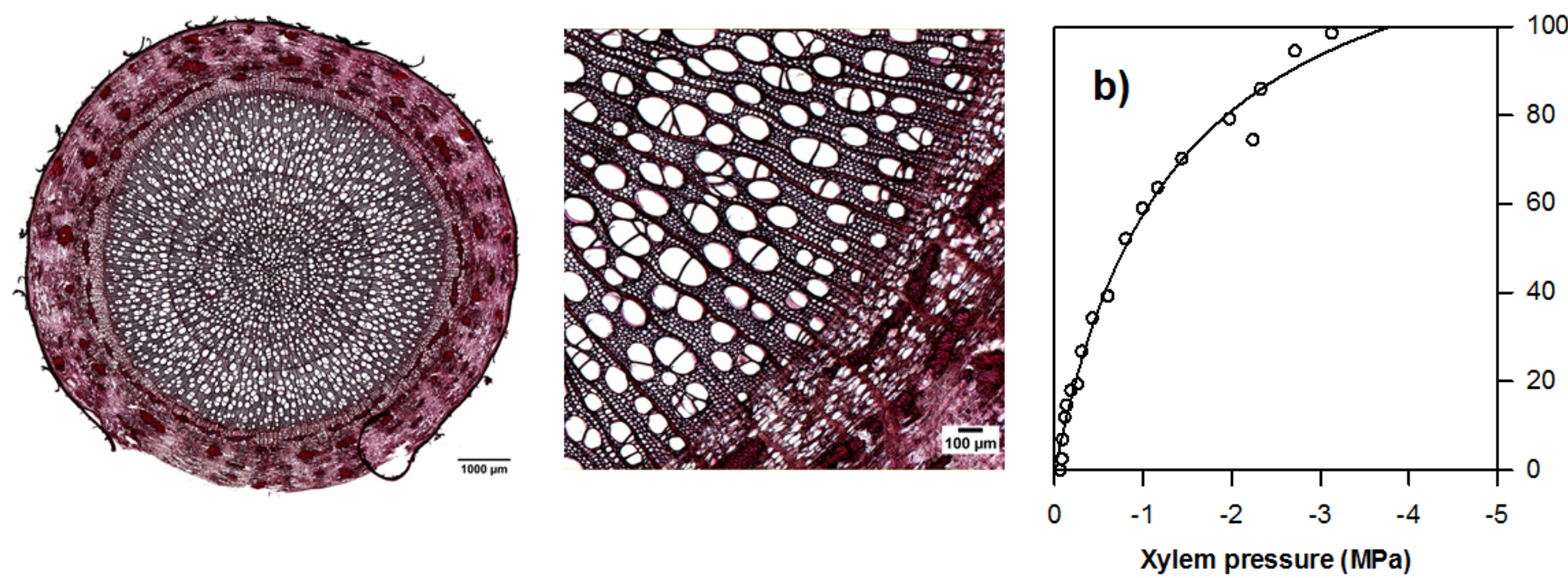

Figure 3.1 Exemplary cross-sectional images of branch (upper left) or coarse root segments (lower left) with sections displayed at higher magnification (upper right and lower right) of the aspen deme US (P. tremuloides). The graphs at the right give xylem vulnerability curves (percent loss of hydraulic conductivity vs. xylem tension) for representative (a) branch segments (characteristic s-shaped curve) or (b) coarse root segments (r-shaped curve). 

Table 3.3. Traits related to plant size and morphology, to biomass production in the period April 2010 to April 2011, and to wood anatomy and hydraulics of branch and coarse root samples of the five aspen demes (four $P$. tremula and one $P$. tremuloides [US] deme). Different letters indicate significant differences in the means between demes ( $P<0.05$, means \pm SE). The number of investigated trees is given in brackets. For abbreviations see Table 3.2.

\begin{tabular}{|c|c|c|c|c|c|c|c|c|c|c|c|c|c|}
\hline \multirow{2}{*}{\multicolumn{2}{|c|}{$\begin{array}{l}\text { Variable } \quad \text { Unit } \\
\text { Stand characteristics }\end{array}$}} & \multicolumn{3}{|l|}{ AU } & \multicolumn{2}{|l|}{$\mathbf{C H}$} & \multicolumn{3}{|l|}{ G2 } & \multicolumn{2}{|l|}{ G8 } & \multicolumn{2}{|l|}{ US } \\
\hline & & & & & & & & & & & & & \\
\hline Height $_{2011}$ & $\mathrm{~m}$ & $161.90 \pm 7.83$ & $\mathrm{a}$ & (10) & $128.58 \pm 6.63$ & b (12) & $131.23 \pm 9.63$ & $\mathrm{~b}$ & (11) & $142.64 \pm 8.27$ & ab (14) & $193.83 \pm 8.89$ & с (15) \\
\hline $\mathrm{RCD}_{2011}$ & $\mathrm{~cm}$ & $16.99 \pm 1.04$ & $\mathrm{a}$ & (10) & $13.47 \pm 0.66$ & b (12) & $14.1 \pm 0.50$ & $\mathrm{ab}$ & (11) & $16.18 \pm 0.82$ & ab (14) & $22.83 \pm 1.14$ & с (15) \\
\hline $\mathrm{AGB}_{2011}$ & g & $92.16 \pm 13.41$ & $\mathrm{a}$ & (10) & $48.34 \pm 6.26$ & b (12) & $53.49 \pm 8.76$ & $\mathrm{~b}$ & (11) & $73.4 \pm 10.94$ & ab (14) & $160.78 \pm 12.21$ & с (15) \\
\hline \multicolumn{14}{|c|}{ Growth-related traits } \\
\hline AGR $_{\text {biomass }}$ & $\mathrm{g} \mathrm{yr}^{-1}$ & $54.79 \pm 9.43$ & $\mathrm{a}$ & (11) & $20.89 \pm 4.66$ & b (10) & $22.13 \pm 4.41$ & $\mathrm{~b}$ & (10) & $39.25 \pm 7.63$ & ab (11) & $108.99 \pm 12.54$ & с (11) \\
\hline $\mathrm{RGR}_{\text {biomass }}$ & $\mathrm{g} \mathrm{g}^{-1} \mathrm{yr}^{-1}$ & $1.25 \pm 0.14$ & $\mathrm{a}$ & (11) & $0.68 \pm 0.08$ & b (10) & $0.82 \pm 0.15$ & $\mathrm{ab}$ & (10) & $0.93 \pm 0.11$ & ab (11) & $2.49 \pm 0.39$ & с (11) \\
\hline \multicolumn{14}{|c|}{ Branch-related traits } \\
\hline \multicolumn{14}{|c|}{ Wood anatomy } \\
\hline$d$ & $\mu \mathrm{m}$ & $22.35 \pm 0.43$ & $\mathrm{a}$ & (8) & $24.32 \pm 0.53$ & ab (11) & $23.40 \pm 0.50$ & $\mathrm{ab}$ & (8) & $22.21 \pm 0.34$ & a $\quad(9)$ & $23.55 \pm 0.29$ & b (9) \\
\hline$d_{\mathrm{h}}$ & $\mu \mathrm{m}$ & $28.6 \pm 0.65$ & $\mathrm{a}$ & (7) & $31.36 \pm 0.75$ & ab (11) & $28.83 \pm 0.57$ & $\mathrm{a}$ & (6) & $26.96 \pm 0.60$ & a $\quad(9)$ & $28.82 \pm 0.55$ & b (11) \\
\hline VD & $\mathrm{n} \mathrm{mm}^{-2}$ & $298.22 \pm 10.29$ & $\mathrm{a}$ & (7) & $270.80 \pm 10.12$ & b (10) & $286.87 \pm 16.26$ & $\mathrm{ab}$ & (8) & $281.80 \pm 13.45$ & ab (11) & $297.37 \pm 9.25$ & a (10) \\
\hline$A_{\text {lumen }}$ & $\%$ & $0.12 \pm 0.01$ & $\mathrm{a}$ & (8) & $0.14 \pm 0.01$ & a (11) & $0.12 \pm 0.01$ & a & $(8)$ & $0.12 \pm 0.01$ & a (11) & $0.14 \pm 0.01$ & a (11) \\
\hline \multicolumn{14}{|c|}{ Hydraulic properties } \\
\hline $\mathrm{P}_{12}$ & & $-1.26 \pm 0.21$ & $\mathrm{a}$ & (10) & $-1.03 \pm 0.35$ & ab (4) & $-2.15 \pm 0.21$ & $\mathrm{~b}$ & (11) & $-1.97 \pm 0.22$ & ab (12) & $-1.97 \pm 0.22$ & $\mathrm{ab} \quad(6)$ \\
\hline$P_{50}$ & & $-2.53 \pm 0.15$ & & (10) & $-2.21 \pm 0.19$ & a (4) & $-2.96 \pm 0.09$ & $\mathrm{~b}$ & (11) & $-2.97 \pm 0.12$ & b (12) & $-2.62 \pm 0.12$ & $\mathrm{ab} \quad(6)$ \\
\hline $\mathrm{P}_{88}$ & & $-3.79 \pm 0.19$ & $\mathrm{ab}$ & (10) & $-3.38 \pm 0.09$ & ab (4) & $-3.78 \pm 0.07$ & $\mathrm{ab}$ & (11) & $-3.97 \pm 0.09$ & b (12) & $-3.27 \pm 0.08$ & a (6) \\
\hline$K_{\mathrm{s}}$ & $\mathrm{kg} \mathrm{m}^{-1} \mathrm{MPa}^{-1} \mathrm{~s}$ & $1.30 \pm 0.13$ & $\mathrm{ab}$ & (10) & $1.12 \pm 0.12$ & ab (11) & $0.94 \pm 0.14$ & $\mathrm{~b}$ & (10) & $1.05 \pm 0.17$ & b (12) & $1.63 \pm 0.15$ & a (14) \\
\hline Safety margin & MPa & $1.57 \pm 0.15$ & ac & (10) & $1.30 \pm 0.19$ & a (4) & $2.20 \pm 0.0 .06$ & $\mathrm{~b}$ & $(10)$ & $1.95 \pm 0.12$ & bc (12) & $1.86 \pm 0.12$ & $\mathrm{ab} \quad(6)$ \\
\hline \multicolumn{14}{|c|}{ Root-related traits } \\
\hline \multicolumn{14}{|c|}{ Wood anatomy } \\
\hline$d$ & $\mu \mathrm{m}$ & $52.03 \pm 0.74$ & $\mathrm{ab}$ & (7) & $53.98 \pm 1.43$ & b (11) & $51.46 \pm 1.79$ & $\mathrm{~b}$ & (11) & $50.23 \pm 1.19$ & b $\quad(9)$ & $56.97 \pm 1.24$ & a (11) \\
\hline$d_{\mathrm{h}}$ & $\mu \mathrm{m}$ & $71.86 \pm 2.43$ & $\mathrm{a}$ & (8) & $75.75 \pm 2.21$ & a (11) & $74.07 \pm 2.77$ & $\mathrm{a}$ & (11) & $73.55 \pm 2.76$ & a $(10)$ & $77.78 \pm 2.38$ & a (11) \\
\hline VD & $\mathrm{n} \mathrm{mm}^{-2}$ & $98.82 \pm 3.66$ & $\mathrm{a}$ & (7) & $104.94 \pm 4.23$ & a (11) & $93.91 \pm 1.16$ & $\mathrm{a}$ & (9) & $98.67 \pm 5.43$ & a $\quad(10)$ & $92.82 \pm 0.85$ & a (9) \\
\hline$A_{\text {lumen }}$ & $\%$ & $0.24 \pm 0.01$ & $\mathrm{a}$ & $(9)$ & $0.27 \pm 0.01$ & a (11) & $0.22 \pm 0.01$ & $\mathrm{a}$ & $(11)$ & $0.21 \pm 0.02$ & a (10) & $0.26 \pm 0.01$ & a (11) \\
\hline
\end{tabular}



The branch sapwood area-specific hydraulic conductivity $\left(K_{\mathrm{s}}\right)$ significantly differed between demes (Table 3.3). The mean vessel diameter $(d)$, hydraulically-weighted vessel diameter $\left(d_{\mathrm{h}}\right)$ and $A_{\text {lumen }}$ were closely related to sapwood area-specific hydraulic conductivity, while no relation was found between VD and $K_{\mathrm{s}}$ (Table 3.4). In the coarse root xylem, similar relationships were observed between $d, d_{\mathrm{h}}$ and $A_{\text {lumen. }}$. Demes with large hydraulically-weighted vessel diameters displayed lower vessel densities in the coarse root xylem (Pearson's $r=-0.31, P<0.05$, Table 3.4). According to the relative abundance of vessel size classes in the xylem and the resulting relative contribution of a diameter class to potential sapwood area-specific hydraulic conductivity derived from the Hagen-Poiseuille equation $\left(K_{\mathrm{p}}\right)$, we grouped the coarse roots into four categories (Figure 3.2). The root categories \#1 to \#4 represent gradients in $d, d_{\mathrm{h}}, d_{\mathrm{wm}}, \mathrm{VD}, K_{\mathrm{p}}$ in the root xylem. Although the root categories \#2 and \#3 did not differ in $d_{\mathrm{h}}$ and $K_{\mathrm{p}}$, the weighted mean vessel diameter $\left(d_{\mathrm{wm}}\right)$ as derived from vessel size distribution enabled a clear separation. Roots in the category \#4 with highest conductivity possessed the by far largest vessels with $40 \%$ of all vessels being wider than $100 \mu \mathrm{m}$. For comparison, mean vessel diameter in the root xylem averaged only at 72-78 $\mu \mathrm{m}$ in the five demes (all demes pooled; Table 3.5).

Table 3.4. Pearson correlation coefficients for linear relationships among four growth-related traits and nine xylem anatomical and wood hydraulic traits of branch segments (below diagonal) and coarse root segments (above diagonal) in the five aspen demes $(\mathrm{n}=25-63)$. Significant correlations are marked by ${ }^{*}(P<0.05),{ }^{* *}(P<0.01),{ }^{* * *}(P<0.001)$ and are printed in bold. $\mathrm{AGR}_{\text {biom }}$, $\mathrm{RGR}_{\text {biom }}$ and $K_{\mathrm{s}}$ were log-transformed prior to analysis. For abbreviations see Table 3.2.

\begin{tabular}{|c|c|c|c|c|c|c|c|c|c|c|c|c|}
\hline & Height $_{2011}$ & $\mathrm{RCD}_{2011}$ & $\mathrm{AGR}_{\text {biom }}$ & $\mathrm{RGR}_{\text {biom }}$ & $d$ & $d_{\mathrm{h}}$ & VD & $A_{\text {lumen }}$ & $K_{\mathrm{s}}$ & $\mathrm{P}_{12}$ & $\mathrm{P}_{50}$ & $\mathrm{P}_{88}$ \\
\hline Height $_{2011}$ & & - & - & - & 0.19 & -0.01 & -0.26 & -0.04 & - & - & - & - \\
\hline $\mathrm{RCD}_{2011}$ & $0.79 * * *$ & & - & - & 0.21 & -0.02 & -0.26 & -0.06 & - & - & - & - \\
\hline $\mathrm{AGR}_{\text {biom }}$ & $0.87 * * *$ & $0.91 * * *$ & & - & 0.26 & 0.04 & -0.26 & 0.02 & - & - & - & - \\
\hline $\mathrm{RGR}_{\text {biom }}$ & $0.49 * * *$ & $0.57 * * *$ & $0.69 * * *$ & & $0.33^{*}$ & 0.22 & -0.17 & 0.23 & - & - & - & - \\
\hline$d$ & -0.11 & -0.08 & -0.11 & 0.06 & & $0.68 * * *$ & -0.18 & $0.81 * * *$ & - & - & - & - \\
\hline$d_{\mathrm{h}}$ & -0.22 & -0.21 & -0.20 & -0.09 & $0.85^{* * *}$ & & $-0.31 *$ & $0.66 * * *$ & - & - & - & - \\
\hline VD & 0.01 & 0.04 & 0.04 & 0.20 & -0.07 & 0.02 & & $0.31 *$ & - & - & - & - \\
\hline$A_{\text {lumen }}$ & 0.01 & 0.08 & 0.05 & 0.08 & $0.65 * * *$ & $0.66^{* * *}$ & $0.62 * * *$ & & - & - & - & - \\
\hline$K_{\mathrm{s}}$ & $0.29 *$ & $0.51 * * *$ & $0.46 * * *$ & $0.28 *$ & $0.44^{* *}$ & $0.47 * *$ & 0.04 & $0.47 * *$ & & - & - & - \\
\hline $\mathrm{P}_{12}$ & -0.07 & -0.16 & -0.08 & 0.13 & 0.26 & 0.24 & 0.11 & 0.08 & -0.02 & & - & - \\
\hline $\mathrm{P}_{50}$ & -0.09 & -0.14 & -0.06 & 0.23 & $0.40 *$ & $0.46 *$ & 0.05 & 0.17 & 0.28 & $0.88 * * *$ & & - \\
\hline $\mathrm{P}_{88}$ & -0.02 & 0.06 & 0.08 & 0.28 & $0.44 *$ & $0.48 * *$ & -0.12 & 0.30 & $0.61 * * *$ & -0.03 & $0.44 * *$ & \\
\hline
\end{tabular}




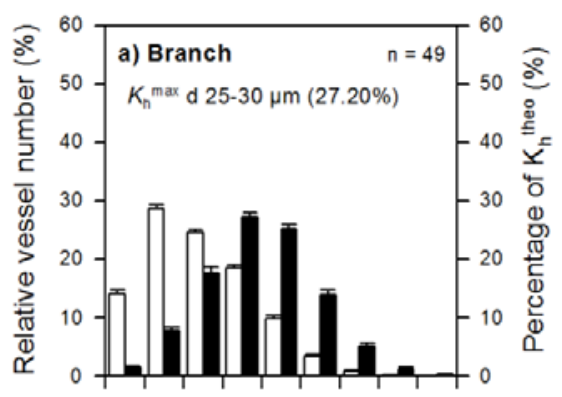

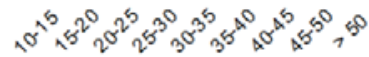

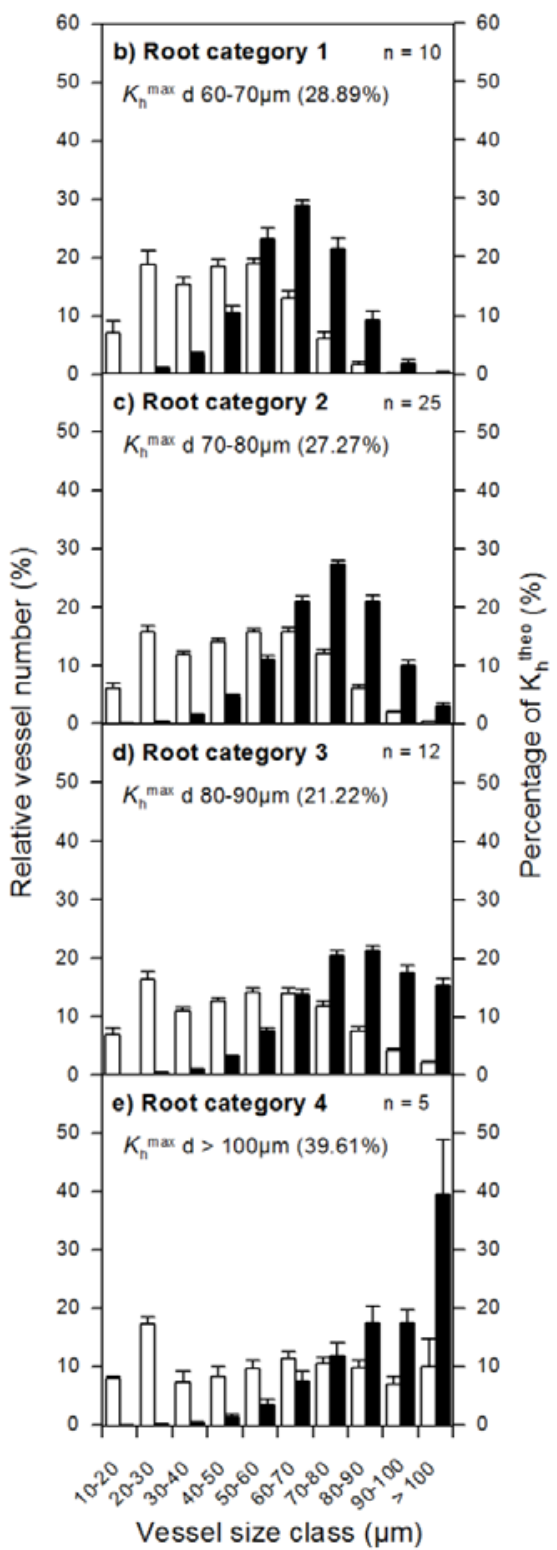

Figure 3.2 Relative abundance of vessels in ten diameter classes (white bars) and relative contribution of a vessel size class to total hydraulic conductivity (in percent; black bars) in the branch and root xylem of the aspen plants. The coarse root samples (b-e) were grouped into four categories differing in the frequency distribution of vessel size classes and the vessel size class which contributed most to total hydraulic conductivity $\left(K_{\mathrm{h}}\right)$. Data are pooled across the five demes. Given are means \pm SE of $n$ replicates (see upper right corner of graph). The size class with largest number of vessels and its relative contribution to $K_{\mathrm{h}}$ is also indicated. 
Table 3.5. Differences in five wood anatomical traits and derived potential sapwood area-specific hydraulic conductivity for branches and four different coarse root categories in the pooled sample of all five demes. The four root categories were distinguished according to relative vessel size distribution and the percental contribution of a specific vessel size class to hydraulic conductivity (see Figure 3.2). Values are means \pm SE, the number of replicates is given (n), for abbreviations see Table 3.2.

\begin{tabular}{lccccccc}
\hline Organ & $\mathrm{n}$ & $\begin{array}{c}d \\
\mu \mathrm{m}\end{array}$ & $\begin{array}{c}d_{\mathrm{h}} \\
\mu \mathrm{m}\end{array}$ & $\begin{array}{c}d_{\mathrm{wm}} \\
\mu \mathrm{m}\end{array}$ & $\begin{array}{c}\mathrm{VD} \\
\mathrm{n} \mathrm{mm}^{-2}\end{array}$ & $\begin{array}{c}K_{\mathrm{p}} \\
\mathrm{kg} \mathrm{m}^{-1} \mathrm{MPa}^{-1} \mathrm{~s}^{-1}\end{array}$ & $\begin{array}{c}A_{\text {xylem }} \\
\mathrm{mm}^{2}\end{array}$ \\
\hline \hline Branch & 42 & $23.39 \pm 0.23$ & $29.35 \pm 0.37$ & 29.35 & $289.55 \pm 5.76$ & $2.88 \pm 0.14$ & $23.37 \pm 1.22$ \\
Root Cat. 1 & 10 & $50.64 \pm 2.16$ & $71.91 \pm 2.12$ & 63.78 & $96.45 \pm 6.51$ & $28.73 \pm 3.26$ & $19.18 \pm 3.80$ \\
Root Cat. 2 & 25 & $52.86 \pm 1.08$ & $76.02 \pm 1.54$ & 73.43 & $98.13 \pm 2.01$ & $36.58 \pm 2.58$ & $19.02 \pm 1.87$ \\
Root Cat. 3 & 12 & $53.21 \pm 1.64$ & $74.63 \pm 2.40$ & 80.84 & $96.97 \pm 4.20$ & $35.79 \pm 4.15$ & $14.41 \pm 3.30$ \\
Root Cat. 4 & 5 & $56.43 \pm 5.27$ & $78.92 \pm 9.38$ & 89.94 & $100.61 \pm 13.28$ & $45.46 \pm 14.05$ & $13.44 \pm 3.65$ \\
\hline
\end{tabular}

Cavitation resistance expressed by the negative pressure causing $50 \%$ loss of conductivity $\left(\mathrm{P}_{50}\right)$ significantly differed between demes (Table 3.3). The $\mathrm{P}_{50}$ value of branch segments varied from -2.21 $\mathrm{MPa}$ in the most vulnerable deme $(\mathrm{CH})$ to -2.96 and $-2.97 \mathrm{MPa}$ in the most resistant demes G2 and G8 (Table 3.3). Significant differences were also found for the mean $\mathrm{P}_{88}$ value (range: -3.38 to $-3.97 \mathrm{MPa}$ ) and the mean $\mathrm{P}_{12}$ value of the branch xylem. Across all demes, the mean $\mathrm{P}_{50}$ scaled positively with vessel size ( $d$ and $d_{\mathrm{h}}$, Pearson's $r=0.40$, and 0.46, $P<0.05$; Table 3.4, Figure 3.3a) but not with VD and $A_{\text {lumen }}$. Moreover, the mean $\mathrm{P}_{50}$ was not related to the hydraulic conductivity of the demes. However, the mean $\mathrm{P}_{88}$ value scaled positively with $K_{\mathrm{s}}$ (Pearson's $r=0.61, P<0.001$ ), indicating that hydraulic conductivity is closely related to the xylem pressure at the 'point of no return', i.e. the limiting pressure before the xylem becomes totally non-conductive (Table 3.4). The hydraulic safety margin, i.e. the difference between midday leaf water potential $\left(\Psi_{\min }\right)$ after and corresponding $\mathrm{P}_{50}$ value, was dependent on genotype as well. The $\Psi_{\min }-\mathrm{P}_{50}$ difference was largest in the German G2 deme and smallest in the Swiss $(\mathrm{CH})$ deme, and it generally increased with decreasing $\mathrm{P}_{50}$ (Figure 3.3b). 


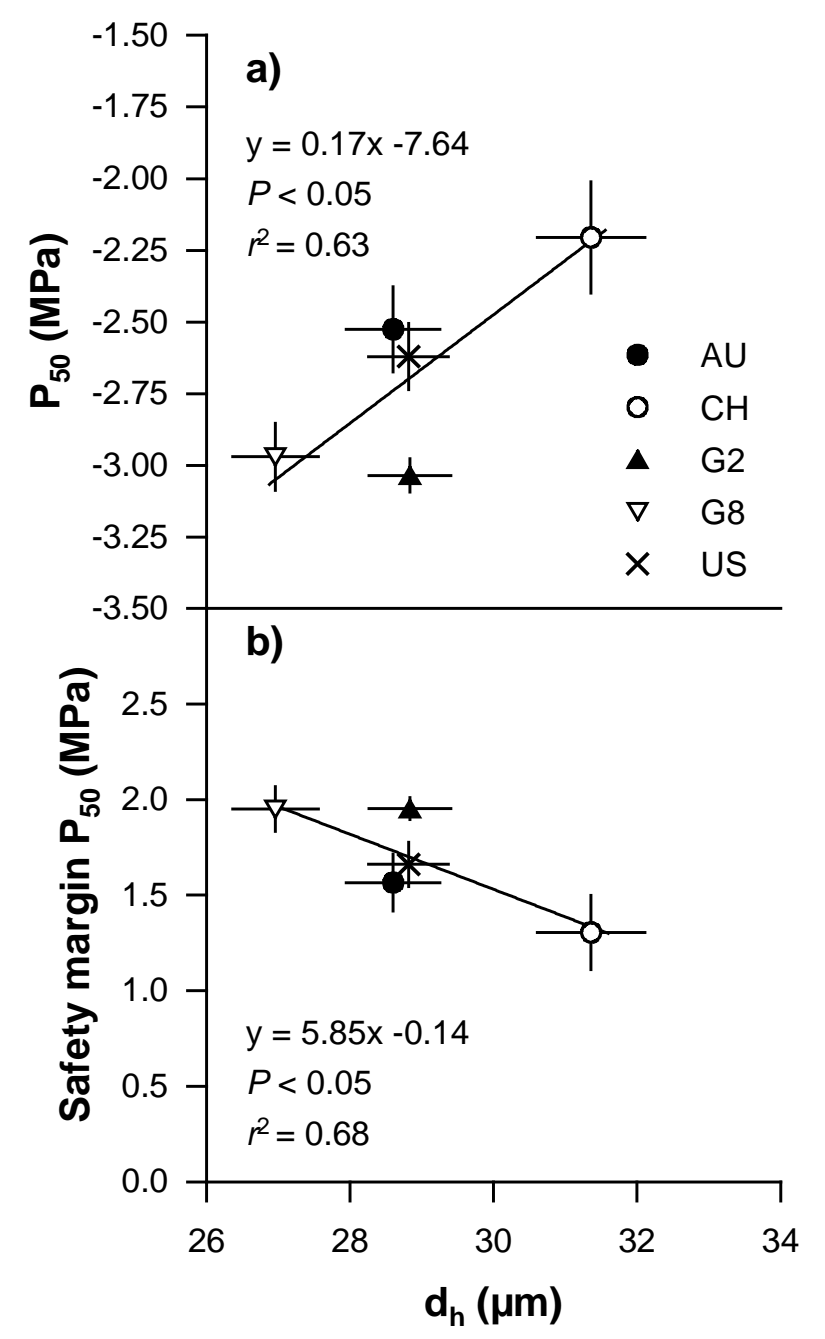

Figure 3.3 Relationship between hydraulically-weighted vessel diameter $\left(d_{\mathrm{h}}\right)$ and (a) cavitation vulnerability $\left(\mathrm{P}_{50}\right)$ or $(\mathrm{b})$ cavitation safety margin (i.e. the difference between minimum water potential observed in the field $\left[\Psi_{\min }\right]$ and $\mathrm{P}_{50}$ ) in the sample of five demes (P. tremula: AU, CH, G2, G8; P. tremuloides: US). $\Psi_{\min }$ after Müller et al. (2012a, b). 
The influence of genetic variation on xylem anatomy and hydraulic properties

The results of the Mantel test revealed a close relation between the phylogenetic distances among the demes according to the AFLP markers, and the variation in $A_{\text {lumen }}$ and the $\mathrm{P}_{88}$ value of the branch xylem. The SSR markers supported this relation and additionally showed a genetic influence on $K_{s}$ in the branch sample. When all anatomical and hydraulic traits were pooled in the Mantel test analysis, significant relations to the genetic variation did not appear (Table 3.6).

Table 3.6. Results of a Mantel test conducted to analyze the relationship between trait variance (first matrix) and genetic variance according to AFLP or SSR markers (second matrix) in the sample of five demes. Significantly correlating traits are printed in bold $(P<0.05)$. For abbreviations see Table 3.2

\begin{tabular}{|c|c|c|c|c|c|}
\hline \multirow[b]{2}{*}{ First matrix } & \multirow[b]{2}{*}{ Second matrix } & \multicolumn{2}{|c|}{ Branch sample } & \multicolumn{2}{|c|}{ Coarse root sample } \\
\hline & & "Mantel's $r$ & Probability $P$ & "Mantel's $r$ & Probability $P$ \\
\hline AGR $_{\text {biomass }}$ & AFLPs & 0.953 & 0.163 & - & - \\
\hline $\mathrm{RGR}_{\text {biomass }}$ & AFLPs & 0.970 & 0.139 & - & - \\
\hline$d_{\mathrm{h}}$ & AFLPs & -0.434 & 0.956 & 0.707 & 0.037 \\
\hline VD & AFLPs & -0.147 & 0.639 & 0.013 & 0.315 \\
\hline$A_{\text {lumen }}$ & AFLPs & 0.292 & 0.027 & -0.018 & 0.511 \\
\hline$K_{\mathrm{s}}$ & AFLPs & 0.330 & 0.341 & 0.532 & 0.146 \\
\hline $\mathrm{P}_{12}$ & AFLPs & -0.296 & 0.822 & - & - \\
\hline $\mathrm{P}_{50}$ & AFLPs & -0.321 & 0.957 & - & - \\
\hline $\mathrm{P}_{88}$ & AFLPs & 0.343 & 0.031 & - & - \\
\hline All anatomical traits & AFLPs & -0.156 & 0.656 & 0.208 & 0.313 \\
\hline All hydraulic traits & AFLPs & -0.282 & 0.813 & 0.541 & 0.139 \\
\hline All traits & AFLPs & -0.156 & 0.656 & 0.543 & 0.127 \\
\hline $\mathrm{AGR}_{\text {biomass }}$ & SSRs & -0.848 & 0.879 & - & - \\
\hline $\mathrm{RGR}_{\text {biomass }}$ & SSRs & -0.875 & 0.908 & - & - \\
\hline$d_{\mathrm{h}}$ & SSRs & -0.356 & 0.748 & 0.700 & 0.049 \\
\hline VD & SSRs & -0.237 & 0.820 & -0.077 & 0.460 \\
\hline$A_{\text {lumen }}$ & SSRs & 0.491 & 0.034 & 0.315 & 0.079 \\
\hline $\mathrm{P}_{12}$ & SSRs & -0.357 & 0.873 & - & - \\
\hline $\mathrm{P}_{50}$ & SSRs & -0.152 & 0.635 & - & - \\
\hline $\mathrm{P}_{88}$ & SSRs & 0.554 & 0.022 & - & - \\
\hline All anatomical traits & SSRs & -0.241 & 0.824 & 0.128 & 0.349 \\
\hline All hydraulic traits & SSRs & -0.043 & 0.391 & 0.364 & 0.175 \\
\hline All traits & SSRs & -0.242 & 0.7864 & 0.367 & 0.169 \\
\hline
\end{tabular}


Aboveground growth performance and its relatedness with xylem anatomy and hydraulic properties

The five demes differed by factors of four to five in their aboveground productivity in the period April 2010 to April 2011 (measured either as absolute [AGR] or relative growth rate [RGR]; 21.0 - $109.0 \mathrm{~g} \mathrm{yr}^{-1}$ for AGR and $0.68-2.49 \mathrm{~g} \mathrm{~g}^{-1} \mathrm{yr}^{-1}$ for RGR, $P<0.001$; Table 3.3).

Among the nine investigated xylem anatomical and hydraulic traits of the branches, only $K_{\mathrm{s}}$ was related to growth rate (AGR and RGR) and also to plant height and RCD. This relation held for the pooled data (Table 3.4) and also when the RGR means of the demes were plotted against $K_{\mathrm{s}}$ (Figure 3.4). This was not the case for vessel size ( $d$ and $d_{\mathrm{h}}$ ). Thus, demes with higher growth rates were characterized by higher measured hydraulic conductivities in the branches, while fast growth was not reflected in specific xylem anatomical properties. 


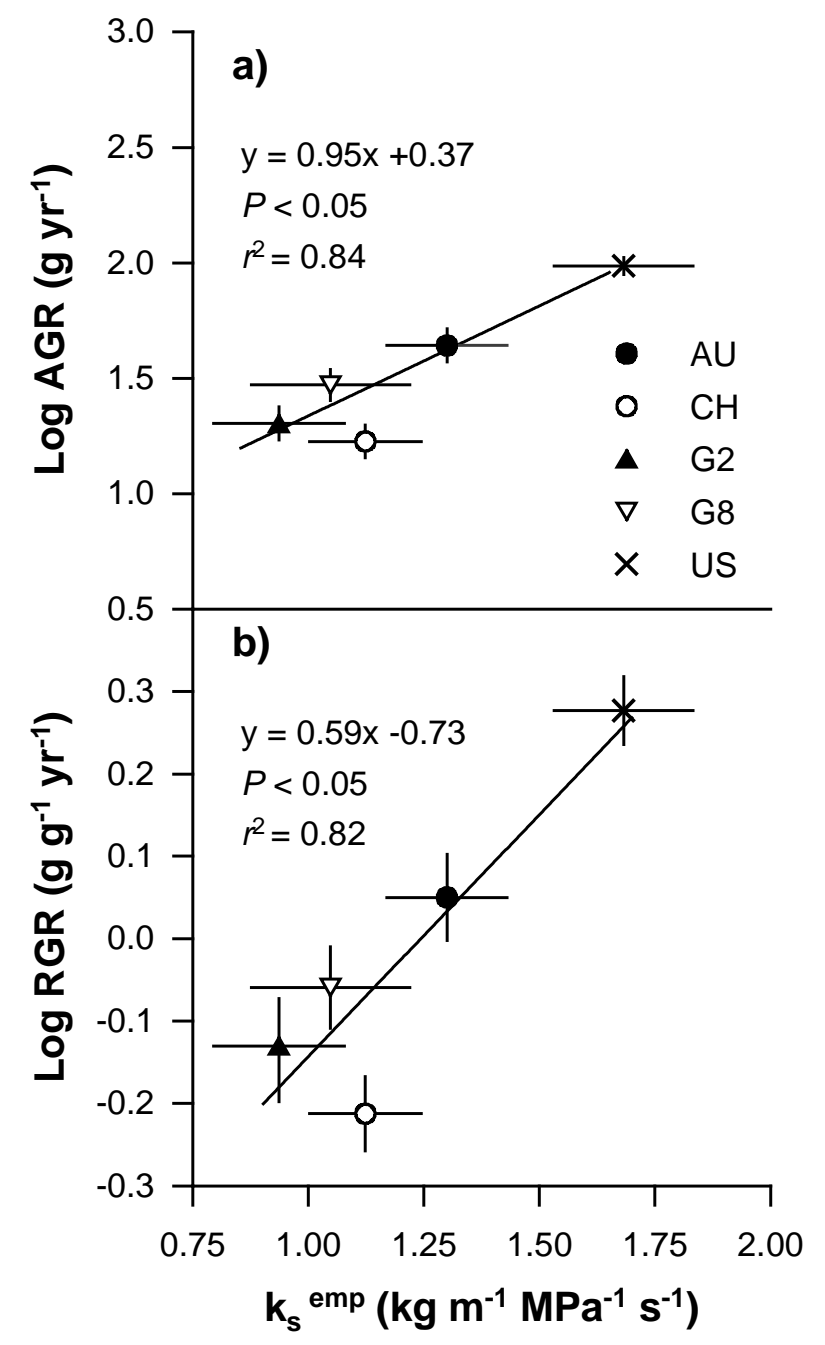

Figure 3.4 Sapwood area-specific hydraulic conductivity $\left(K_{\mathrm{s}}, \mathrm{kg} \mathrm{m}^{-1} \mathrm{MPa}^{-1} \mathrm{~s}^{-1}\right)$ in relation to (a) absolute or (b) relative

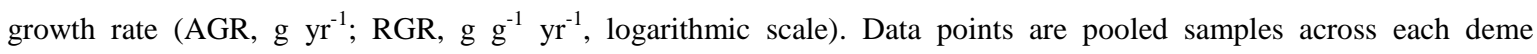
(P. tremula: AU, CH, G2, G8; P. tremuloides: US). 


\section{Discussion}

Intraspecific differences in xylem architecture and hydraulic conductivity in the aspen demes

We found only moderate to low genetic variation in branch xylem anatomical traits among the five aspen demes; only a minority of intraspecific differences (between the P. tremula demes) and also interspecific differences ( $P$. tremula and $P$. tremuloides) were significant. Fichot et al. (2009) compared the stem xylem anatomy of different $P$. deltoides $\times P$. nigra hybrids and found relatively large variation, which they explained by the heterogeneity of the plant material, consisting of unrelated interspecific crossings. Our data seem to support the concept of a close relationship between the two Eurasian and North American aspen species as it appears from genetic and morphological investigations (Eckenwalder 1996).

In contrast to the branches, we observed a high heterogeneity in root-related anatomical and derived hydraulic traits, which enabled a classification of four distinct root categories. We found strong indication for the existence of several 'high-conductivity roots' in these aspen demes, as were described in other temperate broad-leaved tree genera by Rewald et al. (2011) and Köcher et al. (2012). We initially assumed that the four root anatomical categories were mainly an expression of different root diameters, i.e. reflected differences in root age. However, several of the thinnest roots with presumably young age were included in root category \#4 which included the 'high-conductivity roots'. This finding is highly relevant for studies on root functioning, because it shows that roots in a given diameter class can differ largely in their potential sapwood area-specific hydraulic conductivity and presumably also in their vulnerability to drought-induced embolism due to the commonly observed relation between vessel size and cavitation resistance (e.g., Awad et al. 2010, Cai and Tyree 2010); simple inference from root diameter on function is thus not possible. Further, aspen branches and roots of similar diameter are largely different in their anatomical properties with no indication of the existence of 'highconductivity branches'. This large plasticity in root anatomy and functioning is thought to reflect a functional divergence within the root system of trees (McElrone et al. 2004). Surface-directed fine roots may primarily be responsible for nutrient absorption, while deep-reaching roots could mainly serve as water absorbing and conducting organs. 
The branch sapwood area-specific hydraulic conductivity $\left(K_{s}\right)$, on the other hand, differed more between the demes than the measured anatomical traits, even though the observed variation in hydraulic efficiency should relate to anatomical differences. However, despite a close relation of $K_{\mathrm{s}}$ to vessel size, the $60 \%$ larger $K_{\mathrm{s}}$ in the $P$. tremuloides deme (US) than in the G2 deme is hardly explained by differences in vessel size. This suggests that intraspecific differences in hydraulic conductivity must at least partly dependent on other conduit properties such as pit membrane structure.

Compared to other temperate tree species or shrubs, poplars are particularly vulnerable to xylem cavitation, which seems to relate to the species' dependence on ample water supply (Tyree and Ewers 1991, Blake et al. 1996, Rood et al. 2003). By contrast, P. tremula and $P$. tremuloides were found to range among the less vulnerable taxa of the genus due to their adaptation to non-riparian, partly drought-affected habitats (Lieffers et al. 2001, Rood et al. 2007, Anderegg et al. 2012). Our results support the view that $P$. tremula has a far higher cavitation resistance than most other taxa of the genus. The $\mathrm{P}_{50}$ value differed substantially between the most resistant (G2 and G8) and the least resistant demes (CH). The hydraulic safety margin was dependent on genotype and generally increased with decreasing $\mathrm{P}_{50}$. When the hydraulic safety margin is considered as a key measure of drought tolerance (Choat et al. 2012, Delzon and Cochard 2014, Klein et al. 2014), the Swiss deme with its large branch and root vessels must be considered as the most vulnerable genotype. Surprisingly, the deme means of $\mathrm{P}_{88}$, but not of $\mathrm{P}_{50}$, were significantly related to the genetic constitution according to the AFLP and SSR markers, highlighting the importance of the $\mathrm{P}_{88}$-value in angiosperms for predicting the 'point of no return' (Barigah et al. 2013, Urli et al. 2013). The weak genetic differentiation with respect to $\mathrm{P}_{50}$ found between different populations of Fagus sylvatica (Wortemann et al. (2011) and Pinus pinaster (Lamy et al. 2011) supports this observation. Thus, the limiting pressure before the xylem becomes totally non-conductive is an indication of the genotypic influence on drought adaptation, in which selection for a more negative $\mathrm{P}_{88}$ in trees exposed to water shortage may be a key trait. The branch xylem of the four P. tremula demes and the $P$. tremuloides deme was fully embolized ( $\mathrm{P}_{88}$ value) at $-3.5 \mathrm{MPa}$ or below (up to $-4.0 \mathrm{MPa}$ ), which, however, is still much higher than the thresholds reported for the majority of temperate tree species $\left(\mathrm{P}_{88}\right.$ : -4 to $-10 \mathrm{MPa}$; Hacke et al. 2000, Cochard et al. 2008, Urli et al. 2013). In contrast, most of the so far investigated Populus species or poplar hybrids face a fully embolized xylem $\left(\mathrm{P}_{88}\right)$ when the pressure approaches $\sim-1.50$ 
to -2.75 MPa (Cochard et al. 1996, 2007, Harvey and Driessche 1997, Hukin et al. 2005, Fichot et al. 2010). Certain populations or hybrids of $P$. trichocarpa are reported to be even more vulnerable. However, the genetically most distant demes in our study (US vs. G8) were not the most different in terms of cavitation resistance. Thus, the identification of drought-tolerant genotypes for plantation forestry may require empirical testing of hydraulic properties.

Trade-off between growth performance, branch hydraulic conductivity and cavitation resistance

We obtained evidence that a high branch hydraulic conductivity is an important factor causing differences in growth rate between the five aspen demes. In our study, growth rate (AGR and RGR) scaled positively with branch sapwood area-specific hydraulic conductivity $\left(K_{\mathrm{s}}\right)$, which in turn was determined by vessel size ( $d$ and $\left.d_{\mathrm{h}}\right)$ and the lumen to sapwood area ratio $\left(A_{\text {lumen }}\right)$. This confirms our assumption that $K_{\mathrm{s}}$ represents a suitable measure for comparing the productivity of different aspen demes and suggests that the maintenance of a high leaf area in mid-summer (Müller et al. 2012a, b) depends critically on a minimum conductivity of the axes. The capacity for water transport hence represents another growth-determining factor besides the most widely used proxies for a high growth rate, e.g. a high specific leaf area (Poorter and Garnier 1999), a high leaf mass per plant mass (Poorter and Remkes 1990, Walters et al. 1993), high foliar nitrogen contents and low leaf longevity (Wright and Westoby 2000). However, phenological traits may also determine productivity as was shown by Müller et al. (2012a, b) for the aspen demes investigated in this study. In our plants, neither vessel size nor vulnerability to cavitation directly influenced the growth rate of the five demes, even though $K_{\mathrm{s}}$ as well as $\mathrm{P}_{50}$ and $\mathrm{P}_{88}$ were closely related to vessel size. This indicates that efficient water supply in moist periods seems to be more important than the risk of losing conductivity in drought periods. It should be noted, however, that the intra-specific differences in vessel size between the demes were only small in our sample. Interspecific contrasts may well show a significant relation between vessel dimensions and growth.

It has been suggested that xylem vulnerability to cavitation increases with increasing growth rate due to conflicting carbon allocation either to the construction of thicker cell 
walls with less pit-pairs, or to the building of foliar and axial tissues destined to increase canopy carbon gain and growth rate (Wikberg and Ögren 2004). However, empirical data from different species or genotypes do not unequivocally support this trade-off. Even though Cochard et al. (2007) report a close relation between xylem vulnerability and productivity in different poplar and willow clones, Fichot et al. (2010) found that cavitation-resistant genotypes of poplar grew faster than the more vulnerable genotypes. This matches with our results of a lacking relation between $\mathrm{P}_{50}$ in branches and absolute or relative growth rate across the demes. Drought-induced xylem cavitation as a symptom of distress (Delzon and Cochard 2014) might thus be closer related to plant survival than to growth (Urli et al. 2013, Barigah et al. 2013).

Our data suggest that the anatomy of the branch xylem does affect growth mainly through axial conductivity and thus via the supply of water, while cavitation vulnerability seems to influence growth only indirectly through a constraining effect of $\mathrm{P}_{88}$ on hydraulic conductivity. Thus, faster growing demes with higher $K_{\mathrm{s}}$ experienced earlier full blockage of conduits (higher $\mathrm{P}_{88}$ value) than demes with lower $K_{\mathrm{s}}$ and slower growth, while the $\mathrm{P}_{50}$ value was meaningless. Interestingly, the $\mathrm{P}_{88}$ value, and not the $\mathrm{P}_{50}$ value, was dependent on genotype. In the five aspen demes, a trade-off existed between hydraulic efficiency and related growth rate on the one hand, and safety from full conduit blocking on the other.

When relating cavitation resistance to xylem anatomy, only mean vessel diameter and hydraulically-weighted diameter, but not vessel density or relative vessel lumen area, influenced $\mathrm{P}_{50}$ and $\mathrm{P}_{88}$ values in our sample. This is in accordance with the growing evidence that variation in $\mathrm{P}_{50}$, either between or within species, can be explained by differences in vessel size (e.g., Hacke et al. 2006, Maherali et al. 2006, Cai and Tyree 2010, Domec et al. 2010). A similar relatedness between $P_{50}$ and vessel diameter with relatively little intraspecific variation was found in poplar hybrids (Awad et al. 2010). However, contrasting evidence is also available since several authors failed to detect a relation between vessel diameter and cavitation resistance in closely related genotypes or different hybrids of poplar (Cochard et al. 2007, Fichot et al. 2010). The mechanisms underlying the relationship between xylem anatomy and drought resistance of trees are currently intensively debated, yet with a somewhat different focus on wood density and fibre wall thickness (Hacke et al. 2006, Cochard et al. 2007), pit membrane structure 
(Choat et al. 2008, Jansen et al. 2009, Plavcova et al. 2013) and vessel grouping (Lens et al. 2011).

\section{Conclusion}

This study on the growth performance and hydraulic properties of branch segments in five aspen demes revealed considerable intraspecific differences in the about 20 investigated traits, which partly could be related to differences in the genetic constitution. We found a marked variation in vulnerability to cavitation of the branch xylem among the demes and close dependence on vessel size. A key finding is that sapwood area-specific hydraulic conductivity in the branches was significantly related to aboveground productivity while $\mathrm{P}_{50}$ and other hydraulic traits were not. This suggests that axial conductivity and the water transport to the leaves under conditions of ample moisture availability seem to be more important for growth than vulnerability to cavitation in dry periods. The branch xylem's vulnerability to cavitation was found to vary independently from sapwood area-specific hydraulic conductivity among the demes suggesting that the trade-off between growth and xylem safety is not necessarily strong. 


\section{References}

Anderegg W.R.L., Berry J.A., SMith D.D., Sperry J.S., ANDEREgG L.D.L., Field C.B. (2012) The roles of hydraulic and carbon stress in a widespread climate-induced forest die-off. Proceedings of the National Academy of Sciences 109:233-237.

Anfodillo T., Petit G., Crivellaro A. (2013) Axial conduit widening in woody species: a still neglected anatomical pattern. IAWA J 34:352-364.

Awad H., Barigah T., Badel E., Cochard H., Herbette S. (2010) Poplar vulnerability to xylem cavitation acclimates to drier soil conditions. Physiologia Plantarum 139:280-288.

Barigah T.S., Charrier O., Douris M., Bonhomme M., Herbette S., Améglio T., Fichot R., BRignolas F., COCHARD H. (2013) Water stress-induced xylem hydraulic failure is a causal factor of tree mortality in beech and poplar. Annals of Botany 112:1431-1437.

Blake T.J., SPERry J.S., Tschaplinski T.J., WANG S.S. (1996) Water relations. In: StetTler RF, Bradshaw HD, Heilman PE, HincKley TM (eds) Biology of Populus and its implications for management and conservation. NRC Research Press, Ottawa, Canada, pp 401-422

Cai J., Tyree M.T. (2010) The impact of vessel size on vulnerability curves: data and models for within-species variability in saplings of aspen, Populus tremuloides Michx. Plant, Cell \& Environment 33:1059-1069.

Cervera M.T., Storme V., Soto A., Ivens B., Montagu M.V., Rajora O.P., Boerjan W. (2005) Intraspecific and interspecific genetic and phylogenetic relationships in the genus Populus based on AFLP markers. Theoretical and Applied Genetics 111:1440-1456.

Chont B., Cobb A.R., Jansen S. (2008) Structure and function of bordered pits: new discoveries and impacts on whole-plant hydraulic function. New Phytologist 177:608-626.

Choat B., Jansen S., BrodribB T.J., ET AL. (2012) Global convergence in the vulnerability of forests to drought. Nature 491:752-755.

Cochard H., Barigah S.T., KLeinhentz M., Eshel A. (2008) Is xylem cavitation resistance a relevant criterion for screening drought resistance among Prunus species? Journal of Plant Physiology 165:976-982.

Cochard H., CAsella E., MEnCuCCini M. (2007) Xylem vulnerability to cavitation varies among poplar and willow clones and correlates with yield. Tree Physiology 27:1761-1767.

Cochard H., Damour G., Bodet C., Tharwat I., Poirier M., Améglio T. (2005) Evaluation of a new centrifuge technique for rapid generation of xylem vulnerability curves. Physiologia Plantarum 124:410-418. 
Cochard H., Ridolfi M., Dreyer E. (1996) Responses to water stress in an ABAunresponsive hybrid poplar (Populus koreana×trichocarpa cv. Peace) II. Hydraulic properties and xylem embolism. New Phytologist 134:455-461.

Corcuera L., Cochard H., Gil-Pelegrin E., Notivol E. (2011) Phenotypic plasticity in mesic populations of Pinus pinaster improves resistance to xylem embolism (P50) under severe drought. Trees 25:1033-1042.

Delzon S., Cochard H. (2014) Recent advances in tree hydraulics highlight the ecological significance of the hydraulic safety margin. New Phytologist n/a-n/a.

Delzon S., Douthe C., Sala A., Cochard H. (2010) Mechanism of water-stress induced cavitation in conifers: bordered pit structure and function support the hypothesis of seal capillary-seeding. Plant, Cell \& Environment 33:2101-2111.

DOMEC J.-C., SchäFER K., OREN R., KIM H.S., MCCARTHY H.R. (2010) Variable conductivity and embolism in roots and branches of four contrasting tree species and their impacts on whole-plant hydraulic performance under future atmospheric CO2 concentration. Tree Physiology 30:1001-1015.

ECKENWALDER J.E. (1996) Systematics and evolution of Populus. In: STETTLER RF, Bradshaw HD, Heilman PE, HincKley TM (eds) Biology of Populus and its implications for management and conservation. NRC Research Press, Ottawa, Canada, pp 7-32

FAN Z.-X., Zhang S.-B., HAO G.-Y., Ferry SliK J. W., CAO K.-F. (2012) Hydraulic conductivity traits predict growth rates and adult stature of 40 Asian tropical tree species better than wood density. Journal of Ecology 100:732-741.

FAO (2009) State of the world's forests. FAO

Fichot R., Barigah T.S., Chamaillard S., Le Thiec D., Laurans F., Cochard H., BRIGNOLAS F. (2010) Common trade-offs between xylem resistance to cavitation and other physiological traits do not hold among unrelated Populus deltoides $\times$ Populus nigra hybrids. Plant, Cell \& Environment 33:1553-1568.

Fichot R., Laurans F., Monclus R., Moreau A., Pilate G., Brignolas F. (2009) Xylem anatomy correlates with gas exchange, water-use efficiency and growth performance under contrasting water regimes: evidence from Populus deltoides $\times$ Populus nigra hybrids. Tree Physiology 29:1537-1549.

Gilmour J.S.L., Gregor J.W. (1939) Demes: A suggested new terminology. Nature 144:333-333.

Grant M., MitTon J. (2010) Case study: the glorious, golden, and gigantic quaking aspen. Nature Education Knowledge 3(10):40.

Hacke U.G., Sperry J.S., PitTermann J. (2000) Drought experience and cavitation resistance in six shrubs from the Great Basin, Utah. Basic and Applied Ecology 1:31-41. 
HACKe U.G., SPERRY J.S., WheELER J.K., CASTRO L. (2006) Scaling of angiosperm xylem structure with safety and efficiency. Tree Physiology 26:689-701.

HAMmer, HARPER D.A.T., RYAN P.D. (2001) PAST- Palaeontological statistics software package for education and data analysis. 9.

HARVEY H.P., DRIESSCHE R. VAN DEN (1997) Nutrition, xylem cavitation and drought resistance in hybrid poplar. Tree Physiology 17:647-654.

HEINRICHS S. (2010) Response of the understorey vegetation to selection cutting and clear cutting in the initial phase of Norway spruce conversion. Dissertation. Available at: http://hdl.handle.net/11858/00-1735-0000-0006-B691-E, University of Göttingen, Germany

Hukin D., Cochard H., Dreyer E., Thiec D.L., Bogeat-Triboulot M.B. (2005) Cavitation vulnerability in roots and shoots: does Populus euphratica Oliv., a poplar from arid areas of Central Asia, differ from other poplar species? Journal of Experimental Botany 56:2003-2010.

IPCC (2007) Climate change 2007: the physical science basis. Agenda 6:07.

Jansen S., Choat B., Pletsers A. (2009) Morphological variation of intervessel pit membranes and implications to xylem function in angiosperms. American Journal of Botany 96:409-419.

Keuter A., Hoeft I., VeldKAmp E., Corre M.D. (2013) Nitrogen response efficiency of a managed and phytodiverse temperate grassland. Plant and Soil 364:193-206.

Klein T., YAKIR D., Buchmann N., GrÜnzweig J.M. (2014) Towards an advanced assessment of the hydrological vulnerability of forests to climate change-induced drought. New Phytologist 201:712-716.

Köcher P., Horna V., Beckmeyer I., Leuschner C. (2012) Hydraulic properties and embolism in small-diameter roots of five temperate broad-leaved tree species with contrasting drought tolerance. Annals of Forest Science 69:693-703.

Lamy J.-B., Bouffier L., Burlett R., Plomion C., Cochard H., Delzon S. (2011) Uniform selection as a primary force reducing population genetic differentiation of cavitation resistance across a species range. PLOS ONE 6:e23476.

Lamy J.-B., Delzon S., Bouche P.S., Alia R., Vendramin G.G., Cochard H., Plomion C. (2014) Limited genetic variability and phenotypic plasticity detected for cavitation resistance in a Mediterranean pine. New Phytologist 201:874-886.

Lens F., Sperry J.S., Christman M.A., ChoAt B., RABAey D., JANSEn S. (2011) Testing hypotheses that link wood anatomy to cavitation resistance and hydraulic conductivity in the genus Acer. New Phytologist 190:709-723.

LIEFFERS V., LANDHÄUSSER S., HOGG E. (2001) Is the wide distribution of aspen a result of its stress tolerance? In: SHEPPERD WD, BINKLEY D, BARTOS DL, ET AL. (eds) Sustaining aspen in western landscapes: Symposium Proceedings. U.S. Department 
of Agriculture, Forest Service, Rocky Mountain Research Station, Grand Junction, Colorado, pp 311-323

Maherali H., Moura C.F., Caldeira M.C., Willson C.J., Jackson R.B. (2006) Functional coordination between leaf gas exchange and vulnerability to xylem cavitation in temperate forest trees. Plant, Cell \& Environment 29:571-583.

Marron N., Ceulemans R. (2006) Genetic variation of leaf traits related to productivity in a Populus deltoides $\times$ Populus nigra family. Canadian Journal of Forest Research 36:390-400.

Martínez-Vilalta J., Cochard H., Mencuccini M., Sterck F., Herrero A., Korhonen J.F.J., Llorens P., NikinmaA E., Nolè A., Poyatos R., Ripullone F., SASS-KLAASSEN U., ZWEIFEL R. (2009) Hydraulic adjustment of Scots pine across Europe. New Phytologist 184:353-364.

McElrone A.J., Pockman W.T., Martínez-Vilalta J., Jackson R.B. (2004) Variation in xylem structure and function in stems and roots of trees to $20 \mathrm{~m}$ depth. New Phytologist 163:507-517.

Monclus R., Dreyer E., Villar M., Delmotte F.M., Delay D., Petit J.-M., Barbaroux C., Le Thiec D., BrÉChet C., Brignolas F. (2006) Impact of drought on productivity and water use efficiency in 29 genotypes of Populus deltoides $\times$ Populus nigra. New Phytologist 169:765-777.

Müller A., Horna V., Zhang C., Leuschner C. (2012a) Different growth strategies determine the carbon gain and productivity of aspen collectives to be used in shortrotation plantations. Biomass and Bioenergy 46:242-250.

Müller A., Leuschner C., Horna V., Zhang C. (2012b) Photosynthetic characteristics and growth performance of closely related aspen taxa: On the systematic relatedness of the Eurasian Populus tremula and the North American $P$. tremuloides. Flora 207:87-95.

Pakull B., Groppe K., Meyer M., Markussen T., Fladung M. (2009) Genetic linkage mapping in aspen (Populus tremula L. and Populus tremuloides Michx.). Tree Genetics \& Genomes 5:505-515.

Plavcova L., Jansen S., Klepsch M., Hacke U.G. (2013) Nobody's perfect: can irregularities in pit structure influence vulnerability to cavitation? Front Plant Sci. doi: 10.3389/fpls.2013.00453

POORTER H., GARNIER E. (1999) Ecological significance of inherent variation in relative growth rate and its components. In: Pugnaire FI, VALLADARES F (eds) Handbook of functional plant ecology. Marcel Dekker, New York, pp 81-120

PoORTER H., REMKes C. (1990) Leaf area ratio and net assimilation rate of 24 wild species differing in relative growth rate. Oecologia 83:553-559.

R Development Core Team (2011) R: A language and environment for statistical computing. R Foundation for Statistical Computing, Vienna, Austria 
Rewald B., Leuschner C., Wiesman Z., Ephrath J.E. (2011) Influence of salinity on root hydraulic properties of three olive varieties. Plant Biosystems 145:12-22.

RoOd S.B., BRAatne J.H., Hughes F.M.R. (2003) Ecophysiology of riparian cottonwoods: stream flow dependency, water relations and restoration. Tree Physiology 23:11131124.

Rood S.B., Goater L.A., Mahoney J.M., Pearce C.M., Smith D.G. (2007) Floods, fire, and ice: disturbance ecology of riparian cottonwoods. Canadian Journal of Botany 85:1019-1032.

Rosner S., Klein A., Müller U., Karlsson B. (2008) Tradeoffs between hydraulic and mechanical stress responses of mature Norway spruce trunk wood. Tree Physiology 28:1179-1188.

Russo S.E., Jenkins K.L., Wiser S.K., URiarte M., Duncan R.P., CoOMes D.A. (2010) Interspecific relationships among growth, mortality and xylem traits of woody species from New Zealand. Functional Ecology 24:253-262.

SchÄr C., Vidale P.L., LÜThi D., Frei C., HÄBerli C., Liniger M.A., ApPenzeller C. (2004) The role of increasing temperature variability in European summer heatwaves. Nature 427:332-336.

SPARKS J.P., BLACK R.A. (1999) Regulation of water loss in populations of Populus trichocarpa: the role of stomatal control in preventing xylem cavitation. Tree Physiology 19:453-459.

SPERRY J.S., DONNELly J.R., TyReE M.T. (1988) A method for measuring hydraulic conductivity and embolism in xylem. Plant, Cell \& Environment 11:35-40.

SPERRY J.S., SALIENDRA N.Z. (1994) Intra- and inter-plant variation in xylem cavitation in Betula occidentalis. Plant, Cell \& Environment 17:1233-1241.

TYREE M.T. (2003) Hydraulic limits on tree performance: transpiration, carbon gain and growth of trees. Trees 17:95-100.

TyreE M.T., EWERS F.W. (1991) The hydraulic architecture of trees and other woody plants. New Phytologist 119:345-360.

Tyree M.T., Kolb K.J., Rood S.B., PATiÑo S. (1994) Vulnerability to drought-induced cavitation of riparian cottonwoods in Alberta: a possible factor in the decline of the ecosystem? Tree Physiology 14:455-466.

Tyree M.T., Zimmermann M.H. (2002) Xylem structure and the ascent of sap. Springer, Berlin Heidelberg

Urli M., Porté A.J., Cochard H., Guengant Y., Burlett R., Delzon S. (2013) Xylem embolism threshold for catastrophic hydraulic failure in angiosperm trees. Tree Physiology 00:1-12. 
WAlters M.B., Kruger E.L., Reich P.B. (1993) Relative growth rate in relation to physiological and morphological traits for northern hardwood tree seedlings: species, light environment and ontogenetic considerations. Oecologia 96:219-231.

White F.M. (1991) Viscous fluid flow. MacGraw, New York

WIKBERG J., ÖGREN E. (2004) Interrelationships between water use and growth traits in biomass-producing willows. Trees 18:70-76.

Willigen C.V. DER, PAmmenter N.W. (1998) Relationship between growth and xylem hydraulic characteristics of clones of Eucalyptus spp. at contrasting sites. Tree Physiology 18:595-600.

Wortemann R., Herbette S., Barigah T.S., Fumanal B., Alia R., Ducousso A., GOMORY D., RoECKel-Drevet P., COChARD H. (2011) Genotypic variability and phenotypic plasticity of cavitation resistance in Fagus sylvatica L. across Europe. Tree Physiology 31:1175-1182.

WRight I.J., WestoBy M. (2000) Cross-species relationships between seedling relative growth rate, nitrogen productivity and root vs leaf function in 28 Australian woody species. Functional Ecology 14:97-107.

ZhANG C. (2012) Genetic analysis of aspen (Populus tremula L. and Populus tremuloides Michx.) in a diversity experiment. Dissertation, University of Göttingen, Germany

ZhANG J.-L., CAO K.-F. (2009) Stem hydraulics mediates leaf water status, carbon gain, nutrient use efficiencies and plant growth rates across dipterocarp species. Functional Ecology 23:658-667. 


\title{
CHAPTER 4
}

\section{ROOT ORDER- AND ROOT AgE-DEPENDENT RESPONSE OF TWO Poplar SPEcies to BeloWground COMPETITION}

\author{
Peter Hajek, Dietrich Hertel And Christoph Leuschner
}

IN: PlANT AND SOIL (2014) 377:337-355

DOI: 10.1007/s11104-013-2007-3 



\begin{abstract}
Morphology and functioning of fine roots vary with distance from the distal root ending reflecting influences of root order and root age, but changes in tree fine root systems as a response to the presence of conspecific or allospecific competitors have rarely been studied. Our aim was to identify the effect of belowground competition on the morphology and chemical properties of tree fine roots of different order and age. We grew saplings of a fast-growing (Populus trichocarpa) and a relatively slow-growing poplar species ( $P$. tremula) in monoculture (intraspecific competition) and mixture (interspecific competition) in rhizoboxes, enabling the continuous monitoring of root growth, age determination of root segments, and a harvest-based analysis of root orders. Interspecific root competition was highly asymmetric in favor of $P$. trichocarpa. Species comparison in terms of root traits in four root order classes and eight age classes revealed thinner and longer 1st and 2nd order roots in fast-growing $P$. trichocarpa, whereas root $\mathrm{N}$ concentration was higher in $P$. tremula despite its much lower fine root productivity. The competition treatment had only a weak effect on fine root morphology. Comparison of the harvest and window observation data revealed considerable root polymorphism in both species (thicker young pioneer roots with low tissue density at the windows vs. thinner fibrous 1st-order roots without window contact in the soil) suggesting a marked alteration of fine root morphology by the presence of observation windows. Our results on the effects of intraspecific and interspecific competition suggest that modification in fine root traits plays only a minor role in the plants' belowground competitive strategies. Root polymorphism has to be accounted for when interpreting root window and likely also rhizoscope data of future experiments.
\end{abstract}




\section{Introduction}

Fine roots are the plant's interface with the soil with responsibility for anchorage, water and nutrient uptake. Similar to leaves, roots are competing with neighboring plants for resources, and belowground competition has been found to be similarly intense, or even more strong, than aboveground competition (Wilson 1988; Casper and Jackson 1997; Coomes and Grubb 2000). Root competition may act on the neighbors through exploitative competition, i.e. the depletion of water and nutrients in the shared soil volume, or through interference competition, the inhibition of other plants in their access to soil resources (Schenk 2006). Root competition has the potential to decrease the productivity of the competing plants and it may trigger adaptive morphological and physiological responses of the roots and root systems.

Similar to aboveground competition, belowground competition can be more or less sizesymmetric (Casper and Jackson 1997; Schenk 2006) or size-asymmetric (Rewald and Leuschner 2009; Lei et al. 2012). Plants may respond in different ways to competitorinduced decreases in resource availability, (1) through spatial avoidance of overlapping resource exploitation zones by horizontal root system segregation (clustering) or vertical stratification as it was observed for certain tree species in mixed forests or among different crop species in agroforestry systems (Heilman et al. 1994; Puri et al. 1994; Schenk et al. 1999; Hölscher et al. 2002; Schmid and Kazda 2002) , (2) the development of species differences in the seasonal activity of root growth and uptake activity (Eissenstat and Caldwell 1988) or competition-induced alteration of root longevity (Beyer et al. 2013a), and (3) alteration of root morphology for decreasing the cost/benefit ratio of resource capture. Roots may adapt to belowground competition by increasing specific root surface area (SRA) and specific root length (SRL) which would reduce the cost of exploring additional soil volume by the formation of new roots. Various studies in forest ecosystems reported morphological root adaptation in response to the presence of competitors (e.g. Curt and Prévosto 2003; Bolte and Villanueva 2006; Fujii and Kasuya 2008). Due to the large spatial and temporal variability in belowground resource availability, plasticity in fine root traits may be an essential element of plant strategies to cope with belowground competition (Hodge 2004; Berg and Ellers 2010).

Poplar species are of considerable economic and ecological importance and they range among the most widely distributed tree species of the world (e.g. Shepperd et al. 2001; 
MacKenzie 2010; Myking et al. 2011). Despite a highly variable ecology of the taxa in the genus Populus, most poplar species exhibit certain similarities in the morphology and anatomy of the fine root system (Brundrett et al. 1990). On many sites, the roots of poplar species tend to grow rather superficially with a far-reaching lateral root system, while a few sinker roots penetrate deeply into the soil (Heilman et al. 1994; Douglas et al. 2010). Pregitzer et al. (2002) state that Populus species are producing thin roots with much higher specific root length than other North American tree species, allowing fast lateral spread of the root system. Given the very broad range of sites colonized by poplar species in the temperate zone (from moist fertile alluvial soils to nutrient-poor dry sandy soils), one may expect specific adaptations in the root system of different poplar species growing either in alluvial forests or in pioneer forests on poor sandy soil. In fact, several studies emphasized considerable intra- and interspecific differences in the physiological and morphological traits of poplar fine roots (Friend et al. 1991; Pregitzer and Friend 1996).

We used this expected variability in root morphological and functional traits within the same tree genus to investigate root morphological adaptation in response to interspecific and intraspecific belowground competition with assumed asymmetric outcome. In the last decades, it has become increasingly clear that different root segments fulfil different functions and that root age may have a large effect on root functionality even within the category of small-diameter roots (Fitter 1987; Pregitzer et al. 2002; Guo et al. 2004; Valenzuela-Estrada et al. 2008; Rewald et al. 2011). We thus focused on the specific response of different root orders and root segments of different ages, because we expected that such an in-depth analysis would more clearly reveal species differences in the belowground response to competition.

For our experiment on the morphogenetic effects of root competition, we selected two poplar species with largely different ecology, physiology and productivity. European aspen (Populus tremula L.) is adapted to low nutrient availability and it tolerates moderately dry soils (Dickmann and Kuzovkina 2008; Possen et al. 2011). In its large Eurasian distribution range, it is a typical light-demanding, relatively fast-growing pioneer tree species that colonizes bare soil and forms early-successional forest communities together with birch and pine species (Ellenberg and Leuschner 2010). Black cottonwood (Populus trichocarpa Torr. \& Gray) is native to North America and typically grows on nutrient-rich soils in riparian forests, where it can display high growth rates. $P$. trichocarpa is reported 
to be more sensitive to drought than many other poplar species (Rood et al. 2003). Hybrids (e.g. P. trichocarpa x P. deltoides) are frequently used in short-rotation forestry and reforestation on rich and also on less productive soils in Europe (Hofmann 1998).

This paper reports on a competition experiment with two poplar species of contrasting growth rate (Populus tremula and P. trichocarpa) conducted in rhizoboxes that allowed to observe root growth. Study aim was to examine the relative influence of the factors intraspecific or interspecific competition (treatment), species ( $P$. tremula and $P$. trichocarpa), root order and root age on morphological and chemical root traits.

We hypothesized that (i) the fast-growing species ( $P$. trichocarpa) has a higher fine root productivity and interspecific competition is asymmetric in favour of this species, (ii) species differences in fine root morphological and chemical traits are consistent across the root order and age classes, and (iii) competition effects on fine root morphology and chemistry occur mainly in the first order- and juvenile (apical) root segments. 


\section{Materials and methods}

\section{Plant material and experimental design}

The experiment was conducted with saplings of Populus trichocarpa (Black cottonwood) and $P$. tremula (European common aspen) that were propagated from tissue cultures provided by the Department of Forest Botany and Tree Physiology at the University of Göttingen. The cuttings were cultivated in woody plant medium (WPM) (Schenk and Hildebrandt 1972) with sucrose (30 $\left.\mathrm{g} \mathrm{L}^{-1}, 88 \mathrm{mM}\right)$ and gelrite $\left(3 \mathrm{~g} \mathrm{~L}^{-1}\right)$ at a $\mathrm{pH}$ of 5.8 from March 23 to April 14, 2011. Subsequently, the plantlets were converted to hydroponics that contained weekly renewed Long Ashton nutrient solution (Hewitt and Smith 1974) and grew in a photoperiod of $15 \mathrm{~h}$ at $250 \mu \mathrm{mol} \mathrm{m} \mathrm{s}^{-2}$ photosynthetically active radiation to reach appropriate size and acclimatize to the greenhouse conditions. To determine initial plant size and morphological characteristics (Table 4.1), ten saplings of each species were harvested at the time of transplanting to the greenhouse climate chamber (May 24, 2011). The plant containers (rhizoboxes) used in the experiment consisted of two transparent plexiglass plates $(42 \mathrm{~cm} \times 30 \mathrm{~cm}, \mathrm{w} \times \mathrm{h}$ ) and a $4 \mathrm{~cm}$ wide plastic frame with a perforated ground element to allow water percolation out of the box. Bolts and wing nuts locked the plates together and enabled easy removal of the plexiglass plates for accessing the rhizosphere behind them. During the experiment, all boxes were kept covered with aluminium foil to reduce temperature fluctuation in the boxes and to exclude light penetration into the rhizosphere and algal growth behind the plates. The boxes were rearranged in the greenhouse every second week for avoiding effects of possible illumination intensity gradients and mutual shading between neighbouring plants. The rhizoboxes were filled with approximately $4590 \mathrm{~cm}^{3}$ medium-grained, quarzitic sand with a $\mathrm{pH}$ value of 6.7 (in $1 \mathrm{M} \mathrm{KCl}$ solution). The $\mathrm{C}$ and $\mathrm{N}$ concentrations of the substrate were $0.46 \pm 0.05$ and $0.10 \pm 0.01 \mathrm{mg} \mathrm{g}^{-1}$, respectively. We preferred this relatively homogenous substrate over forest soil because the extraction of the finest roots upon harvest is usually less complete from a loamy humus-richer substrate such as forest soil than from this type of sand, and a uniform soil water distribution is better achieved in the latter. Two different treatments were established to investigate intraspecific and interspecific competition effects between the two poplar species. In the mono-specific treatments (mono), each box was planted with two plants of the same species ( $P$. tremula $n=12$, $P$. trichocarpa $n=12$ ), whereas the mixed treatment (mix) comprised one P. tremula and one $P$. trichocarpa plant per box $(n=$ 
12). All 36 rhizoboxes were arranged in a climatized greenhouse chamber in the Experimental Botanical Garden of the University of Göttingen. They were kept for $135 \mathrm{~d}$ under controlled climatic conditions, i.e. relative air humidity 65\%, daytime temperature maximum $20.0^{\circ} \mathrm{C}$, nighttime temperature minimum $10.0^{\circ} \mathrm{C}$, light flux density depending on plant height 120-170 $\mu \mathrm{mol} \mathrm{m} \mathrm{m}^{-2} \mathrm{~s}^{-1}$ (EYE Clean-Ace MT400DL/BH, Iwasaki Electric CO., LTD., Tokyo, Japan). Day length was set to 14 hours (08:00 a.m. - 10:00 p.m.). All plants were regularly watered to field capacity. Additionally, the rhizoboxes were fertilized in weekly intervals with $250 \mathrm{ml}$ of $20 \%$ Shive solution (Baumeister 1954) added to the irrigation water. According to our experience, this nutrient concentration creates a moderately fertile growing substrate for tree saplings, where inherent species differences in growth rate should well be detectable. We tried to avoid any situation of nutrient limitation.

Table 4.1. Some characteristics of the experimental plants at the start of the experiment. Significant differences between species are printed in bold (T-test, $n=10, P<0.05$, mean $\pm \mathrm{SE}$ ).

\begin{tabular}{lccc}
\hline Trait & P. tremula & P. trichocarpa & P value \\
\hline \hline & & & \\
Shoot- and leaf-related variables & & & \\
& & & \\
Shoot height (cm) & $\mathbf{1 3 . 0 6} \pm \mathbf{1 . 9 7}$ & $\mathbf{2 4 . 0 5} \pm \mathbf{1 . 7 0}$ & $<\mathbf{0 . 0 0 1}$ \\
& & & \\
Number of leaves (n) & $5.70 \pm 1.14$ & $7.20 \pm 0.96$ & n.s. \\
SLA (cm ${ }^{2}$ g $^{-1}$ ) & $\mathbf{4 8 6 . 1} \pm \mathbf{2 1 . 5 9}$ & $\mathbf{3 7 4 . 6 2} \pm \mathbf{2 7 . 6 0}$ & $<\mathbf{0 . 0 0 1}$ \\
& & & \\
Plant biomass & & & \\
Total aboveground biomass (mg) & $157.08 \pm 57.40$ & $146.37 \pm 32.03$ & n.s. \\
Total belowground biomass (mg) & $75.87 \pm 24.68$ & $38.86 \pm 14.64$ & n.s. \\
Total plant biomass (mg) & $233.10 \pm 81.31$ & $185.38 \pm 46.14$ & n.s. \\
Cumulative root length (cm) & $304.09 \pm 97.49$ & $450.39 \pm 99.01$ & n.s. \\
& & & \\
Root-related variables & & & \\
Mean root diameter (mm) & $\mathbf{0 . 4 3} \pm \mathbf{0 . 0 2}$ & $\mathbf{0 . 3 2} \pm \mathbf{0 . 0 1}$ & $<\mathbf{0 . 0 0 1}$ \\
SRA (cm ${ }^{2}$ g $^{-1}$ ) & $\mathbf{4 5 4 . 5 9} \pm \mathbf{2 1 . 3 8}$ & $\mathbf{1 2 0 8 . 8} \pm \mathbf{8 4 . 2 5}$ & $<\mathbf{0 . 0 0 1}$ \\
SRL (m g ${ }^{-1}$ ) & $\mathbf{4 0 . 9 1} \pm \mathbf{3 . 3 4}$ & $\mathbf{1 4 6 . 3 8} \pm \mathbf{1 2 . 0 2}$ & $<\mathbf{0 . 0 0 1}$ \\
RTD (g cm & & & \\
\hline
\end{tabular}

SLA, specific leaf area; SRA, specific root area; SRL, specific root length; RTD, root tissue density 
Above- and belowground biomass and plant growth rate

After $135 \mathrm{~d}$ of cultivation, the plants were harvested. Shoot biomass (consisting of stem (including branches) and leaves) and root biomass (coarse roots $>2 \mathrm{~mm}$ in diameter, fine roots $<2 \mathrm{~mm}$ ) were sorted into these four fractions and their dry weight was determined (70 $\left.{ }^{\circ} \mathrm{C}, 48 \mathrm{~h}\right)$. The individual root branches in the mixed boxes were carefully removed from the substrate for tracing them back to the shoot for species detection. Fine and coarse root density (root biomass per soil volume; unit $\mathrm{g} \mathrm{L}^{-1}$ ) refers to the fine or coarse root biomass of both plants in a rhizobox (volume: $4590 \mathrm{~cm}^{3}$ ). The relative growth rate (RGR, $m g \mathrm{~g}^{-1} \mathrm{~d}^{-1}$ ) was calculated separately for leaves, stem and coarse and fine roots by subtracting the initial weight of the respective plant organs from the corresponding mass at harvest and relating the difference to the duration of the experiment (May 24 to October 6, 2011) and initial weight. The relative growth rates of the aboveground and belowground organs were used to calculate the relative competitive ability index (CA) as defined in Rewald and Leuschner (2009) (Eq.1),

$$
\mathrm{CA}=\left(\mathrm{RGR}_{\text {mix }}-\mathrm{RGR}_{\text {mono }}\right) \times \mathrm{RGR}_{\text {mix }}{ }^{-1}
$$

with $\mathrm{RGR}_{\text {mix }}$ and $\mathrm{RGR}_{\text {mono }}$ being the relative growth rates (above- or belowground) of a species in the mono or mix treatments.

\section{Root order-related analysis}

Ten randomly chosen root subsamples per species and treatment were removed from the root system. The samples consisted of fine root branches of approximately $20 \mathrm{~cm}$ maximum length with a maximum root diameter of $2.0 \mathrm{~mm}$. Because the plexiglass front screen might inhibit root proliferation and thus could create artificial growing conditions, we sampled roots in the soil 1-2 cm distant from the plate in the box interior for the root order segmentation where we assumed undisturbed root growth. The subsamples were cut into the different root order sections applying the morphometric dissection method as described in Fitter (1982), Fitter (1987), Berntson (1997), and Pregitzer et al. (2002), defining the meristematic endings as lowest root order (\#1). Analysis of the fifth root order was not possible due to the low number of samples in that class. After dissection under a 
stereo microscope at $20 \times$ magnification, all root segments of a given root order class were spread out in a water bath and digitized using a transmitting scanner system (Epson Expression 1680 1.0, Japan). The image data were processed with the software WinRhizo (WinRhizo 2005c, Régent Instruments Inc., Quebec, QC, Canada) to determine root surface area, total root length and mean root diameter. Thereafter, the analysed root samples were oven-dried at $70{ }^{\circ} \mathrm{C}$ for $48 \mathrm{~h}$. Specific root area (SRA, $\mathrm{cm}^{2} \mathrm{~g}^{-1}$ ) and specific root length (SRL, $\mathrm{m} \mathrm{g}^{-1}$ ) were calculated from root area and root length divided by dry mass. Root tissue density (RTD, $\mathrm{g} \mathrm{cm}^{-3}$ ) was obtained from root dry mass divided by root volume. Root $\mathrm{C}$ and $\mathrm{N}$ concentrations were measured by gaschromatography in an elemental analyser (Vario III EL, elementar Analysensysteme GmbH, Hanau, Germany).

\section{Root age-related analysis}

Sequential digital images of the soil visible at the plexiglass windows were taken at high resolution (400 dpi) to record root growth in the boxes. The recording started on August 18 (i.e. $86 \mathrm{~d}$ after the experiment's start) and covered in weekly rotation all 36 boxes until October 6 at the end of the experiment. During this procedure, the rhizoboxes were carefully placed on a frame with embedded flatbed scanner (EPSON Perfection V10, Japan); this frame fixed the box and enabled good matching between the repeated pictures taken from a rhizobox screen. The mount was inclined by less than $45^{\circ}$ to avoid soil disturbance and loss of substrate from the box during the scanning process. Subsequently, the sequence of images of a rhizobox plate was displayed in chronological order on a computer screen and all newly grown root segments were drawn on an overlying acetate sheet (DIN A4) using permanent markers of different colours to distinguish between root age classes. We defined root age as the time elapsed since the segment's first appearance on the plexiglass plate. These root system maps enabled to cut the root system into root fragments of defined age (eight classes) (Table 4.2). In case of the mixed treatments, the single root segments had to be traced towards the respective trees by carefully removing the substrate around the respective roots to ensure species differentiation of the samples. All dissected root segments were cleaned from adherent sand and stored separately in petri dishes filled with demineralized water at $4{ }^{\circ} \mathrm{C}$ until further analysis. The determination of root morphological characteristics of all 308 samples was carried out as described for root order analysis (see above). Additionally, root segments of all age classes were examined 
for colour and categorized into visual types (Table 4.2) to describe changes in root pigmentation over time. Root C and N concentrations were determined in 141 oven-dried subsamples ( $2-5 \mathrm{mg}$ ) from the 16 root categories ( 2 species, 8 age classes). In case of $P$. tremula, several samples had to be pooled to reach the required minimum of $2 \mathrm{mg}$ dried root material.

Table 4.2. Classification of root segments according to age, root morphology and surface properties as visible at the observation windows.

\begin{tabular}{cccc}
\hline Age class & $\begin{array}{c}\text { Root age } \\
\text { (weeks) }\end{array}$ & Root pigmentation and texture & Development processes \\
\hline \hline I & 1 & most distal root tissues, whitish & birth of root, no branching \\
III & 2 & light brown or orange & first side branches developed (second order roots) \\
IV & 4 & well pigmented, maroon brown or orange, & marked root shrinkage, secondary growth, increased root \\
shrunken texture & pigmentation/browning followed by cortical cell death \\
V & 4 & maroon & \\
VI & 6 & dark brown & root browning \\
VII & 7 & dark brown & lignification \\
VIII & $>8$ & basal coarse roots, ocher, mostly woody habit & \\
\hline
\end{tabular}

\section{Statistical analyses}

All statistical analyses were carried out with the software $\mathrm{R}$, version 2.13.2 ( $\mathrm{R}$ Development Core Team 2011). The datasets were tested for normal distribution with the Shapiro \& Wilk test $(P<0.05)$; non-normally distributed data were log-transformed to meet the assumptions of parametric tests. To account for heteroscedasticity, the fitted values were plotted against the residuals and inspected graphically. Significant differences between means of the relative growth rates from the respective biomass fractions and the different root traits (diameter, RTD, SRA, SRL, root N concentration, C/N ratio) were determined using the $\mathrm{lm}$ function with multiple comparisons of means (two-way ANOVA) and the general linear hypotheses (glht) procedure with Tukey's post hoc test, included in the 'multcomp' -package. Species differences in initial plant characteristics were analysed with a two-sample t-test. 
Within a species, differences among the treatments and root orders were tested for all root parameters with linear mixed-effects models ('lme'-function in package 'nlme', Pinheiro and Bates 2013) with plant nested in box as the random term. Treatment (mono vs. mix) and root order (four levels) were set as fixed effect factors. The same approach was used for the factor age class (eight levels). Within all subsets of root orders and age classes, Tukey's HSD test was used to test for differences in morphological and chemical parameters between species and between treatments. To test for species differences in the traits for a given root order, the data of the two treatments were pooled. A Principal Components Analysis (PCA) was carried out with the software CANOCO 4.5 for Windows (Ter Braak and Smilauer 2002) covering all investigated above- and belowground plant traits. Significance was determined at $P<0.05$ throughout. 


\section{Results}

Species differences in plant biomass and growth rate

Considerable differences in aboveground biomass production were observed between the two species which had roughly similar biomass when planted ( 150 mg per plant, Table 4.1). After $135 \mathrm{~d}$, P. tremula reached a mean total aboveground biomass of $0.6 \pm 0.1 \mathrm{~g}$ with equal contribution of leaf and stem biomass (Figure 4.1a) but no differences between the mono and mix treatments. In contrast, $P$. trichocarpa had achieved a mean total aboveground biomass of $13.1 \pm 0.95 \mathrm{~g}$ in the mono treatment and of $20.8 \pm 1.8 \mathrm{~g}$ in the mixed treatment with more leaf than stem biomass being produced (Figure 4.1a).
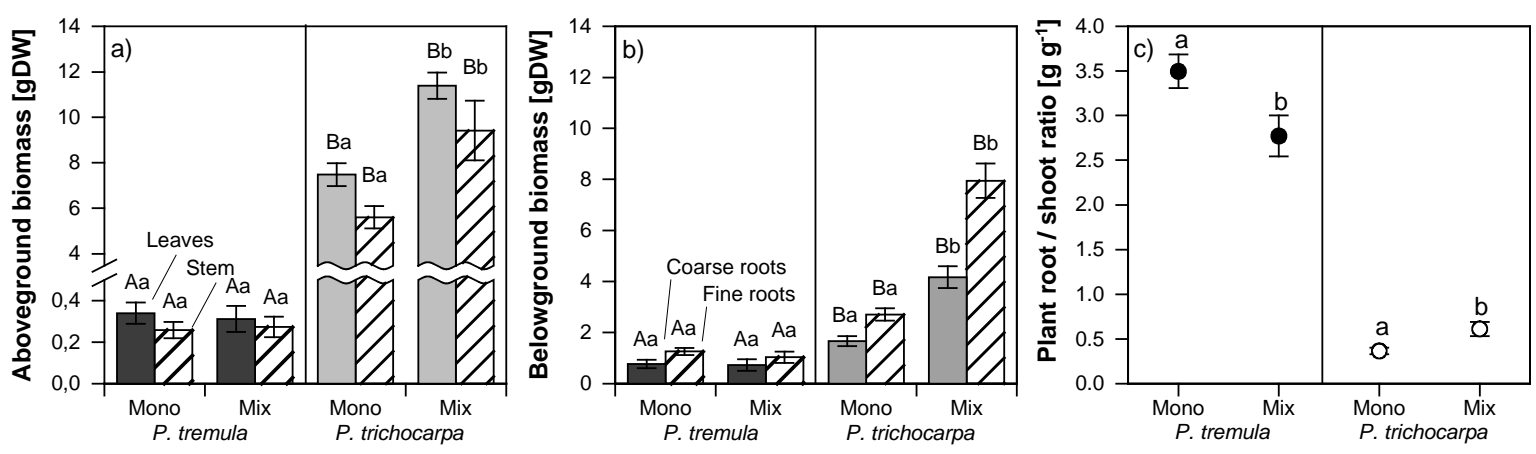

Figure 4.1 Biomass of leaves and stem (a), of coarse and fine roots (b) and aboveground/belowground biomass ratio (c) of the 18-wk-old P. tremula and P. trichocarpa saplings in the mono or mix boxes. Given are means \pm SE of single plants. Significant intraspecific differences between the treatments of a species are indicated by different small letters, interspecific differences by different capital letters (Tukey’s HSD test, $n=9-23, P<0.05$ ).

Consequently, the species differed greatly in their aboveground relative growth rates (RGR, given in $\mathrm{mg} \mathrm{g}^{-1} \mathrm{~d}^{-1}$ ) of the leaf and stem fractions (Table 4.3), indicated by the significant interaction term (species $\times$ treatment) for all different plant fractions in the ANOVA $(P<0.0001)$. The mean total root biomass per plant at harvest was low in $P$. tremula and not affected by the treatment (mono: $2.03 \mathrm{~g}$; mix: $1.76 \mathrm{~g}$ ). This was similarly valid for the coarse and fine root fractions (Figure 4.1b). In contrast, $P$. trichocarpa produced much more root biomass (mono: 4.37; mix: $12.11 \mathrm{~g}$ ), which significantly differed between the mono and mixed treatments in all root fractions. Coarse and fine root density (the root biomass of both plants in a box per soil volume) was significantly higher in the mix treatment (1.02 \pm 0.11 and $1.93 \pm 0.16 \mathrm{~g} \mathrm{~L}^{-1}$ for coarse and fine roots, respectively) than the two mono treatments ( $P$. tremula: $0.35 \pm 0.07$ and $0.57 \pm 0.06$; P. trichocarpa: $0.73 \pm 0.09$ and $1.18 \pm 0.15 \mathrm{~g} \mathrm{~L}^{-1}$ for coarse and fine roots, respectively). The relative 
growth rate (RGR) of the belowground components of $P$. tremula was not affected by the treatment. The fine root productivity of $P$. trichocarpa was more than 3-times higher in the mix than in the mono treatment $(P<0.0001)$ and $P$. trichocarpa reached a 34-times higher relative fine root growth rate than $P$. tremula when planted together in the mixed boxes (Table 4.3). The competitive ability index (CA), which compares the relative growth rates (RGR) of the target species ( $P$. tremula or $P$. trichocarpa) in interspecific interaction (mixed) with the growth in intraspecific interaction (mono), was low for the root system of $P$. tremula (-0.156) and high for that of $P$. trichocarpa (0.639) pointing to highly asymmetric belowground competition in the mixed boxes. A similar relation was observed for the CA values calculated for aboveground biomass production (CA for P. tremula: 0.02, for $P$. trichocarpa: 0.371 ). The superiority of $P$. trichocarpa was more pronounced in the belowground than the aboveground compartment. Consequently, both species differed largely in their root/shoot (R/S) ratios with a generally higher ratio in $P$. tremula and a significant decrease from the mono to the mix treatment, while P. trichocarpa had much lower ratios and increased R/S in the mix treatment (Figure 4.1c).

Table 4.3. Relative growth rates (RGR, given in $\mathrm{mg} \mathrm{g}^{-1} \mathrm{~d}^{-1}$ ) of $P$. tremula and P. trichocarpa plant organs (leaves, stems, coarse and fine roots) of saplings grown under intraspecific (mono) and interspecific (mix) competition in the period from April 24 to October 6, 2011. Significant differences between the two treatments within a species are printed in bold (Tukey's HSD test, $P<0.05$, mean \pm SE; each 12 replicate samples in the mono treatment and 9 samples in the mix treatment).

\begin{tabular}{|c|c|c|c|c|c|c|}
\hline \multirow[b]{2}{*}{ Plant organ } & \multicolumn{3}{|c|}{ P. tremula } & \multicolumn{3}{|c|}{ P. trichocarpa } \\
\hline & mono & mix & $\boldsymbol{P}$ & Mono & Mix & $\boldsymbol{P}$ \\
\hline AG total & $25.11 \pm 3.74$ & $24.58 \pm 4.66$ & 0.930 & $651.25 \pm 47.52$ & $1035.61 \pm 89.46$ & 0.002 \\
\hline Leaves & $9.97 \pm 2.47$ & $8.79 \pm 2.90$ & 0.759 & $364.53 \pm 24.97$ & $559.12 \pm 28.87$ & $<0.0001$ \\
\hline Stem & $5.31 \pm 1.79$ & $6.04 \pm 2.22$ & 0.799 & $278.22 \pm 24.94$ & $472.40 \pm 66.58$ & 0.02 \\
\hline BG total & $199.94 \pm 29.12$ & $173.02 \pm 41.81$ & 0.603 & $839.93 \pm 76.86$ & $2326.04 \pm 204.19$ & $<0.0001$ \\
\hline Coarse roots & $5.77 \pm 1.21$ & $5.41 \pm 1.70$ & 0.866 & $12.43 \pm 1.49$ & $31.10 \pm 3.19$ & $<0.0001$ \\
\hline Fine roots & $5.47 \pm 1.29$ & $4.25 \pm 1.80$ & 0.585 & $44.55 \pm 4.61$ & $145.11 \pm 12.90$ & $<0.0001$ \\
\hline
\end{tabular}

Total aboveground production (AG); total belowground production (BG) 
Changes in root morphology and chemistry with root order

The root harvests (roots inside the boxes without front plate contact) showed that mean root diameter increased in both species almost linearly with ascending root order; $P$. tremula tended to have larger mean diameters in the higher root orders than $P$. trichocarpa (Figure 4.2a). Root tissue density (RTD) increased slightly from the second to the forth order in both species (from 0.17 to $0.23 \mathrm{~g} \mathrm{~cm}^{-3}$ in $P$. tremula and from 0.17 to $0.19 \mathrm{~g} \mathrm{~cm}^{-3}$ in P. trichocarpa) (Figure 4.2b). Both specific root area (SRA) and specific root length (SRL) decreased asymptotically with ascending root order. SRL (but not SRA) was significantly larger in $P$. trichocarpa than in $P$. tremula in root order \#1 and \#2 reflecting the particularly thin and long root endings in this species (Figure 4.2d). Root $\mathrm{N}$ concentration showed a strong decrease with ascending root order in P. trichocarpa but varied little between root orders \#2 to \#4 in P. tremula. Root $\mathrm{N}$ concentration was higher in P. tremula than in P. trichocarpa (Figure 4.2e and f). 

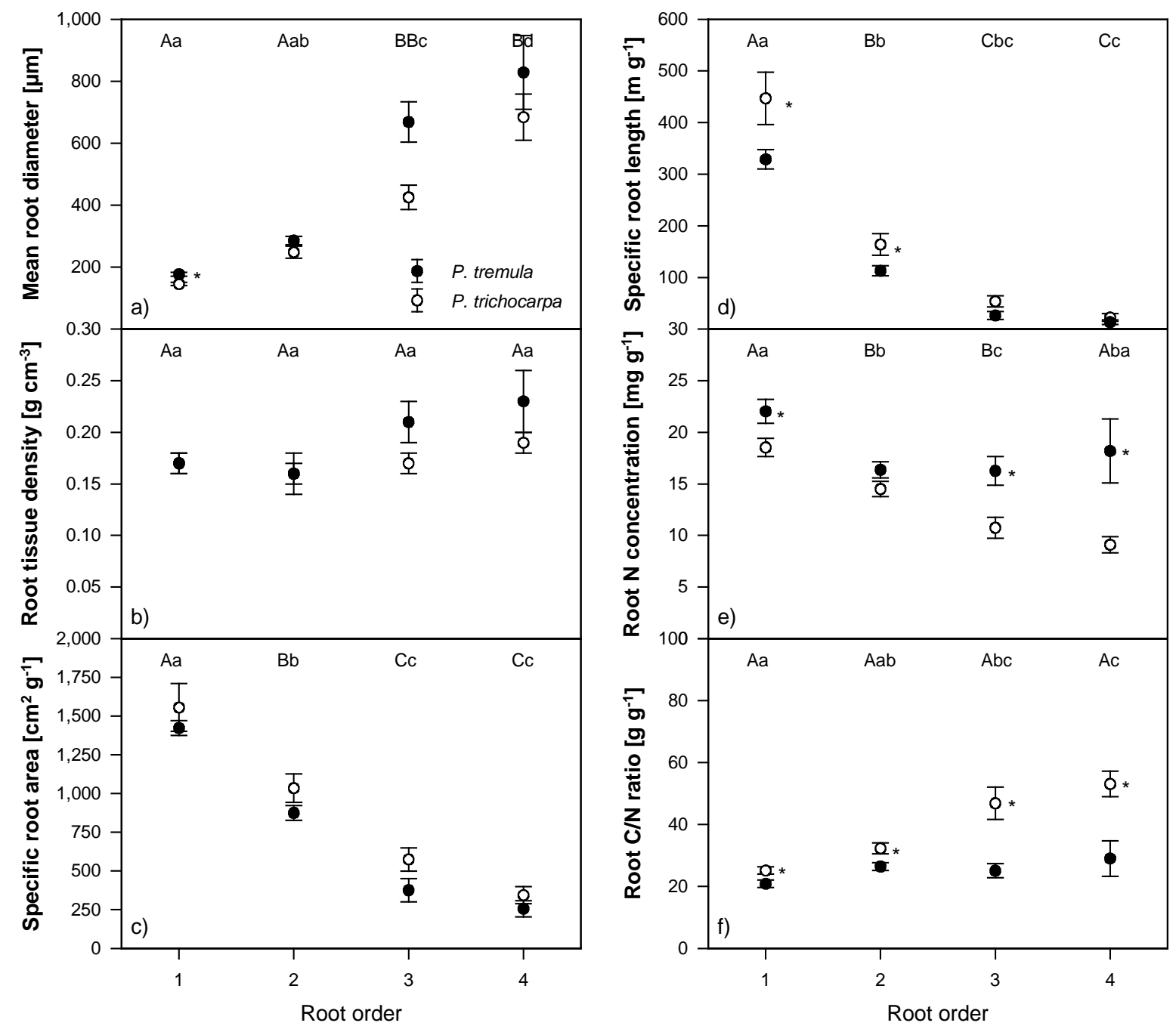

Figure 4.2 Root morphological and chemical traits [mean diameter, root tissue density (RTD), specific root area (SRA) and specific root length (SRL), root $\mathrm{N}$ concentration and root $\mathrm{C} / \mathrm{N}$ ratio] of four root orders (1-4) of the species $P$. tremula and $P$. trichocarpa. The number of samples varied per root order and species ( $P$. tremula: 1 st order, $n=11-14$; 2nd order, $n=10-14$; 3rd order, $n=9-14$; 4th order, $n=5-7$ and $P$. trichocarpa: 1 st order, $n=10$; 2nd order, $n=9-10$; 3rd order, $n=9-10$; 4th order, $n=8-9$ ). Significant differences between root orders are marked with different upper case (P. tremula) and lower case ( $P$. trichocarpa) letters. Significant interspecific differences of the respective root orders are marked with an asterisk (Tukey's HSD test, $P<0.05$, means $\pm \mathrm{SE}$ ).

The mixed-effects model revealed that root order was the single most important factor determining root morphology and chemistry (Table 4.4). Species had no effect on any of the parameters when analysed alone; however, the order $\times$ species interaction influenced root diameter, SRL, root $\mathrm{N}$ and $\mathrm{C} / \mathrm{N}$ significantly indicating that the species effect becomes only visible in the order-related analysis (Table 4.4) but not in the bulk analysis of the pooled data. 
Table 4.4. Results of linear mixed-effects models (lme) on the influence of root order (1-4), treatment (mono, mix) and species (P. tremula and P. trichocarpa) including all the interaction terms on six root morphological and chemical traits. Shown are degrees of freedom (df) and the $F$ and $P$ value of the respective variables and the model itself. Variables with significant influence are printed in bold $(P<0.05)$.

\begin{tabular}{|c|c|c|c|c|c|c|c|}
\hline \multirow{2}{*}{ Source of variation } & \multirow[b]{2}{*}{$\mathrm{df}$} & \multicolumn{2}{|c|}{ Diameter } & \multicolumn{2}{|c|}{ RTD } & \multicolumn{2}{|c|}{ SRA } \\
\hline & & $\mathrm{F}$ & $P$ & $\mathrm{~F}$ & $P$ & $\mathrm{~F}$ & $P$ \\
\hline Model & 1 & 550.89 & $<0.001$ & 448.44 & $<0.001$ & 462.63 & $<0.001$ \\
\hline Order & 3 & 82.63 & $<0.001$ & 5.51 & $<0.001$ & 190.54 & $<0.001$ \\
\hline Species & 1 & 9.38 & 0.09 & 1.35 & 0.37 & 3.39 & 0.21 \\
\hline Treatment & 1 & 3.51 & 0.08 & 0.21 & 0.65 & 0.17 & 0.69 \\
\hline Order x species & 3 & 3.52 & 0.02 & 1.35 & 0.27 & 0.14 & 0.94 \\
\hline Order $\mathrm{x}$ treatment & 3 & 6.43 & 0.001 & 2.17 & 0.10 & 7.15 & 0.001 \\
\hline Species $x$ treatment & 1 & 4.21 & 0.06 & 1.18 & 0.29 & 2.40 & 0.14 \\
\hline \multirow[t]{3}{*}{$\begin{array}{l}\text { Order } x \text { treatment } x \\
\text { species }\end{array}$} & 3 & 0.51 & 0.68 & 1.84 & 0.15 & 1.10 & 0.36 \\
\hline & & \multicolumn{2}{|c|}{ SRL } & \multicolumn{2}{|c|}{ Root N } & \multicolumn{2}{|c|}{ Root C/N } \\
\hline & $\mathrm{df}$ & $\mathrm{F}$ & $P$ & $\mathrm{~F}$ & $P$ & $\mathrm{~F}$ & $P$ \\
\hline Model & 1 & 261.08 & $<0.001$ & 1341.62 & $<0.001$ & 703.01 & $<0.001$ \\
\hline Order & 3 & 251.93 & $<0.001$ & 79.71 & $<0.001$ & 36.26 & $<0.001$ \\
\hline Species & 1 & 4.41 & 0.17 & 29.05 & 0.12 & 37.25 & 0.10 \\
\hline Treatment & 1 & 0.51 & 0.48 & 16.00 & 0.001 & 7.52 & 0.01 \\
\hline Order $\mathrm{x}$ species & 3 & 4.80 & 0.01 & 21.63 & $<0.001$ & 15.88 & $<0.001$ \\
\hline Order $\mathrm{x}$ treatment & 3 & 3.19 & 0.03 & 1.19 & 0.33 & 2.41 & 0.08 \\
\hline Species $x$ treatment & 1 & 8.49 & 0.01 & 2.77 & 0.12 & 0.13 & 0.73 \\
\hline $\begin{array}{l}\text { Order } \mathrm{x} \text { treatment } \mathrm{x} \\
\text { species }\end{array}$ & 3 & 3.37 & 0.03 & 7.13 & 0.001 & 4.67 & 0.01 \\
\hline
\end{tabular}

Effects of intra- and interspecific competition on the morphology and chemistry of different root orders

Despite the contrasting fine root densities in the mono and mix treatments, root morphology was only weakly influenced by the type of competitive interaction, i.e. intraor interspecific (Table 4.4). None of the root morphological traits (mean fine root diameter, RTD, SRA, SRL) was affected by the contrast of intra- and interspecific competition across all root orders (P. tremula: Figure 4.3a-d, P. trichocarpa: Figure 4.3g-j and Table 4.4). Significant effects of the presence of allo- or conspecific competitors were only observed for tissue chemistry (root $\mathrm{N}$ concentration, $P$. tremula: Figure 4.3e-f, $P$. trichocarpa: Figure 4.3k-l and Table 4.4). The Principal Components Analysis (PCA) on the relative importance of the influencing factors root order, species ( $P$. tremula and $P$. 
trichocarpa) and competition treatment (mono vs. mixed) revealed the key role played by root order for root morphology (high loading on the first axis: -0.960 ; positive relations of root order to SRA, SRL and root N concentration, negative relations to root diameter and root tissue density; Table 4.5). Species correlated with axis 2 and was positively related with root $\mathrm{N}$ concentration, but not related to the other root morphological traits that were mostly associated with root order. Finally, treatment correlated with the PCA axis 3 with low eigenvalue (0.143) and showed no closer association with any of the investigated root parameters. The first three axes of the PCA explained $89 \%$ of the total variance of all components. Additionally, multifactorial analyses (linear mixed effects models) were conducted to test for influences of root order and treatment (mono vs. mixed) on the respective root morphological and chemical traits. Root order had a significant effect on all investigated root traits, while the competition treatment had a significant influence on root $\mathrm{N}$ concentration and root $\mathrm{C} / \mathrm{N}$ ratio. Significant interaction terms 'order $\times$ treatment' were found for the traits root diameter, SRA and SRL (Table 4.4) indicating specific competition effects on morphology in certain root orders. For SRL, the interaction 'species $x$ treatment' suggests that root length development may respond differently to intra- and interspecific competition in the two species. 


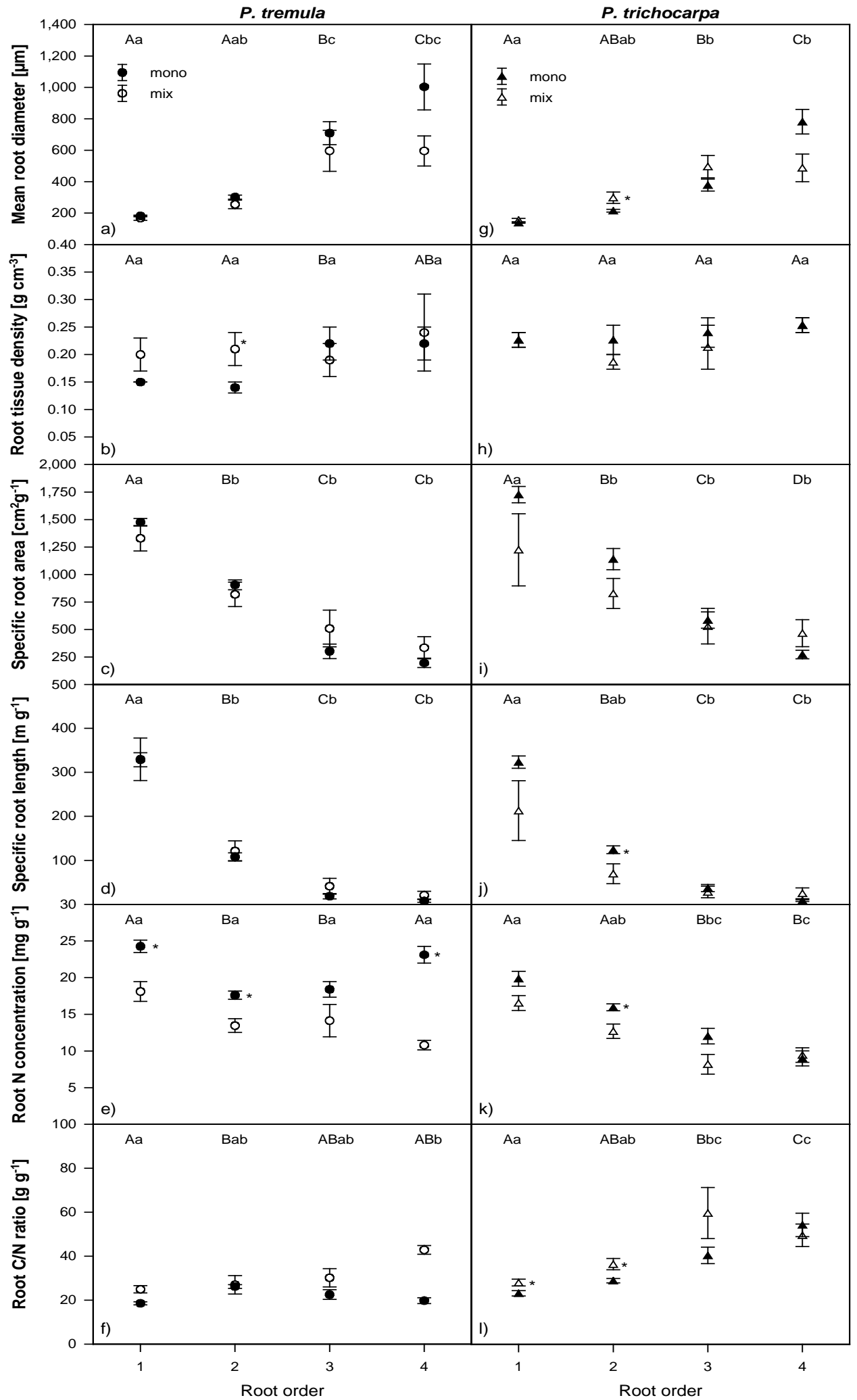

Figure 4.3 Root morphological and chemical traits of four different root orders (1-4) of the species $P$. tremula and $P$. trichocarpa as affected by treatment (mono vs. mix). The number of samples varied per root order and treatment $(P$. tremula: mono, $n=3-5$; mix, $n=4-9$; P. trichocarpa: mono, $n=6$; mix, $n=2-4)$. Significant differences between root orders of the mono and the mixed treatment are marked with upper case letters and lower case letters, respectively. Significant differences among treatments within a specific root order are marked with an asterisk (Tukey’s HSD test, $P<$ 0.05 , means $\pm \mathrm{SE}$ ). 
Table 4.5. Results of a Principal Components Analysis (PCA) including the investigated root morphological and chemical parameters, root order, species and treatment. Given are the proportion of variation explained by the four axes (eigenvalues, EV) and the loadings of each component along the four explanatory axes with the closest correlation to the respective axis marked in bold. For abbreviations see Table 4.1.

\begin{tabular}{|c|c|c|c|c|c|}
\hline Variables & $\mathrm{EV}$ & $\begin{array}{c}\text { Axis } 1 \\
-0.523 \\
\end{array}$ & $\begin{array}{c}\text { Axis } 2 \\
-0.226 \\
\end{array}$ & $\begin{array}{c}\text { Axis } 3 \\
-0.143 \\
\end{array}$ & $\begin{array}{l}\text { Axis } 4 \\
-0.065 \\
\end{array}$ \\
\hline Root order & & -0.960 & -0.070 & -0.158 & -0.076 \\
\hline Species & & 0.154 & -0.779 & -0.465 & -0.349 \\
\hline Treatment & & -0.098 & -0.503 & 0.823 & 0.076 \\
\hline \multicolumn{6}{|c|}{ Root morphology-related variables } \\
\hline Root diameter & & -0.894 & 0.274 & -0.199 & -0.046 \\
\hline RTD & & -0.587 & 0.436 & 0.406 & -0.531 \\
\hline SRA & & 0.986 & 0.017 & 0.049 & -0.102 \\
\hline SRL & & 0.930 & 0.090 & 0.071 & -0.307 \\
\hline \multicolumn{6}{|c|}{ Root chemistry-related variable } \\
\hline Root N & & 0.493 & 0.817 & -0.108 & 0.042 \\
\hline
\end{tabular}

Changes in root morphology and chemistry with root age

According to the analysis of the roots at the plexiglass plates, all investigated root morphological and chemical parameters were significantly influenced by root age $(P<$ 0.001, Table 4.6). We observed a continuous decrease in the mean diameter of the root fragments visible at the front plates with increasing age in both species. Mean diameter was smaller in $P$. tremula than in $P$. trichocarpa in the weeks 2-3 after root appearance but the difference disappeared in older roots. 
Table 4.6. Results of linear mixed-effects models (lme) on the influence of root age class (1-8), treatment (mono, mix) and species (P. tremula and P. trichocarpa) including all interaction terms on six root morphological and chemical traits. Shown are the degrees of freedom (df) and the $\mathrm{F}$ and $P$ value of the respective variables and the model itself. Variables with significant influence are printed in bold. The effect of some factors could not be calculated due to insufficient sample size; they were indicated with dashes. For abbreviations see Table 4.1.

\begin{tabular}{|c|c|c|c|c|c|c|c|}
\hline \multirow{2}{*}{ Source of variation } & \multirow{2}{*}{$\mathrm{df}$} & \multicolumn{2}{|c|}{ Diameter } & \multicolumn{2}{|c|}{ RTD } & \multicolumn{2}{|c|}{ SRA } \\
\hline & & $\mathrm{F}$ & $P$ & $\mathrm{~F}$ & $P$ & $\mathrm{~F}$ & $P$ \\
\hline Model & 1 & 1247.75 & $<0.001$ & 568.82 & $<0.001$ & 1159.53 & $<0.001$ \\
\hline Age & 7 & 54.31 & $<0.001$ & 29.88 & $<0.001$ & 41.17 & $<0.001$ \\
\hline Species & 1 & 4.44 & 0.04 & 6.66 & 0.01 & 5.02 & 0.03 \\
\hline Treatment & 1 & 8.43 & 0.004 & 0.13 & 0.72 & 2.67 & 0.10 \\
\hline Age $x$ species & 7 & 4.00 & 0.001 & 1.99 & 0.06 & 0.88 & 0.53 \\
\hline Age $x$ treatment & 7 & 1.58 & 0.14 & 1.22 & 0.29 & 0.69 & 0.68 \\
\hline Species $x$ treatment & 1 & 0.01 & 0.91 & 0.03 & 0.87 & 0.10 & 0.75 \\
\hline \multirow[t]{3}{*}{$\begin{array}{l}\text { Age } x \text { species } x \\
\text { treatment }\end{array}$} & 7 & 1.57 & 0.15 & 0.38 & 0.91 & 1.12 & 0.35 \\
\hline & & \multicolumn{2}{|c|}{ SRL } & \multicolumn{2}{|c|}{ Root N } & \multicolumn{2}{|c|}{ Root C/N } \\
\hline & $\mathrm{df}$ & $\mathrm{F}$ & $P$ & $\mathrm{~F}$ & $P$ & $\mathrm{~F}$ & $P$ \\
\hline Model & 1 & 491.82 & $<0.001$ & 633.9 & $<0.001$ & 633.9 & $<0.001$ \\
\hline Age & 7 & 22.46 & $<0.001$ & 14.89 & $<0.001$ & 14.89 & $<0.001$ \\
\hline Species & 1 & 15.96 & 0.001 & 15.37 & - & 15.37 & - \\
\hline Treatment & 1 & 11.74 & 0.001 & 17.95 & 0.001 & 17.95 & 0.001 \\
\hline Age $x$ species & 7 & 5.10 & $<0.001$ & 5.23 & $<0.001$ & 5.23 & $<0.001$ \\
\hline Age $x$ treatment & 7 & 0.58 & 0.77 & 1.43 & 0.21 & 1.43 & 0.21 \\
\hline Species $x$ treatment & 1 & 0.83 & 0.36 & 2.24 & 0.16 & 2.24 & 0.16 \\
\hline $\begin{array}{l}\text { Age } x \text { species } x \\
\text { treatment }\end{array}$ & 7 & 2.06 & 0.05 & 0.71 & 0.67 & 0.71 & 0.67 \\
\hline
\end{tabular}

The largest diameters were measured in the youngest roots (1-wk-old) with $\sim 800 \mu \mathrm{m}$ (Figure 4.4a), comparable to the diameters recorded in the 4th order roots without front plate contact (P. tremula: 930 and P. trichocarpa: $910 \mu \mathrm{m})$. Thus, the age-related analysis (roots at front plate) and the order-related analysis (harvest data; roots without plate contact) produced partly contrasting results on diameter change with root age or root order. Root tissue density increased constantly with age but RTD was significantly higher in $P$. tremula in the 2- to 6-wk-old segments. Specific root area was nearly constant across the age classes from week 1 to week 7 in both species and declined to 0.21 and $0.14 \mathrm{~cm}^{2} \mathrm{~g}^{-1}$ in P. tremula and P. trichocarpa in 19-wk-old root segments (> 8, Figure 4.4c). Specific root length was lowest in young and in old root segments in both species due to its inverse relation to the square of root diameter. $P$. trichocarpa with thicker roots generally had smaller SRA and SRL values than $P$. tremula across the age sequence (Figure 4.4c and d). 
Root $\mathrm{N}$ concentration decreased from week 1 to 4 in both species and remained constant thereafter; 19-wk-old root segments had higher ( $P$. tremula) or lower ( $P$. trichocarpa) concentrations than 7-wk-old roots (Figure 4.4e and f). The changes in morphology and chemistry are in accordance with the age-related changes in root pigmentation and texture (Table 4.2).
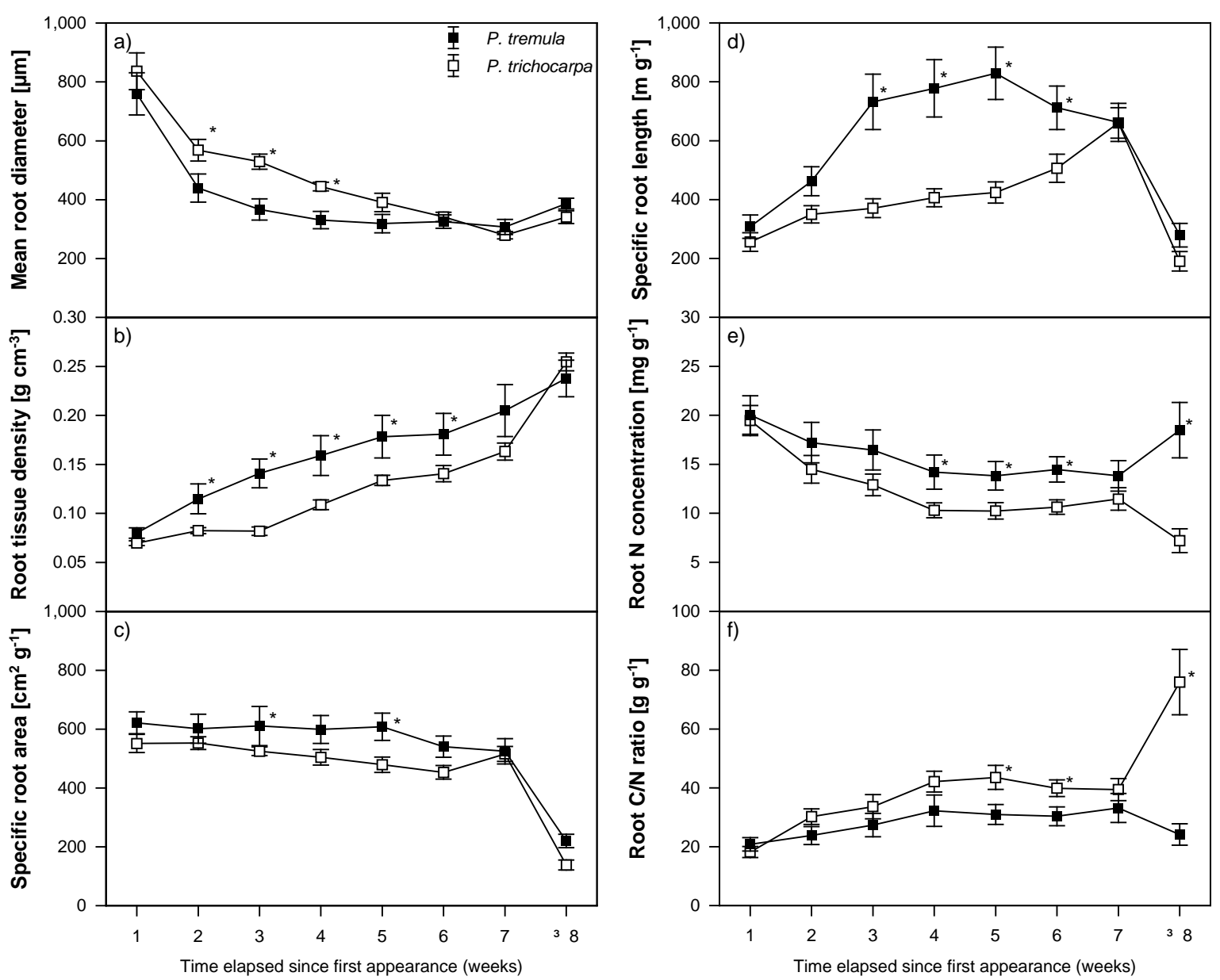

Figure 4.4 Effects of root age on root morphological (a-d) and chemical (e-f) traits. Given are means \pm SE of 1-7 and 19-wk-old root sections of the species $P$. tremula and $P$. trichocarpa. The number of samples varied between age classes and species for morphological traits (P. tremula, $n=9-29$; P. trichocarpa, $n=15-19)$ and chemical traits (P. tremula, $n$ = 6-9; $P$. trichocarpa, $n=8-10$ ), respectively. Significant interspecific differences within age classes are marked with an asterisk (Tukey's HSD test, $P<0.05$ ). 
Effects of intra- and interspecific competition on root morphology and chemistry across the age sequence

The analysis of the age-related data with mixed-effects models and PCA indicates that root age was (similar to root order) a key determinant of root morphology and chemistry while species and treatment were of secondary importance influencing only four of the six traits and with lower significance than root age (Table 4.6 and Table 4.7).

Table 4.7. Results of a Principal Components Analysis (PCA) including the investigated root morphological and chemical parameters, root age, species and treatment. Given are the proportion of variation explained by the four axes (eigenvalues, EV) and the loadings of each component along the four explanatory axes with the closest correlation to the respective axis marked in bold. For abbreviations see Table 4.1.

\begin{tabular}{|c|c|c|c|c|}
\hline Variables & $\begin{array}{c}\text { Axis 1 } \\
-0.396 \\
\end{array}$ & $\begin{array}{c}\text { Axis } 2 \\
-0.299 \\
\end{array}$ & $\begin{array}{c}\text { Axis } 3 \\
-0.136 \\
\end{array}$ & $\begin{array}{r}\text { Axis } 4 \\
-0.126 \\
\end{array}$ \\
\hline Root age & 0.968 & -0.032 & 0.048 & -0.023 \\
\hline Species & -0.013 & 0.636 & -0.037 & -0.750 \\
\hline Treatment & 0.038 & 0.623 & -0.481 & 0.589 \\
\hline \multicolumn{5}{|c|}{ Root morphology-related variables } \\
\hline Root diameter & -0.790 & 0.460 & 0.277 & 0.171 \\
\hline RTD & 0.905 & -0.204 & 0.251 & 0.172 \\
\hline SRA & -0.726 & -0.515 & -0.422 & -0.072 \\
\hline SRL & 0.117 & -0.860 & -0.436 & -0.126 \\
\hline \multicolumn{5}{|c|}{ Root chemistry-related variable } \\
\hline Root N & -0.498 & -0.584 & 0.586 & 0.136 \\
\hline
\end{tabular}

The rootlets of $P$. tremula and $P$. trichocarpa tended to have smaller diameters, higher SRL and higher root $\mathrm{N}$ concentration in the mono treatments than in the mix treatment (Figure 4.5a, d, e, f, g, j, k, l) while the differences in RTD and SRA were less pronounced (Figure 4.5b, c, h, i). The results of the PCA demonstrate that root age is a similarly important determinant on axis 1 (eigenvalue 0.396) with close association with all root traits except for root diameter and SRL (Table 4.7). Axis 2 (eigenvalue 0.299) revealed species and treatment as factors with high and equal loadings and root diameter and SRL as correlating root traits. 


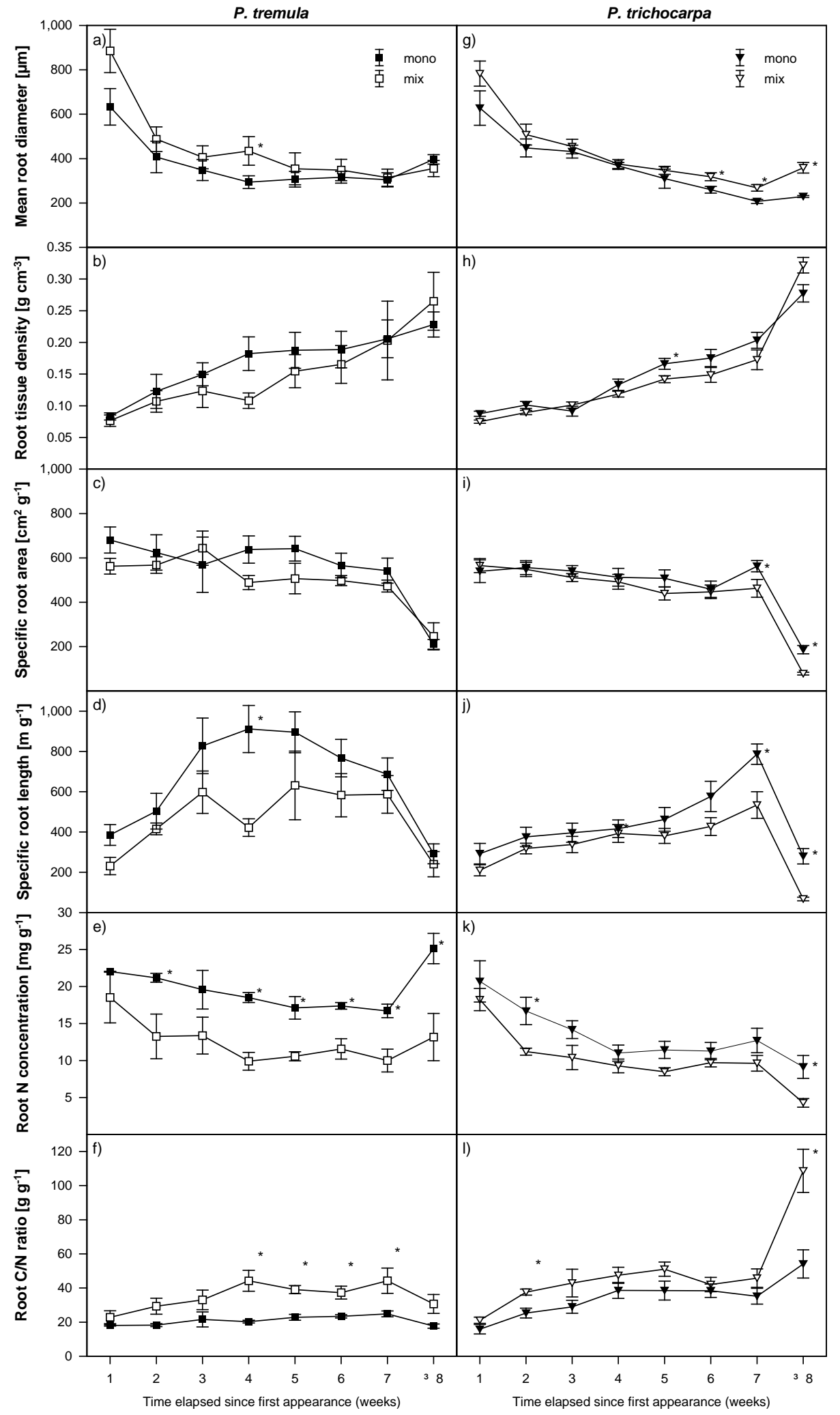

Figure 4.5 Root morphological (a-d) and chemical (e-f) traits of 1-7 and 19-wk-old root sections of the species $P$. tremula and $P$. trichocarpa as affected by treatment (mono vs. mixed). The number of samples varied per age class and treatment for root morphological traits ( $P$. tremula: mono, $n=4-22$; mix, $n=5-7$; $P$. trichocarpa: mono, $n=6-11$; mix, $n=6-8$ ) and chemical traits (P. tremula: mono, $n=3-4$; mix, $n=3-5$; P. trichocarpa: mono, $n=4-6$; mix, $n=3-4$ ), respectively. Significant differences among treatments within a specific root age are marked with an asterisk (Tukey's HSD test, $P<0.05$, means $\pm \mathrm{SE}$ ). 


\section{Discussion}

Asymmetric belowground competition

The two poplar species with adaptation to rather infertile ( $P$. tremula) or fertile sites (P. trichocarpa) differed largely in their productivity in monoculture under defined growth conditions. P. trichocarpa was more productive not only aboveground but also belowground, supporting our hypothesis (1). The relatively fertile growing substrate likely has enhanced the species difference in productivity. In mixture, $P$. trichocarpa nearly tripled its belowground productivity compared to the growth with intraspecific competition and may have profited from the presence of slower growing $P$. tremula with its relatively low fine and coarse root density. Thus, intraspecific belowground competition must have been much stronger than interspecific competition and the outcome of root competition between the two species was highly asymmetric: P. trichocarpa appears as the winner with more soil space explored while $P$. tremula showed a non-significant tendency of decrease in belowground productivity in comparison to growth in monoculture. The asymmetry is well reflected in the largely different competitive ability indices (CA) of the two species.

Our experiment further shows that the asymmetry can be larger in the belowground than the aboveground interaction between two tree species. This may be relevant in initial stages of plantations where the saplings may be exposed to root competition while shoot competition is not yet significant. Since $P$. trichocarpa increased its root productivity in the presence of $P$. tremula to a much greater extent than aboveground productivity, this suggests that intraspecific competition intensity in the P. trichocarpa monocultures was higher belowground than aboveground and/or P. trichocarpa has a particularly high competitive ability belowground. In the presence of a weak competitor, $P$. trichocarpa was then able to expand its root system into the unexplored soil space which apparently was not as easily possible in the canopy space. This interpretation is in line with the observed increase in root/shoot ratio in $P$. trichocarpa from the mono to the mix treatment. One may argue that the large increase in fine root productivity of $P$. trichocarpa in mixture was partly caused by the relatively small fine root density of the weak competitor P. tremula. This might indicate that competition was relatively unimportant in the P. tremula mono treatment but was significant in mixture. The fine root density of P. tremula in the mono treatment $\left(0.6 \mathrm{~g} \mathrm{~L}^{-1}\right)$ is comparable to densities found in two-yr-old $P$. tremuloides plants in a field experiment of Powell and Bork (2004), while P. trichocarpa exceeded these values 
in our experiment by a factor of two $\left(1.2 \mathrm{~g} \mathrm{~L}^{-1}\right)$ which relates to the much higher aboveground biomass. The high fine root density in the mix treatment of our experiment $\left(1.9 \mathrm{~g} \mathrm{~L}^{-1}\right.$ ) is well comparable to densities reported from poplar plantations (Al Afas et al. 2008). Since the root density in mixture exceeded not only the density in the most productive monoculture ( $P$. trichocarpa) but also the hypothetical sum of the root density reached by the two species in the mono treatments, the presence of $P$. tremula seems to have promoted root growth of $P$. trichocarpa beyond a simple replacement effect. That $P$. trichocarpa produced less root biomass in the mono than the mixed treatment, might also result from elevated soil resource exploitation by two plants of this productive species as compared to the mixture. Irrespective of the underlying mechanism, there is a need to investigate nutrient and water uptake kinetics and root exudation of the competing species in future studies.

Species differences in root properties along the fine root branching network

Despite being adapted to largely different soil conditions in their natural habitats, the two species were remarkably similar in their first-order rootlets, i.e. the putatively most active root segments. The two species showed also similar trends in the change of root morphological and chemical traits from the first to the forth order root segments, which is in accordance with our second hypothesis. The fast-growing species $P$. trichocarpa had somewhat thinner first-order roots with higher SRL than the corresponding $P$. tremula roots while the $\mathrm{N}$ concentration in this root segment was lower in the former. The $\mathrm{N}$ concentration differences between the species increased towards higher root orders, while the morphological differences were insignificant in the 3 rd and $4^{\text {th }}$ order class. $P$. trichocarpa with its thinner and longer fine root endings achieved much higher above- and belowground growth rates which could well be explained by higher nutrient and water uptake rates per invested root mass in this species. This would support the assumption that fast-growing species require root systems with high resource uptake rates which are generally related to high SRA and SRL (Comas and Eissenstat 2004). On the other hand, root activity tends to increase with root $\mathrm{N}$ concentration and this parameter was significantly larger in P. tremula roots in three of the four root orders examined. Thus, it appears that morphological adaptation (longer and thinner roots) supported the higher root growth rate in $P$. trichocarpa while the lower $\mathrm{N}$ concentrations suggests that no marked 
physiological adaptation to enhanced root activity did exist in this species. Furthermore, root tissue density was not lower in the most distal root segments of $P$. trichocarpa suggesting that high root growth rates are not closely related to tissue density.

Effects of intra- and interspecific competition on the morphology of different root orders

The root system of $P$. trichocarpa showed much greater apparent growth stimulation than the shoot system when shifting from a conspecific to an allospecific neighbor. Poplar roots have been described as plant organs with high morphological plasticity (Block et al. 2006) which suggested adaptations in root surface area, length and tissue density as a response to the doubling of fine root density from the mono to the mix treatment and the presence of allospecific instead of conspecific neighbors. However, this was not the case. Similar insensitivity of tree fine root morphology to changing competitive environments was observed by Curt and Prévosto (2003) and Beyer et al. (2013b). On the other hand, we observed significant treatment effects on root $\mathrm{N}$ concentration in both species; P. tremula reduced its $\mathrm{N}$ concentration in the mix compared to the mono treatment in three of the four root orders significantly while $P$. trichocarpa did so in the 2nd root order only. Thus, as a likely response to the much higher root density in the mixed boxes, both species responded with reduced $\mathrm{N}$ accumulation in the roots which most likely reflects a reduction of $\mathrm{N}$ availability when root density is high. The more pronounced decrease in $\mathrm{N}$ concentration in $P$. tremula than in $P$. trichocarpa might be linked to the weaker belowground competitive ability of the former species. It could explain the (slight) decrease in root production from the mono to the mix treatment. P. trichocarpa, on the other hand, increased its root production despite some reduction in root $\mathrm{N}$ concentration which suggests that the two species have adopted largely different strategies of soil exploration with their root systems. The higher responsiveness of root chemistry than root morphology to alteration in the competitive environment could reflect different temporal scales of adaptation, more shortterm in the case of root $\mathrm{N}$ levels and more long-term in case of morphological change.

\section{Age-dependent change in root morphology and chemistry and effects of competition}

The age-related analysis of fine root morphology and chemistry bases on the imagery taken on the front windows of the rhizoboxes; these observations shall be related to the root 
topological data obtained from the harvests. One main finding of our study is that both analytical approaches are only partly matching because the root material used for the two analyses is not identical (even though belonging to the same plant). Moreover, the growing conditions for the roots used for optical age-related investigation and harvest-based orderrelated examination are apparently different. All four morphological traits were significantly influenced by root age, i.e. the time since appearance behind the front plate. This is in line with the trait heterogeneity observed along individual tree fine root branches by, e.g. Wells and Eissenstat (2002) and Hishi (2007). Since the variation in age across different root orders is linked to the branching structure with the youngest root segments produced by apical meristems, we assumed strong similarity among juvenile one-wk-old root segments and first order roots. Surprisingly, this was not the case and both approaches of root system analysis generated partly deviating results. (1) We found a large discrepancy in mean root diameter between the most distal (1st order) and youngest root segments and the diameter trend with increasing root age: Mean diameter was about four times higher in the youngest roots on the observation window than in the 1st order root segments harvested in the (more remote) soil. Moreover, root diameter increased from the 1st to the 4th order roots as expected, but showed a surprising decrease from high 600-900 $\mu \mathrm{m}$ in the youngest to $\sim 400 \mu \mathrm{m}$ in the older root sections. As the youngest roots were in our study in many cases not the smallest roots, there is strong evidence that the two sampling approaches may have collected roots of different architectural and functional differentiation (Hishi 2007); this phenomenon may be related to 'heterorhizy'(Noelle 1910; Persson 2002). The observed range of 1- to 19-wk-old root segments was not homogenously distributed over the four or five root order classes identified in the boxes, which suggests that the morphogenetic development of the ageing root and its branching proceeded differently in the undisturbed more remote part of the soil and in direct contact to the observation window. The youngest (one-wk-old) roots at the windows had similar $\mathrm{N}$ concentrations as the 1st-order roots deeper in the soil, but they were in both species much thicker with smaller SRL and SRA than the latter. (2) Perhaps most important is the much lower RTD of the youngest roots at the windows (0.05-0.10 vs. $0.15-0.20 \mathrm{~g} \mathrm{~cm}^{-3}$ ) which may explain their large diameter. These young rootlets have been termed 'pioneer roots' (Sutton and Tinus 1983) and their highly different morphology may in part be a consequence of the presence of the plexiglass plate which forms a mechanical barrier for root elongation (Withington et al. 2003) probably altering the anatomical differentiation of the young root 
and its branching patterns. A kind of 'root dimorphism' with first order roots with a root tip (fibrous roots) and pioneer roots primarily for soil exploration have been observed in poplar species including $P$. trichocarpa by Zadworny and Eissenstat (2011) and Bagniewska-Zadworna et al. (2012); this phenomenon may contribute to the assumed high root plasticity in the genus Populus. However, a dimorphism between short ectomycorrhizal 1st order roots and rapidly growing 'long roots' has been observed in other tree genera as well (Lyford 1980; Polverigiani et al. 2011).

First order roots as elements of the 'typical' branching pattern and pioneer roots seem to have different lifespans which may point at different functionalities of the two root morphotypes. Block et al. (2006) reported a wide range of longevities (30 to $300 \mathrm{~d}$, median $95 \mathrm{~d})$ for 1 st order roots of $P$. trichocarpa while pioneer roots seem to persist longer as they undergo secondary growth (Eissenstat and Achor 1999). Likely functions are expansion growth in the case of the pioneer roots which form the main axes of the growing root system, and nutrient and water absorption in case of the 1st order roots. The fact that both root types had similar $\mathrm{N}$ concentrations $\left(\sim 20 \mathrm{mg} \mathrm{g}^{-1}\right)$ in their most distal parts in our experiment, suggests that they are metabolically very active (Pregitzer et al. 1998).

As in the order-related analysis, the presence of conspecific vs. allospecific competitors had an only weak effect on root morphology, but altered root $\mathrm{N}$ concentration (lower $\mathrm{N}$ concentrations in the mix treatment). Most differences between the mono and mix treatments in root diameter, SRA, SRL and RTD were not significant and, more important, the trends between the mono and mix boxes were partly of opposite direction to those observed in the order-related analysis. In contradiction to our hypothesis (3), we did not observe a higher responsiveness of first order roots than older root segments. This leads us to the assumption that the fine root morphology of these two poplar species is not very sensitive to alteration in competition intensity (30-350 \% higher fine root density in the mixed than the mono boxes ) and to the type of competitive interaction (intra- vs. interspecific) . This may be attributable to the fact that root density and thus assumed belowground competition intensity varied from low/moderate to high but did not include a treatment with a single plant and low root density. 


\section{Conclusion}

Our competition experiment with two ecologically contrasting poplar species confirmed earlier reports on the close relation between root order and root age, and root morphology, chemistry and probably also functionality along a fine root branch. Species differences in fine root traits were significant only in certain root order or root age classes, which might have been overlooked in a less precise bulk analysis of fine root biomass. This suggests that studies on fine root functioning and root responses to environmental factors should focus on selected (preferably most distal) root orders or age classes.

The specific growing conditions at the transparent front plate seem to trigger the development of particularly thick pioneer roots with low tissue density that were missing (or rare) in the soil of the box interior. This observation may have consequences for the interpretation of rhizoscope data on fine root growth because the plexiglass observation tubes represent similar impenetrable barriers for root growth as the plates in our rhizoboxes. We strongly recommend accounting for the phenomenon of heterorhizy in future studies on fine root dynamics in growth containers and in the field.

Our results on the effects of intraspecific and interspecific competition on root traits in poplar suggest that competition-induced root morphological adaptation may not be the rule. Increased competition intensity caused a decrease in root $\mathrm{N}$ concentration probably due to enhanced resource depletion in the shared soil which could result in changes in nutrient and water uptake capacity, root growth and turnover. A closer look on possible physiological consequences of root competition should guide future research in the field. Future experiments about competition effects on root morphology should be expanded to more natural situations with forest soil and to roots infected by the characteristic mycorrhizal fungi, and should preferably use a higher number of tree species in the trials. 


\section{References}

Al Afas N., Marron N., Zavalloni C., Ceulemans R. (2008) Growth and production of a short-rotation coppice culture of poplar--IV: Fine root characteristics of five poplar clones. Biomass and Bioenergy 32:494-502.

BAgNiewsKa-ZADWORnA A., BYCZYK J., Eissenstat D.M., OleKsyn J., ZADWORNY M. (2012) Avoiding transport bottlenecks in an expanding root system: Xylem vessel development in fibrous and pioneer roots under field conditions. American Journal of Botany 99:1417-1426.

BAuMEISTER W. (1954) Mineralstoffe und Pflanzenwachstum. Gustav Fischer, Stuttgart

Berg M.P., ElLERS J. (2010) Trait plasticity in species interactions: a driving force of community dynamics. Evolutionary Ecology 24:617-629.

BERNTSON G.M. (1997) Topological scaling and plant root system architecture: developmental and functional hierarchies. New Phytologist 135:621-634.

Beyer F., Hertel D., Jung K., Fender A.-C., Leuschner C. (2013a) Competition effects on fine root survival of Fagus sylvatica and Fraxinus excelsior. Forest Ecology and Management 302:14-22.

Beyer F., Hertel D., Leuschner C. (2013b) Fine root morphological and functional traits in Fagus sylvatica and Fraxinus excelsior saplings as dependent on species, root order and competition. Plant and Soil 1-14.

Block R., VAn Rees K., Knight J. (2006) A review of fine root dynamics in Populus plantations. Agroforestry Systems 67:73-84.

Bolte A., VillanueVA I. (2006) Interspecific competition impacts on the morphology and distribution of fine roots in European beech (Fagus sylvatica L.) and Norway spruce (Picea abies (L.) Karst.). European Journal of Forest Research 125:15-26.

Brundrett M., Murase G., Kendrick B. (1990) Comparative anatomy of roots and mycorrhizae of common Ontario trees. Canadian Journal of Botany 68:551-578.

CASPER B.B., Jackson R.B. (1997) Plant competition underground. Annual Review of Ecology and Systematics 28:545-570.

ComAs L.H., EISSENSTAT D.M. (2004) Linking fine root traits to maximum potential growth rate among 11 mature temperate tree species. Functional Ecology 18:388397.

CoOmes D.A., GRUBB P.J. (2000) Impacts of root competition in forests and woodlands: a theoretical framework and review of experiments. Ecological Monographs 70:171207.

Curt T., PrÉvosto B. (2003) Rooting strategy of naturally regenerated beech in Silver birch and Scots pine woodlands. Plant and Soil 255:265-279. 
DicKMAnN D.I., Kuzovkina J. (2008) Poplars and willows of the world, with emphasis on silviculturally important species. Rome, Italy: FAO Forest Management Division Working Paper IPC/9-2 129.

Douglas G.B., McIvor I.R., PotTer J.F., Foote L.G. (2010) Root distribution of poplar at varying densities on pastoral hill country. Plant and Soil 333:147-161.

EisSENSTAT D.M., ACHOR D.S. (1999) Anatomical characteristics of roots of citrus rootstocks that vary in specific root length. New Phytologist 141:309-321.

Eissenstat D.M., CALDwEll M.M. (1988) Seasonal timing of root growth in favorable microsites. Ecology 69:870-873.

ELLENBerg H., Leuschner C. (2010) Vegetation Mitteleuropas mit den Alpen in ökologischer, dynamischer und historischer Sicht, 6th ed. Ulmer, Stuttgart

FITTER A.H. (1987) An architectural approach to the comparative ecology of plant root systems. New Phytologist 106:61-77.

FITTER A.H. (1982) Morphometric analysis of root systems: application of the technique and influence of soil fertility on root system development in two herbaceous species. Plant, Cell \& Environment 5:313-322.

Friend A.L., Scarascia-MugnozzA G., Isebrands J.G., HeILMAn P.E. (1991) Quantification of two-year-old hybrid poplar root systems: morphology, biomass, and ${ }^{14} \mathrm{C}$ distribution. Tree Physiology 8:109 -119.

FUJII S., KASUYA N. (2008) Fine root biomass and morphology of Pinus densiflora under competitive stress by Chamaecyparis obtusa. Journal of Forest Research 13:185189.

GuO D., MitChell R., HendRICKs J. (2004) Fine root branch orders respond differentially to carbon source-sink manipulations in a longleaf pine forest. Oecologia 140:450457.

Heilman P.E., EkUAN G., Fogle D. (1994) Above- and below-ground biomass and fine roots of 4-year-old hybrids of Populus trichocarpa $\times$ Populus deltoides and parental species in short-rotation culture. Canadian Journal of Forest Research 24:1186-1192.

HewitT E.J., Smith T.A. (1974) Plant mineral nutrition. The English Universities Press, London

HisHI T. (2007) Heterogeneity of individual roots within the fine root architecture: causal links between physiological and ecosystem functions. Journal of Forest Research 12:126-133.

HodGE A. (2004) The plastic plant: root responses to heterogeneous supplies of nutrients. New Phytologist 162:9-24. 
HOFMANN M. (1998) Bewirtschaftung schnellwachsende Baumarten auf landwirtschaftlichen Flächen im Kurzumtrieb. Forschungsinstitut für schnellwachsende Baumarten. Merkblatt 11.

HÖlscher D., Hertel D., Leuschner C., HotTKowitz M. (2002) Tree species diversity and soil patchiness in a temperate broad-leaved forest with limited rooting space. Flora 197:118-125.

Lei P., Scherer-Lorenzen M., Bauhus J. (2012) Belowground facilitation and competition in young tree species mixtures. Forest Ecology and Management 265:191-200.

LYFORD W.H. (1980) Development of the root system of northern red oak (Quercus rubra L.). Harvard University, Harvard Forest

MACKenZIE N. (2010) Ecology, conservation and management of aspen: a literature review. Scottish Native Woods, Aberfeldy

Myking T., Bøhler F., Austrheim G., Solberg E.J. (2011) Life history strategies of aspen (Populus tremula L.) and browsing effects: a literature review. Forestry 84:61-71.

NoELlE W. (1910) Studien zur vergleichenden Anatomie und Morphologie der Koniferenwurzeln mit Rücksicht auf die Systematik. Botanische Zeitung 68:169266.

PERSSON H.A. (2002) Root systems of arboreal plants. In: WAISEL Y, Eshel A, KAFKAFi U (eds) Plant roots, the hidden half. 3rd ed. Marcel Dekker, New York, pp 287-313

PinHeiro J., BAtes D. (2013) nlme: Linear and Nonlinear Mixed Effects Models.

Polverigiani S., McCormack M.I., Mueller C.W., Eissenstat D.M. (2011) Growth and physiology of olive pioneer and fibrous roots exposed to soil moisture deficits. Tree Physiology 31:1228-1237.

Possen B.J.H.M., Oksanen E., Rousi M., Ruhanen H., Ahonen V., Tervahauta A., HEINONEN J., HEISKANEN J., KÄRENLAMPI S., VAPAAVUORI E. (2011) Adaptability of birch (Betula pendula Roth) and aspen (Populus tremula L.) genotypes to different soil moisture conditions. Forest Ecology and Management 262:13871399.

Powell G.W., BorK E.W. (2004) Competition and facilitation in mixtures of aspen seedlings, alfalfa, and marsh reedgrass. Canadian Journal of Forest Research 34:1858-1869.

Pregitzer K.S., DeForest J.L., Burton A.J., Allen M.F., Ruess R.W., Hendrick R.L. (2002) Fine root architecture of nine North American trees. Ecological Monographs 72:293-309.

Pregitzer K.S., Friend A.L. (1996) The structure and function of Populus root systems. In: StetTler RF, Bradshaw HD, Heilman PE, HincKley TM (eds) Biology of 
Populus and its implications for management and conservation. NRC Research Press, Ottawa, Canada, pp 331-353

Pregitzer K.S., LASKOWSKi M.J., Burton A.J., Lessard V.C., ZAK D.R. (1998) Variation in sugar maple root respiration with root diameter and soil depth. Tree Physiology 18:665-670.

Puri S., Singh V., Bhushan B., Singh S. (1994) Biomass production and distribution of roots in three stands of Populus deltoides. Forest Ecology and Management 65:135-147.

R Development Core Team (2011) R: A language and environment for statistical computing. R Foundation for Statistical Computing, Vienna, Austria

ReWAld B., Ephrath J.E., RAChMileVitch S. (2011) A root is a root is a root? Water uptake rates of Citrus root orders. Plant, Cell \& Environment 34:33-42.

REWALD B., LEUSCHNER C. (2009) Belowground competition in a broad-leaved temperate mixed forest: pattern analysis and experiments in a four-species stand. European Journal of Forest Research 128:387-398.

RoOd S.B., BrAatne J.H., Hughes F.M.R. (2003) Ecophysiology of riparian cottonwoods: stream flow dependency, water relations and restoration. Tree Physiology 23:11131124.

SCHENK H.J. (2006) Root competition: beyond resource depletion. Journal of Ecology 94:725-739.

SCHENK H.J., CALlaWAy R.M., MaHAll B.E. (1999) Spatial root segregation: Are plants territorial? In: FITTER AH, RAFFAELLI D (eds) Advances in Ecological Research, Vol 28. Academic Press Ltd-Elsevier Science Ltd, London, pp 145-180

SCHENK R.U., HildebrandT A.C. (1972) Medium and techniques for induction and growth of monocotyledonous and dicotyledonous plant cell cultures. Canadian Journal of Botany 50:199-204.

SCHMID I., KAzDA M. (2002) Root distribution of Norway spruce in monospecific and mixed stands on different soils. Forest Ecology and Management 159:37-47.

ShepPerd W.D., Binkley D., BARTos D.L., StOhlgren T.J., EskeW L.G. (2001) Sustaining aspen in western landscapes: Symposium Proceedings. U.S. Department of Agriculture, Forest Service, Rocky Mountain Research Station, Grand Junction, Colorado

SutTON R.F., TinUs R.W. (1983) Root and root system terminology. Forest Science 29:a0001-z0001.

Ter BraAk C.J.F., SMilauer P. (2002) Canoco for Windows version 4.5. Biometris-Plant Research International, Wageningen 
Valenzuela-Estrada L.R., Vera-Caraballo V., Ruth L.E., Eissenstat D.M. (2008) Root anatomy, morphology, and longevity among root orders in Vaccinium corymbosum (Ericaceae). American Journal of Botany 95:1506 -1514.

WeLls C.E., EISSENSTAT D.M. (2002) Beyond the roots of young seedlings: the influence of age and order on fine root physiology. Journal of Plant Growth Regulation 21:324-334.

WiLSON J.B. (1988) Shoot competition and root competition. Journal of Applied Ecology 25:279.

Withington J.M., Elkin A.D., BuŁaj B., Olesiński J., Tracy K.N., Bouma T.J., OlEKSYN J., ANDERSON L.J., MODRZYŃSKI J., REICH P.B., EISSENSTAT D.M. (2003) The impact of material used for minirhizotron tubes for root research. New Phytologist 160:533-544.

ZADWORNY M., EISSENSTAT D.M. (2011) Contrasting the morphology, anatomy and fungal colonization of new pioneer and fibrous roots. New Phytologist 190:213-221. 

Chapter 5

SYNTHESIS 



\section{Synthesis}

In this paragraph I will integrate the main findings obtained from my three different studies: the 'POPDIV' field experiment, the 'Cavitron' approach and the rhizobox root competition experiment on eight genetically closely related $P$. tremula demes and two additional species ( $P$. tremula and $P$. trichocarpa).

The first of the following three chapter sections relates to the results on the intra- and interspecific (genetic) trait variation as observed on aboveground (branches and leaves) and belowground (coarse and fine roots) plant organs of aspen demes differing in their genetic relatedness. The aim is to explain the potential role of intra- and interspecific trait variation as an indicator for ecological requirements and species adaptation to different environments.

The second of the following sections describes, how the main findings on intra- and interspecific trait variation, above- and belowground trait coordination and phylogenetic relatedness integrate with overall growth performance of the investigated species assemblages.

I am closing with a discussion about the dynamics of belowground competition in terms of root morphological adaptations with particular focus on the most distal root endings in an ecologically contrasting species constellation to complete my analysis of belowground processes in poplar species. 


\section{The intra- and interspecific trait variation in Populus}

In my study, intraspecific (genetic) diversity within genetically closely related aspen demes manifested in branch xylem anatomy and axial hydraulic conductivity as well as in belowground, coarse and fine root-related properties. In Chapter 2, intraspecific differences in fine root morphology and chemistry amongst the eight aspen demes became evident. The within-deme (mostly environmental) variation in fine root morphological traits was relatively high compared to between-deme (genetic) variation. This overall high variability can be attributed to the functional role of fine roots. The strong trait plasticity of single rootlets represents an important precondition of the short-lived fine roots to cope with the temporal and spatial variability in belowground resource availability and heterogeneous soil structures. This is in line with the observed absence of a strong genetic component coding for the fine root parameters investigated in Chapter 2, in contrast to aboveground traits (leaf size, SLA) which were well coordinated with the phylogenetic relatedness among the demes. An exception was the low genotypic variation of the mean fine root diameter between demes. As the investigated root segments comprise different single fine root sections (root orders) along the hierarchical branching structure, the mean root diameter across all sections does not account for the inherent heterogeneity among fine roots along the branching architecture and, thus, is an ecological rather meaningless trait. Hence, a root order-based analysis of the poplar fine root system as carried out in Chapter 4 is recommended for various morphological traits to account for different functions attributed to different root order positions.

In Chapter 3, the intraspecific variation in branch and coarse root anatomical and hydraulic traits of five aspen demes was determined. Deme-specific differences in anatomy and hydraulics were significant at branch level and could partly be related to the phylogenetic distances among demes. The intraspecific variation in vulnerability to cavitation of branch xylem was significant and strongly dependent on vessel size. In contrast, no intraspecific differences among the demes were observed for coarse root-related traits. Instead, the large within-deme variation in coarse root properties manifested in the existence of a few coarse roots with extraordinary large vessels $(>100 \mu \mathrm{m})$. These 'high conductivity roots' seemed not to be restricted to a specific root diameter class, stating that root diameter is not an appropriate measure to describe root functional divergences - a subject which certainly merits further consideration in any studies involving coarse roots. The large variation 
observed in coarse root xylem anatomy and hydraulics may indicate the functional plasticity i.e. the capability of coarse roots to provide sufficiently constant water supply along the entire water-flow path of trees under heterogeneous belowground microsite parameters. It remains speculative, whether the strategy of plants to sacrifice their peripheral fine roots as a result of irreparable xylem cavitation during periods of drought in order to prevent xylem cavitation in coarse roots applies to poplar species.

The intraspecific variation in resistance to cavitation of branch xylem as indicated by the $\mathrm{P}_{50}$ value was primarily associated with vessel size ( $d$ and $d_{\mathrm{h}}$ ) and significantly related to the phylogenetic distances among demes. Accordingly, a trade-off between forming larger vessels to enhance hydraulic efficiency and taking the increasing risk of vulnerability to xylem cavitation seems to apply for the demes in this study. The relatedness of hydraulic efficiency and aboveground growth performance is presented in the section below.

All aspen demes (P. tremula and P. tremuloides) exhibit outstanding resistances to xylem cavitation compared to other taxa of the genus (Lieffers 2001, Schreiber et al. 2011). The $\mathrm{P}_{88}$ values, indicators for the 'critical embolism level' before the xylem becomes totally non-conductive, ranged between -3.5 and -4.0 MPa what is even comparable to thresholds reported for a majority of temperate tree species (Urli et al. 2013). Moreover, the $\mathrm{P}_{88}$ values were related to the genetic distance between demes. Those attributes would enable the identification of more drought tolerant ecotypes on the basis of hydraulic traits.

In summary, most of the investigated aboveground leaf- or branch-related traits such as morphology, xylem anatomy and vulnerability to xylem cavitation exhibited significant intraspecific differences among aspen demes and were closely related to between-deme genetic distances. In contrast, the xylem anatomy, hydraulic features and morphological properties of poplar coarse and fine roots were of high (phenotypic) plasticity but low phylogenetic control. This is in accordance with the multifunctional structure of roots and the heterogeneous distribution of belowground resources in the soil. I suggest a morphometric approach based on the separation of root orders for coping with the hierarchical heterogeneity in anatomy and function of the branching structure of the fine root system. 


\section{Determinants of growth performance in Populus}

In Chapter 2 and 3, the high levels of intra- and interspecific trait variation partially corresponded to differences in growth performance among the investigated aspen demes. Root morphological characteristics which are typically associated with high resource uptake rates, and consequently enable fast growth (high SRA and SRL), were not related to higher relative growth rates among demes. This is in line with the recently published results of Tobner et al. (2013) who also found only weak coordination between aboveground relative growth rates and fine root traits among American temperate trees. Instead, leaf morphology remained the most significant growth-determining plant characteristic and was strongly coordinated with the genetic constitution of the demes used in this study. Considering the importance of leaf phenology for growth performance (Müller 2011), it is most likely that variation in early, rapid root development as suggested by Pallardy and Kozlowski (1979), Heilman et al. (1994) and Tschaplinski et al. (1998) triggers fast growth by providing trees with a greater surface area for resource uptake in the early growing season. Moreover, a detailed approach, based on root orders explained the different growth strategies of the species $P$. tremula and P. trichocarpa. Thus, I recommend to use this approach to detect species- or deme-specific differences along the hierarchically branching root axis (root orders) of fine roots.

A large range of variation in branch xylem anatomy became evident among the five selected aspen demes in Chapter 3. Starting from the assumption that the efficiency of the plants' hydraulic system is an important prerequisite of biomass production, the wood anatomical and hydraulic properties of branches and coarse roots were investigated to identify the most relevant growth determinant amongst these traits. Indeed, intraspecific variation in the empirically determined hydraulic conductivity of branches was well correlated with the inherent differences in growth performance among the aspen demes. In contrast, variation in xylem anatomy or hydraulic conductivity of coarse roots deviated from this pattern and was not correlated with aboveground productivity.

High productivity is coupled with large water requirements in poplar (Monclus et al. 2006), thus fast growing demes can be expected to respond more sensitive to water deficits. In the context of climate change scenarios (e.g. IPCC 2013) it is therefore of major importance to consider the intraspecific variability in the capability to withstand increasing drought exposure. We assumed that an increased resistance to xylem cavitation (associated 
with smaller vessel diameter) among aspen demes to come at the expense of growth performance (associated with wide vessels). However, a common trade-off between forming larger vessels to enhance hydraulic efficiency versus taking the increased risk of vulnerability to xylem cavitation was not evident across all demes in this study.

Surprisingly, the aboveground plant productivity as well as the $\mathrm{P}_{88}$ value was correlated with the empirically determined hydraulic conductivity $\left(K_{s}\right)$ but no relationship was found between plant growth performance or xylem safety and the potential hydraulic conductivity $\left(K_{\mathrm{p}}\right)$. In both cases, those observations may hint to a deme-specific variation in pit membrane properties and contact area between vessels which may strongly determine hydraulic conductivity and xylem safety. Those influences of pit wall properties on hydraulic traits are most likely masked, when hydraulic conductivity is derived theoretically from vessel features of xylem cross sections, e.g. diameter of the xylem conduits (Hacke et al. 2006; Fichot et al. 2010).

In summary, the investigated fine or coarse root parameters (morphology, xylem anatomy and hydraulic properties) proved to be less reliable predictors for aboveground growth performance on an intraspecific scale. The low phylogenetic relatedness of root-specific traits explains the huge belowground trait variation (high plasticity). This arguably makes those traits unsuitable selection criteria for breeding approaches. In contrast, the hydraulic efficiency of the branch xylem turned out to be an important growth determinant among aspen demes. Considering the weak relation between xylem safety and aboveground productivity, these results suggests that axial conductivity and the water transport towards the leaves under conditions of ample moisture availability seem to be more important for growth than resistance to cavitation in dry periods. 


\section{Root competitive interaction in Populus}

The presented results of Chapter 4 confirmed earlier reports on a strong control of the root order position or the age of a root segment on the respective fine root traits within both poplar species. Such patterns in trait variation were likewise described across different tree species for anatomical, physiological and morphological root characteristics among root sections of a distinct age (Hishi 2007) or along the hierarchically branching network comprising different root orders (Pregitzer and Friend 1996; Pregitzer et al. 2002; Wang et al. 2006; Guo et al. 2008). We found the morphological fine root characteristics which are typically associated with high resource uptake rates, such as high specific root area (SRA) or specific root length (SRL) (Comas and Eissenstat 2004) in the fine root system of the fast-growing species $P$. trichocarpa.

The different growth performance of P.tremula and P. trichocarpa, accounted for asymmetric belowground competition in favor of $P$. trichocarpa. Considering that poplar root systems are growing close to the soil surface and exhibit a lateral, wide-spread root network which produces sinker roots to reach deeper soil layers (Douglas et al. 2010), their fast colonization of the soil suggests, that belowground competition occurs prior to aboveground canopy closure (Pregitzer and Friend 1996). Consequently, root competition may fundamentally determine stand productivity in poplar plantings before aboveground competition becomes significant. However, the competition treatments had only a minor influence on fine root morphology of both species. Since the modification in fine root morphological traits was of minor importance for the plants' belowground competitive strategies it remains open, as to whether temporal or spatial niche segregation is more likely to occur as a competition response between poplar root systems.

A further result of the study was the observation of two different root categories when compared fine roots of the box interior with data from roots we observed directly at the transparent front plates. We classified roots with low tissue density and larger diameter, primarily observed at the transparent front plate, as young pioneer roots and thinner fibrous roots without window contact in the inner soil of the box as absorbing fine roots. The ability of poplars to grow different types of roots (root polymorphism) may influence the interpretation of future rhizoscope data and could bias estimates on fine root dynamics or belowground carbon budget. 


\section{Concluding remarks}

Research on fine roots is crucial to understand the functional role of belowground traits for high biomass yield and species adaptation to drought considering potentially changing habitat conditions due to climate warming. The presented study ranges among the first to describe the complex poplar coarse and fine root system on an intraspecific scale as well as belowground competitive processes between ecologically contrasting poplar species.

The large intraspecific variability in root traits can be attributed to the functional role of fine roots suggesting that the strong trait variability accounts for the within-species potential to respond to heterogeneous soil conditions. Further research on fine root properties is needed to seek for the potential phylogenetic control of distinct root traits considering the root age and root order position in order to characterize specific belowground resource acquisition and allocation strategies within species. This can help to predict genotypic differences in aboveground growth performance.

This study showed that hydraulic properties of branches have to be considered when selecting plant material for highly productive plantations on drought affected sites. The intraspecific variation in xylem anatomy and hydraulics was related to differences in the genetic constitution and the overall vulnerability to xylem cavitation in aspen was low. The axial conductivity and the water transport to the leaves under conditions of ample moisture availability seem to be more important for growth than resistance to xylem cavitation in dry periods. In order to differentiate hydraulic conductivity and xylem safety between genotypes, further investigations should consider variation in pit membrane properties and inter vessel connections.

In contrast to branches, large trait variation was observed in coarse root xylem anatomy and hydraulics what may indicate a functional plasticity in longitudinal direction of the root axis in order to provide sufficiently constant water supply along the entire water-flow path of trees. In conclusion, root anatomy-related analysis should guide future investigations which may also include fine root mortality rates within in poplar root systems as well as genetic analyses to better understand adaptation to drought events. Investigations on fine root mortality rates may help to better understand overall plant strategies to cope with drought, because sacrifice of fine roots during drought events may 
occur as root response to drought in order to prevent xylem embolism within adhesive higher order roots.

Distinctive growth-determining fine root characteristic could be found in the most distal root endings which therefore exhibit the most essential root parts to be investigated in future root studies. It is strongly recommended to consider root polymorphism as observed for poplar roots in this study, specifically when interpreting rhizoscope data. 


\section{References}

Beyer F., Hertel D., Leuschner C. (2013) Fine root morphological and functional traits in Fagus sylvatica and Fraxinus excelsior saplings as dependent on species, root order and competition. Plant and Soil 373:143-156.

Cai J., Tyree M.T. (2010) The impact of vessel size on vulnerability curves: data and models for within-species variability in saplings of aspen, Populus tremuloides Michx. Plant, Cell \& Environment 33:1059-1069.

COMAS L.H., EISSENSTAT D.M. (2004) Linking fine root traits to maximum potential growth rate among 11 mature temperate tree species. Functional Ecology 18:388397.

Douglas G.B., McIvor I.R., PotTer J.F., Foote L.G. (2010) Root distribution of poplar at varying densities on pastoral hill country. Plant and Soil 333:147-161.

Fichot R., Barigah T.S., Chamaillard S., Le Thiec D., Laurans F., Cochard H., BRIGNOLAS F. (2010) Common trade-offs between xylem resistance to cavitation and other physiological traits do not hold among unrelated Populus deltoides $\times$ Populus nigra hybrids. Plant, Cell \& Environment 33:1553-1568.

Guo D., Xia M., Wei X., Chang W., LiU Y., Wang Z. (2008) Anatomical traits associated with absorption and mycorrhizal colonization are linked to root branch order in twenty-three Chinese temperate tree species. New Phytologist 180:673-683.

HACKe U.G., SPerry J.S., WheEler J.K., CASTRO L. (2006) Scaling of angiosperm xylem structure with safety and efficiency. Tree Physiology 26:689-701.

Heilman P.E., EKuAn G., Fogle D. (1994) Above- and below-ground biomass and fine roots of 4-year-old hybrids of Populus trichocarpa $\times$ Populus deltoides and parental species in short-rotation culture. Canadian Journal of Forest Research 24:1186-1192.

IPCC (2013) Summary for Policy Makers. Climate Change 2013: The Physical Science Basis. Contribution of Working Group I to the Fourth Assessment Report of the Intergovernmental Panel on Climate Change (Cambridge Univ Press, Cambridge, UK and New York).

HISHI T. (2007) Heterogeneity of individual roots within the fine root architecture: causal links between physiological and ecosystem functions. Journal of Forest Research 12:126-133.

LIEFFERS V., LANDHÄUSSER S., HoGg E. (2001) Is the wide distribution of aspen a result of its stress tolerance? In: SHEPPERD WD, BINKLEY D, BARTOS DL, ET AL. (eds) Sustaining aspen in western landscapes: Symposium Proceedings. U.S. Department of Agriculture, Forest Service, Rocky Mountain Research Station, Grand Junction, Colorado, pp 311-323

MÜLLER A. (2011) Variability of physiological traits and growth performance in aspen assemblages differing in genetic relatedness. Dissertation, University of Göttingen 
Monclus R., Dreyer E., Villar M., Delmotte F.M., Delay D., Petit J.-M., Barbaroux C., Le Thiec D., Bréchet C., Brignolas F. (2006) Impact of drought on productivity and water use efficiency in 29 genotypes of Populus deltoides $\times$ Populus nigra. New Phytologist 169:765-777.

PALLARDY S., KozlowsKi T. (1979) Early root and shoot growth of Populus clones. Silvae Genetica 28:153-156.

Pregitzer K.S., DeForest J.L., Burton A.J., Allen M.F., Ruess R.W., Hendrick R.L. (2002) Fine root architecture of nine North American trees. Ecological Monographs 72:293-309.

Pregitzer K.S., Friend A.L. (1996) The structure and function of Populus root systems. In: StetTler RF, Bradshaw HD, Heilman PE, Hinckley TM (eds) Biology of Populus and its implications for management and conservation. NRC Research Press, Ottawa, Canada, pp 331-353

Schreiber S.G., Hacke U.G., HAmAnn A., Thomas B.R. (2011) Genetic variation of hydraulic and wood anatomical traits in hybrid poplar and trembling aspen. New Phytologist 190:150-160.

Tobner C.M., Paquette A., Messier C. (2013) Interspecific coordination and intraspecific plasticity of fine root traits in North American temperate tree species. Frontiers in Functional Plant Ecology 4:242.

TsChaplinsKi T.J., Tuskan G.A., Gebre G.M., TodD D.E. (1998) Drought resistance of two hybrid Populus clones grown in a large-scale plantation. Tree Physiology 18:653-658.

Urli M., Porté A.J., Cochard H., Guengant Y., Burlett R., Delzon S. (2013) Xylem embolism threshold for catastrophic hydraulic failure in angiosperm trees. Tree Physiology 00:1-12.

WANG Z., GuO D., WANG X., Gu J., MeI L. (2006) Fine root architecture, morphology, and biomass of different branch orders of two Chinese temperate tree species. Plant and Soil 288:155-171.

Westoby M., WRight I.J. (2006) Land-plant ecology on the basis of functional traits. Trends in Ecology \& Evolution 21:261-268.

Withington J.M., Reich P.B., Oleksyn J., Eissenstat D.M. (2006) Comparisons of structure and life span in roots and leaves among temperate trees. Ecological Monographs 76:381-397. 


\section{SUMMARY}

Short-rotation forestry (SRF) systems provide sustaining resource supply that is needed to meet the rapidly increasing demand in wood products and renewable energy. Poplar species (Populus spp.) are frequently used for such plantations as they maintain high yield along wide environmental ranges. Specifically aspen (Populus tremula and P. tremuloides) reach considerable productivity even on poor soils and exhibit relatively high drought tolerance when compared to other taxa of the genus. However, the use of aspen in SRF systems is not well established. The aim of this study was to investigate the intra- and interspecific variation of above- and belowground functional traits which determine differences in environmental adaptation, drought tolerance, competitive strength and hence overall species performance in different aspen demes and two further poplar species $(P$. tremula and $P$. trichocarpa). This information may contribute to optimize yield and reducing the risk of failure in plantings under current and future climates.

Major differences in functional above- and belowground traits of aspen demes of particular environmental adaptation became evident in the course of this study (Chapter 2). However, variance within the aspen fine root system properties is considerably high and above- and belowground trait correspondence remains inconsistent. Fine root properties are to a lesser extent related to genetic distance among demes than leaf-related properties. The high degree of plasticity in belowground (fine root) traits compared to aboveground traits implies a heterogeneous response to high spatial and temporal variability of belowground resources what may be of relevance for species growth performance. This may also explain why the variation in fine root morphological traits was not directly linked to differences in growth among the demes. Instead, much of the within-deme variation of the investigated root morphological traits may be explained by differentiating single root sections according to the hierarchical branching structure (root orders).

The intraspecific variation in wood anatomical and hydraulic properties of branches and coarse roots in five genetically distinct demes were related to variation in aboveground productivity and drought resistance (Chapter 3). Genotypic differences in the dependence of growth on branch xylem hydraulic efficiency and on hydraulic safety (cavitation vulnerability) were found. By contrast, a large variation in coarse root anatomical and hydraulic traits did not determine growth performance or drought resistance among the 
demes but manifest in the observation of 'high-conductivity roots' with extraordinarily large vessels which state the functional heterogeneity within the poplar root system.

Belowground competition effects on physiologically important fine root morphological and chemical properties of $P$. tremula and $P$. trichocarpa saplings along roots of different order and age were identified (Chapter 4). First, the strong control exerted by the root order position or the age of a root segment on different root traits became evident and enabled species differentiation according to the investigated traits. The minor influence of different competition treatments on fine root morphology and chemistry suggests that morphological adaptation in response to competition is not a mandatory phenomenon. Moreover, the comparison of harvest data (fine roots of the box interior) and direct root growth observations (at a transparent front plate) revealed a mismatch between the two types of data suggesting that root polymorphism may strongly impact the interpretation of rhizoscope data.

This study is the first to describe the inherent complexity and heterogeneity of the poplar root system in its anatomy, morphology and function on an intraspecific as well as interspecific scale. Further experiments and detailed root analysis within long-term field studies are needed for a better understanding of belowground root-related processes in poplar species. 
APPENDIX 


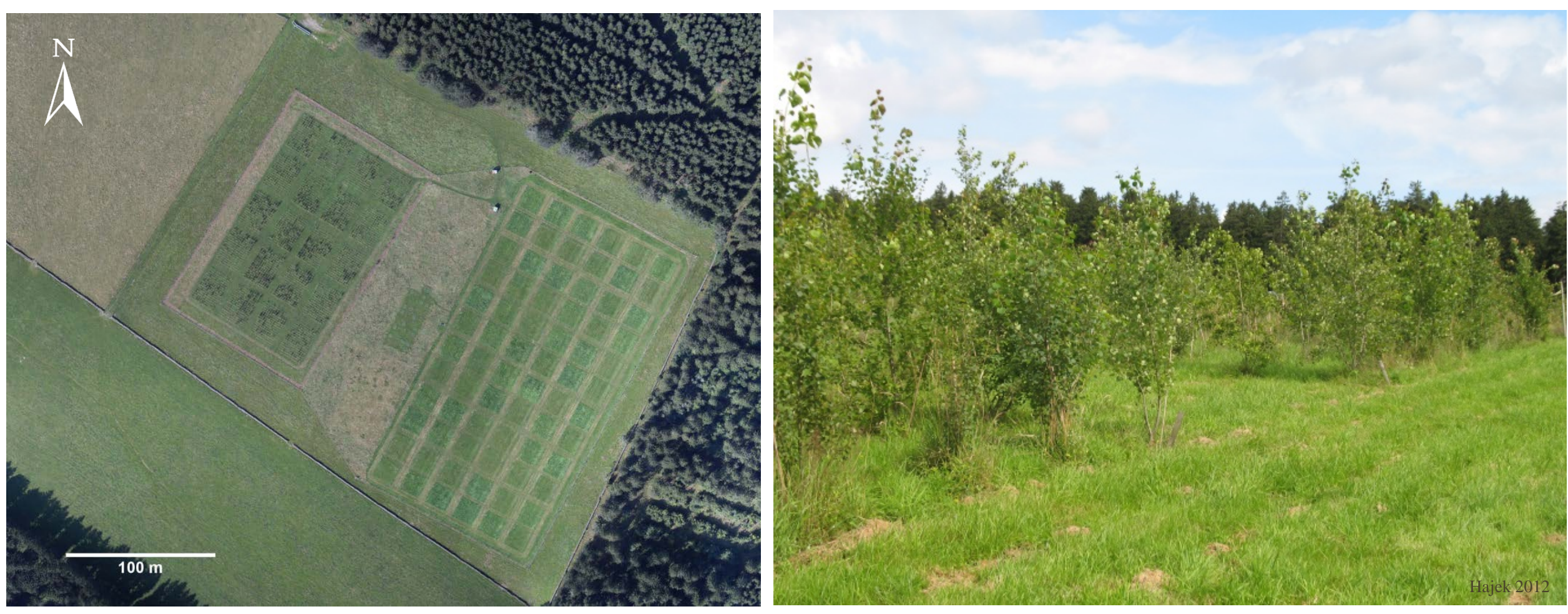

Figure A 1 Left: aerial photo of the POPDIV field trail (facing northwest) and the neighboring GrassMan experimental site (facing southeast) taken in September 2012 (S. Dobers). Right: 4-yr old $P$. tremula and $P$. tremuloides saplings at the experimental site in an eastward direction in July 2012. 

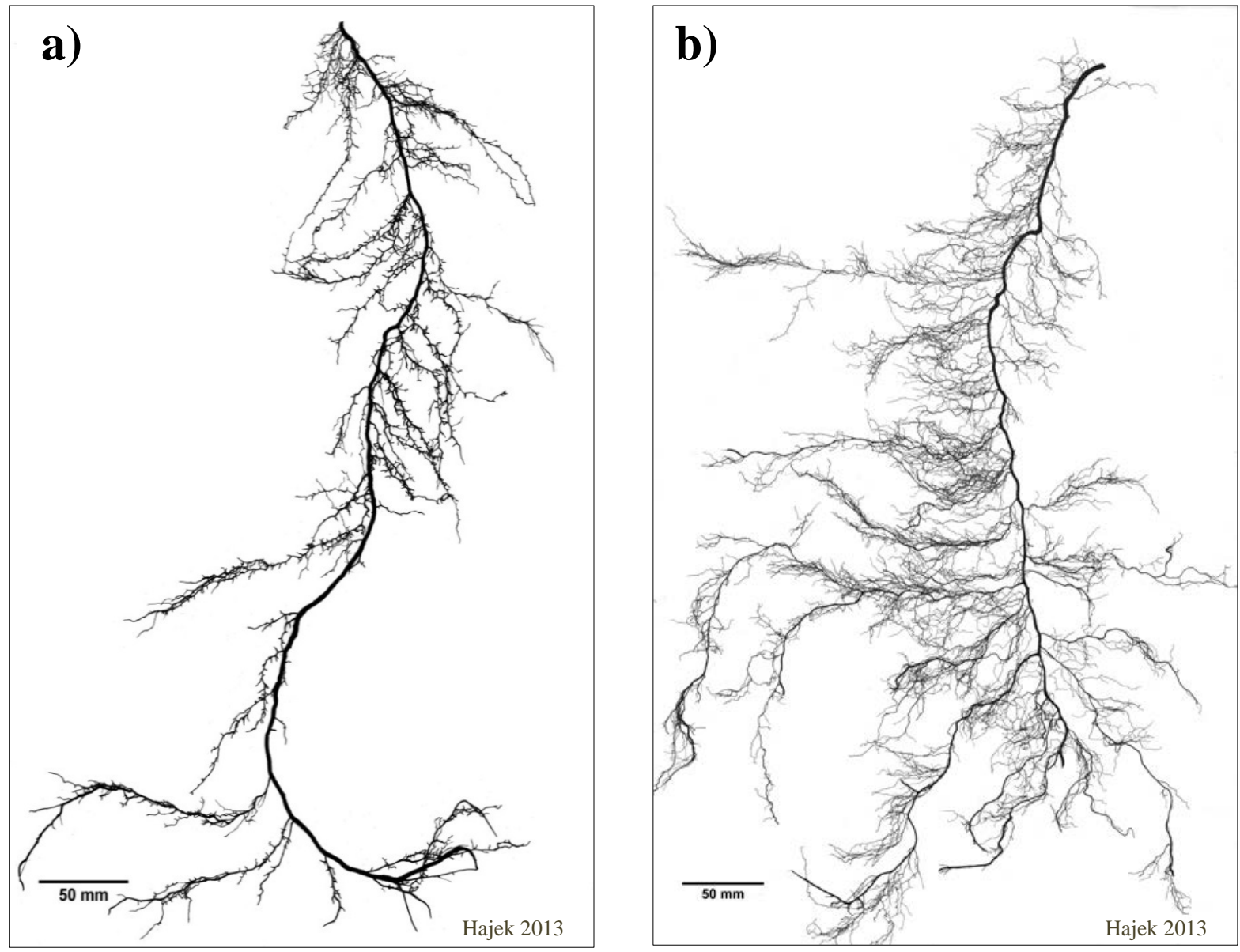

Figure A 2 Example of the typical differences in the fine root structure of $P$. tremula (a) and $P$. trichocarpa (b). Total length $(\mathrm{cm})$, surface area $\left(\mathrm{cm}^{2}\right)$ and mean diameter $(\mathrm{mm})$ of the respective sample are given: $P$. tremula: $597 \mathrm{~cm}, 52 \mathrm{~cm}^{2}$ and $0.28 \mathrm{~mm}$; P. trichocarpa: $1655 \mathrm{~cm}, 92 \mathrm{~cm}^{2}$ and $0.18 \mathrm{~mm}$. The analysis was carried out with WinRhizo $2005 \mathrm{c}$. 

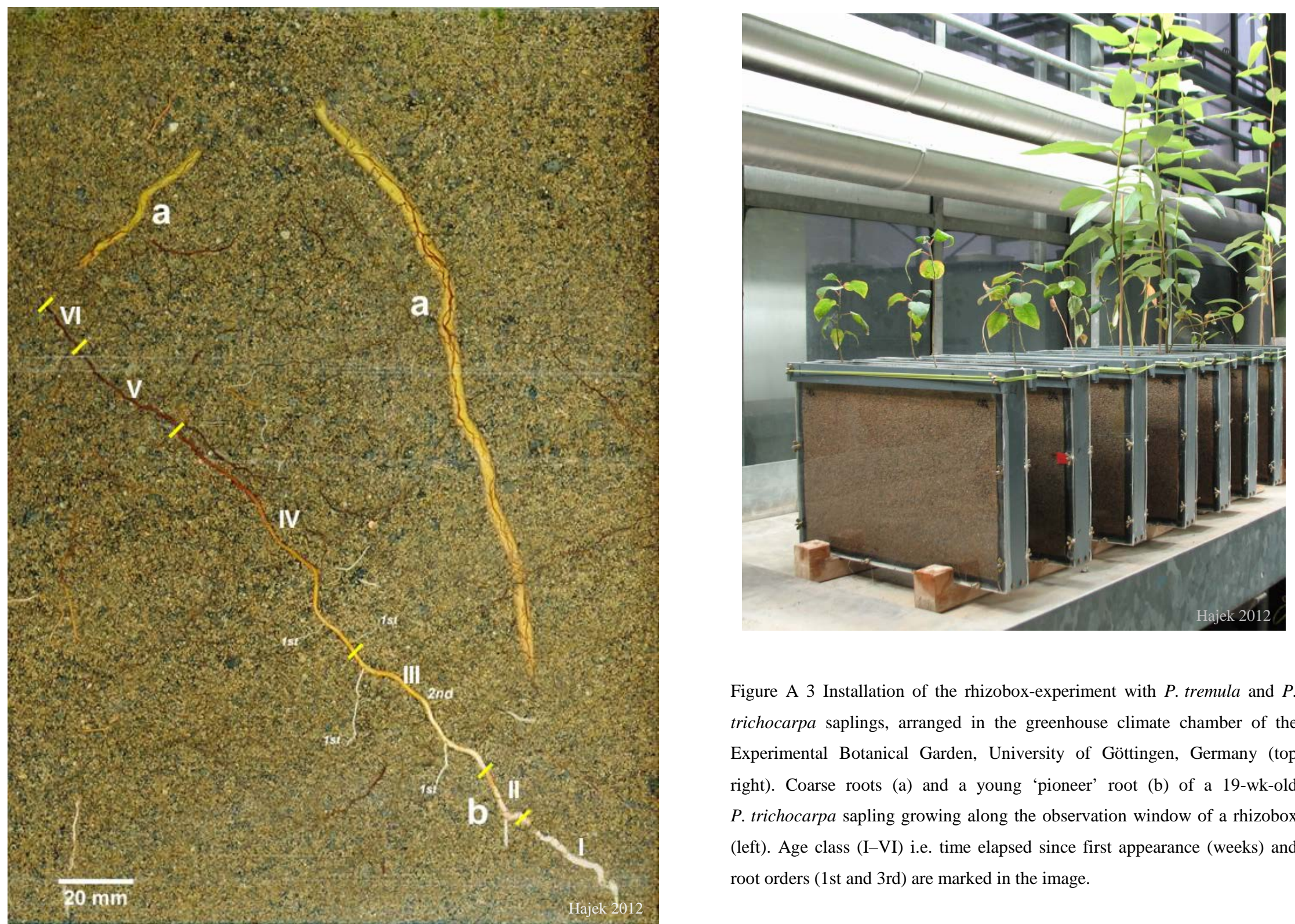

Figure A 3 Installation of the rhizobox-experiment with $P$. tremula and $P$. trichocarpa saplings, arranged in the greenhouse climate chamber of the Experimental Botanical Garden, University of Göttingen, Germany (top right). Coarse roots (a) and a young 'pioneer' root (b) of a 19-wk-old $P$. trichocarpa sapling growing along the observation window of a rhizobox (left). Age class (I-VI) i.e. time elapsed since first appearance (weeks) and root orders (1st and 3rd) are marked in the image. 
Table A 1. Summary of linear regression analyses on the dependence of xylem cross-sectional area $\left(A_{\text {xylem}}\right.$, mm $\left.{ }^{2}\right)$ on segment cross-sectional area $\left(A_{\text {cross }}, \mathrm{mm}^{2}\right)$ for branches and coarse roots of the five aspen demes (equation: $A_{\text {xylem }}=\mathrm{a}+\mathrm{b} \times A_{\text {cross }}$ ). The intercept a and slope $\mathrm{b}$, the number of samples (n), the adjusted coefficient of determination $\left(r^{2}\right)$, the $P$-value, and the mean fraction of xylem cross-sectional area in segment cross-sectional area $\left(A_{\text {xylem }} / A_{\text {cross }}\right.$, mean $\pm \mathrm{SE}$ ) are given.

\begin{tabular}{|c|c|c|c|c|c|c|}
\hline \multirow[b]{2}{*}{ Deme } & \multicolumn{5}{|c|}{$A_{\text {xylem }}=\mathrm{a}+\mathrm{b} \times A_{\text {cross }}$} & \multirow[b]{2}{*}{$A_{\text {xylem }} / A_{\text {cross }}$} \\
\hline & $n$ & $\mathrm{a}$ & $\mathrm{b}$ & $r^{2}$ & $P$ & \\
\hline \multicolumn{7}{|c|}{ Branches } \\
\hline AU & 19 & -3.431 & 0.696 & 0.99 & $<0.001$ & $0.61 \pm 0.01$ \\
\hline $\mathrm{CH}$ & 21 & -1.289 & 0.621 & 0.96 & $<0.001$ & $0.57 \pm 0.01$ \\
\hline G2 & 17 & -1.862 & 0.632 & 0.98 & $<0.001$ & $0.57 \pm 0.01$ \\
\hline G8 & 23 & -3.310 & 0.655 & 0.98 & $<0.001$ & $0.55 \pm 0.01$ \\
\hline US & 26 & -3.213 & 0.666 & 0.99 & $<0.001$ & $0.59 \pm 0.01$ \\
\hline All & 110 & -2.529 & 0.653 & 0.98 & $<0.001$ & $0.58 \pm 0.01$ \\
\hline \multicolumn{7}{|l|}{ Roots } \\
\hline $\mathrm{AU}$ & 14 & -0.829 & 0.482 & 0.97 & $<0.001$ & $0.46 \pm 0.01$ \\
\hline $\mathrm{CH}$ & 16 & -0.780 & 0.459 & 0.97 & $<0.001$ & $0.41 \pm 0.01$ \\
\hline G2 & 17 & -1.625 & 0.496 & 0.97 & $<0.001$ & $0.45 \pm 0.01$ \\
\hline G8 & 17 & -1.594 & 0.409 & 0.96 & $<0.001$ & $0.36 \pm 0.01$ \\
\hline US & 16 & 0.070 & 0.458 & 0.97 & $<0.001$ & $0.45 \pm 0.01$ \\
\hline All & 85 & -1.319 & 0.469 & 0.96 & $<0.001$ & $0.42 \pm 0.01$ \\
\hline
\end{tabular}


Table A 2. Coefficient of determination $\left(r^{2}\right)$ and level of significance $(P)$ for a linear regression analysis on the relation between sapwood area-specific hydraulic conductivity $\left(K_{\mathrm{s}}\right)$ normalized to different positions along the branch segments (maximum, mean or minimum xylem area without pith and bark) and three different anatomical traits (average vessel diameter $(d)$, hydraulically weighted vessel diameter $\left(d_{\mathrm{h}}\right)$ and potential sapwood area-specific conductivity $\left(K_{\mathrm{p}}\right)$ and sapwood area-specific hydraulic conductivity measured with the Cavitron $\left(K_{\mathrm{s}}^{\text {cavi }}, \mathrm{kg} \mathrm{m}^{-1} \mathrm{MPa}^{-1} \mathrm{~s}^{-1}\right)$ by dividing the maximum hydraulic conductivity measured at low speed by the maximum sapwood area of the sample.

\begin{tabular}{|c|c|c|c|c|c|c|c|}
\hline \multirow[b]{2}{*}{ Variable } & \multirow[b]{2}{*}{$n$} & \multicolumn{2}{|c|}{$K_{\mathrm{s}} A_{\text {xylem }}^{\max }$} & \multicolumn{2}{|c|}{$K_{\mathrm{s}} A_{\text {xylem }}^{\text {mean }}$} & \multicolumn{2}{|c|}{$K_{\mathrm{s}} A_{\text {xylem }}^{\min }$} \\
\hline & & $r^{2}$ & $P$ & $r^{2}$ & $P$ & $r^{2}$ & $P$ \\
\hline \multicolumn{8}{|c|}{ Branch-related traits } \\
\hline$d$ & 43 & 0.32 & $<0.001$ & 0.26 & $<0.001$ & 0.16 & 0.004 \\
\hline$d_{\mathrm{h}}$ & 42 & 0.22 & 0.001 & 0.19 & 0.002 & 0.13 & 0.007 \\
\hline$K_{p}$ & 42 & 0.29 & $<0.001$ & 0.27 & $<0.001$ & 0.19 & 0.002 \\
\hline$K_{\mathrm{s}}$ & 41 & 0.64 & $<0.001$ & 0.63 & $<0.001$ & 0.36 & $<0.001$ \\
\hline \multicolumn{8}{|c|}{ Root-related traits } \\
\hline$d$ & 17 & 0.23 & 0.03 & 0.09 & 0.11 & 0.03 & 0.25 \\
\hline$d_{\mathrm{h}}$ & 17 & 0.13 & 0.08 & 0.10 & 0.11 & 0.02 & 0.30 \\
\hline
\end{tabular}





\section{ACKNOWLEDGEMENTS}

First and foremost, I want to thank Prof. Dr. Christoph Leuschner for giving me the opportunity to work in this multifaceted research field and to develop and answer my research questions spanning from root tips to the outer tree canopies. I am grateful for all the personal input, the constructive guidance in preparing the manuscripts and the support throughout the work on my thesis.

Second, hearty thanks go to my supervisor Dr. Dietrich Hertel for helping to familiarize me with the fascinating aspects of fine root research and for providing helpful support in all aspects of scientific and administrative concern.

Furthermore, I would like to thank Prof. Dr. Markus Hauck for his attendance at my thesis committee and for his co-examination of this work.

My best thanks go to Prof. Dr. Andrea Polle, director of the Göttingen Poplar Diversity Experiment. I further wish to acknowledge the Ministry of Science and Culture of Lower Saxony and the 'Niedersächsisches Vorab' for funding the cluster of excellence 'Functional Biodiversity Research' and my scholarship therein. I also want to thank Dr. Bernhard Schuldt for his instruction on the intricacies of the Cavitron technique and Dr. Laura Rose for providing critical comments helping to improve this work.

In addition to these notable persons, I am indebted to all people who accompanied me during my stay in Göttingen. This includes the members of the Department of Plant Ecology, the TA's, the garden staff of the Experimental Botanical Garden as well as all my employed student assistants. I am grateful for their skillful, continuous willingness to help in the field and the laboratory, whereby everyone contributed to the success of this work in a particular way.

Ann-Catrin, I want to thank you for all your patience, encouragement and your invaluable support throughout the last years. Your guidance essentially contributed to reach this point in my life. Thank you so much.

Finally, I want to express my gratitude to my family, specifically Anna and Gertrud. I thank both of you for your support during the past years and the appreciation of all my interests and ideas. 
Editorial Board for Biodiversity and Ecology Series

Prof. Dr. Hermann Behling, Dept. of Palynology and Climate Dynamics

Prof. Dr. Erwin Bergmeier, Dept. of Vegetation Analysis and Phytodiversity

Prof. Dr. Susanne Bögeholz, Dept. of Didactics of Biology

Prof. Dr. Norbert Elsner, Dept. of Neurobiology

Prof. Dr. Thomas Friedl, Dept. of Experimental Phycology

Prof. Dr. Gerhard Gerold, Dept. of Landscape Ecology

Prof. Dr. S. Robbert Gradstein, Dept. of Systematic Botany

Prof. Dr. Bernd Herrmann, Dept. of Historical Anthropology and Human Ecology

Prof. Dr. Peter Kappeler, Dept. of Sociobiology

Prof. Dr. Christoph Leuschner, Dept. of Plant Ecology and Ecosystems Research

Prof. Dr. Michael Mühlenberg, Dept. of Conservation Biology

Prof. Dr. Joachim Reitner, Dept. of Geobiology

Prof. Dr. Matthias Schaefer, Dept. of Animal Ecology

Prof. Dr. Wolfgang Schmidt, Dept. of Silviculture of the Temperate Zones and Forest

Ecology

Prof. Dr. Henner Simianer, Dept. of Animal Breeding

Prof. Dr. Teja Tscharntke, Dept. of Agroecology

Prof. Dr. Stefan Vidal, Dept. of Agroentomology

Prof. Dr. Rainer Willmann, Dept. of Animal Morphology, Systematics and Evolutionary

Biology

Prof. Dr. Gert Wörheide, Dept. of Geobiology

Members of the Göttingen Centre for Biodiversity and Ecology

Coloured cover images by Göttingen Centre for Biodiversity and Ecology

(legend top to bottom)

1 Mixed deciduous forest in the Hainich region (Central Germany)

2 Different insect taxa on the flowers of a thistle (Cirsium sp.)

3 Glomeris sp., a member of the decomposing soil fauna in forest ecosystems

4 Pleodorina californica (Chlorophyceae), colony-forming freshwater phytoplankton species

5 Grasshopper Tettigonia cantans, distributed from the Pyrenees to Northeastern China

6 Microcebus berthae (Cheirogaleidae), the smallest extant Primate species (Madagascar)

7 Tropical rain forest (Greater Daintree, Australia)

8 Lethocolea glossophylla (Acrobolbaceae), a liverwort of alpine mountain ranges in South America

9 Part of a coral reef in the Red Sea 